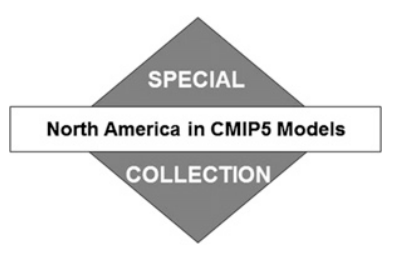

\title{
North American Climate in CMIP5 Experiments: Part III: Assessment of Twenty-First-Century Projections*
}

\author{
Eric D. Maloney, ${ }^{\mathrm{a}}$ SuzAna J. CAMARgo, ${ }^{\mathrm{b}}$ Edmund Chang, ${ }^{\mathrm{c}}$ Brian Colle, ${ }^{\mathrm{c}}$ Rong Fu, ${ }^{\mathrm{d}}$ \\ KERRIE L. GEIL, ${ }^{\mathrm{e}}$ QI Hu, ${ }^{\mathrm{f}}$ XIANAN JIANG, ${ }^{\mathrm{g}}$ NATHANIEL JOHNSON, ${ }^{\mathrm{h}}$ KRISTOPHER B. KARNAUSKAS, ${ }^{\mathrm{i}}$ \\ JAMES KINTER, ${ }^{\mathrm{j}, \mathrm{k}}$ BENJAMIN KIRTMAN, ${ }^{1}$ SANJIV KUMAR, ${ }^{\mathrm{k}}$ BAIRD LANGENBRUNNER, ${ }^{\mathrm{m}}$ \\ Kelly LOMBARdo, ${ }^{\mathrm{n}}$ LindSEY N. LONG, ${ }^{\mathrm{o}, \mathrm{p}}$ ANNARITA MARIOTTI, ${ }^{\mathrm{q}}$ JOYCE E. MEYERSON,${ }^{\mathrm{m}}$ \\ Kingtse C. Mo, ${ }^{\mathrm{p}}$ J. DAVID NEELIN,${ }^{\mathrm{m}}$ ZAITAO PAN, ${ }^{\mathrm{r}}$ RICHARd SEAGER, ${ }^{\mathrm{b}}$ YOLANDE SERRA, ${ }^{\mathrm{e}}$ \\ Anji Seth, ${ }^{\mathrm{s}}$ Justin ShefField, ${ }^{\mathrm{t}}$ Julienne Stroeve, ${ }^{\mathrm{u}}$ Jeanne Thibeault, ${ }^{\mathrm{s}}$ Shang-Ping Xie, \\ ChUnZai WANG, ${ }^{\mathrm{v}}$ BRUCE WyMAn, ${ }^{\mathrm{w}}$ AND Ming ZHAO ${ }^{\mathrm{w}}$ \\ ${ }^{a}$ Department of Atmospheric Science, Colorado State University, Fort Collins, Colorado \\ ${ }^{\mathrm{b}}$ Lamont-Doherty Earth Observatory, Columbia University, Palisades, New York \\ ${ }^{\mathrm{c}}$ School of Marine and Atmospheric Sciences, Stony Brook University, State University of New York, Stony Brook, New York \\ ${ }^{\mathrm{d}}$ Department of Geological Sciences, The University of Texas at Austin, Austin, Texas \\ ${ }^{\mathrm{e}}$ Department of Atmospheric Sciences, The University of Arizona, Tucson, Arizona \\ ${ }^{\mathrm{f}}$ Department of Earth and Atmospheric Sciences, University of Nebraska-Lincoln, Lincoln, Nebraska \\ ${ }^{\mathrm{g}}$ Joint Institute for Regional Earth System Science and Engineering, University of California, Los Angeles, Los Angeles, California \\ ${ }^{\mathrm{h}}$ International Pacific Research Center, University of Hawai'i at Mānoa, Honolulu, Hawaii \\ ${ }^{\mathrm{i}}$ Woods Hole Oceanographic Institution, Woods Hole, Massachusetts \\ ${ }^{\mathrm{j}}$ Atmospheric, Oceanic and Earth Sciences Department, George Mason University, Fairfax, Virginia \\ ${ }^{\mathrm{k}}$ Center for Ocean-Land-Atmosphere Studies, Fairfax, Virginia \\ ${ }^{1}$ Division of Meteorology and Physical Oceanography, University of Miami, Miami, Florida \\ ${ }^{\mathrm{m}}$ Department of Atmospheric and Oceanic Sciences, University of California, Los Angeles, Los Angeles, California \\ ${ }^{\mathrm{n}}$ Department of Marine Sciences, University of Connecticut, Avery Point, Connecticut \\ ${ }^{\circ}$ Wyle Science, Technology and Engineering, College Park, Maryland \\ ${ }^{\mathrm{P}}$ Climate Prediction Center, NOAA/NWS/NCEP, College Park, Maryland \\ ${ }^{\mathrm{q}}$ NOAA/Climate Program Office, Silver Spring, Maryland \\ ${ }^{\mathrm{r}}$ Department of Earth and Atmospheric Sciences, St. Louis University, St. Louis, Missouri \\ ${ }^{\mathrm{s}}$ Department of Geography, University of Connecticut, Storrs, Connecticut \\ ${ }^{\mathrm{t}}$ Department of Civil and Environmental Engineering, Princeton University, Princeton, New Jersey \\ ${ }^{\mathrm{u}}$ National Snow and Ice Data Center, University of Colorado Boulder, Boulder, Colorado \\ ${ }^{\vee}$ Atlantic Oceanographic and Meteorological Laboratory, Miami, Florida \\ ${ }^{\mathrm{w}}$ Geophysical Fluid Dynamics Laboratory, Princeton, New Jersey
}

(Manuscript received 6 May 2013, in final form 22 November 2013)

\begin{abstract}
In part III of a three-part study on North American climate in phase 5 of the Coupled Model Intercomparison Project (CMIP5) models, the authors examine projections of twenty-first-century climate in the representative concentration pathway 8.5 (RCP8.5) emission experiments. This paper summarizes and synthesizes results from several coordinated studies by the authors. Aspects of North American climate change that are examined include changes in continental-scale temperature and the hydrologic cycle, extremes events, and storm tracks, as well as regional manifestations of these climate variables. The authors also examine changes in the eastern North Pacific and North Atlantic tropical cyclone activity and North American intraseasonal to decadal variability, including changes in teleconnections to other regions of the globe. Projected changes are generally consistent with those previously published for CMIP3, although CMIP5 model projections differ importantly from those of CMIP3 in some aspects, including CMIP5 model agreement on increased central California precipitation. The paper also highlights uncertainties and limitations based on current results as priorities for further research. Although many projected changes in North American climate are consistent across CMIP5 models, substantial intermodel disagreement exists in other aspects. Areas of disagreement include projections of changes in snow water equivalent on a regional basis, summer Arctic sea ice extent, the magnitude and sign of regional precipitation changes, extreme heat events across the northern United States, and Atlantic and east Pacific tropical cyclone activity.
\end{abstract}

\footnotetext{
* Supplemental information related to this paper is available at the Journals Online website: http://dx.doi.org/10.1175/JCLI-D13-00273.s1.
}

Corresponding author address: Eric D. Maloney, Department of Atmospheric Science, Colorado State University, 1371 Campus Delivery, Fort Collins, CO 80523-1371.

E-mail: emaloney@atmos.colostate.edu 


\section{Introduction}

The twenty-first-century projections generated by phase 5 of the Coupled Model Intercomparison Project (CMIP5; Taylor et al. 2012) are analyzed here to assess climate change in North America (NA). This study accompanies two companion papers (Sheffield et al. 2013a, hereafter Part I; Sheffield et al. 2013b, hereafter Part II) that assess the CMIP5 models' potential to accurately simulate regional climate in the twentieth century. Additionally, it provides an overview and is a first step toward integrating the understanding of climate projection results from the individual papers in the Journal of Climate special collection entitled "North American climate in CMIP5 experiments." This paper first examines the changes in the continent-wide distribution of seasonal precipitation and temperature in simulations making use of representative concentration pathway 8.5 (RCP8.5; Taylor et al. 2012). It then focuses on a select set of regional climate features. These changes are considered in the context of the ability of models to accurately simulate current climate, discussed in the two companion papers (Part I and Part II), which is generally comparable to that of CMIP3 models, with some improvement noted for individual models.

Previous projections of NA climate change (e.g., CMIP3) have been evaluated as part of earlier climate assessments (Solomon et al. 2007). The CMIP3 consensus projection indicated that, by 2080-99, annual mean temperature increases are very likely across NA with the greatest changes in northern Canada and Alaska, where $10^{\circ} \mathrm{C}$ mean wintertime temperature increases are projected in some scenarios (Solomon et al. 2007). Increases in annual mean precipitation are projected for the northern tier of the United States, northward into Canada, with projected decreases for the southwest United States, east Pacific warm pool, Caribbean, and adjacent land areas (e.g., Neelin et al. 2006; Seager et al. 2007; Seager and Vecchi 2010).

Beyond mean state changes, CMIP3 models predict a general increase in precipitation intensity (e.g., Diffenbaugh et al. 2005; Mahajan et al. 2012), particularly in the northern tier of the United States and Canada (Tebaldi et al. 2006). Increases in the duration and severity of drought are projected in regions such as Central America and midlatitude NA (e.g., Sheffield and Wood 2008), of which increased temperatures and evapotranspiration are major components (Francina et al. 2010; Gutzler and Robbins 2011; Wehner et al. 2011). A general increase in heat waves, decrease in cold extremes, decrease in frost days, and increase in length of the growing season have been projected across large portions of NA (Meehl and
Tebaldi 2004; Diffenbaugh et al. 2005; Biasutti et al. 2012; Christiansen et al. 2011; Diffenbaugh and Scherer 2011; Duffy and Tebaldi 2012; Lau and Nath 2012), projected trends that are generally consistent with observed trends in such quantities over the last century (Alexander et al. 2006). Decreases in the duration of the snowpack have been projected for many regions, in particular low altitude areas of the Pacific Northwest and Rockies (e.g., Brown and Mote 2009; Elsner et al. 2010). Such changes are likely to lead to earlier spring snowmelt in many areas of the west (e.g., Hay et al. 2011). While model agreement is good on projected overall snow water equivalent declines in many areas by the end of the twenty-first century, some models show increases in snowpack along the Arctic Rim by 2100 (e.g., Brown and Mote 2009), particularly at the height of the winter season, even though the length of the snow season shortens (e.g., Räisänen 2008).

The projected response of NA climate in future emission scenarios is often more nuanced on the regional and local scales than for the continental-scale features, especially when considering the evolution during the seasonal cycle. For example, Rauscher et al. (2008) noted an earlier onset of the midsummer drought in Mexico and Central America in model projections for the end of the twenty-first century. Previous studies project a redistribution of precipitation in monsoon regimes such as the southwest United States with reduced spring rainfall and increased late rainy season rainfall (Seth et al. 2010, 2011; Biasutti and Sobel 2009). Ruiz-Barradas and Nigam (2010) showed that projections for the twenty-first century indicate a wetter north-central United States during spring (increase in number of extreme springs) and a drier southwest United States but little consistency in summer rainfall tendencies among models in these same regions. The uncertainty in projected summer precipitation extends to adjacent land areas of the Gulf of Mexico (Biasutti et al. 2012). Studies using CMIP3 projections suggest that, while the total number of North Atlantic tropical cyclones (TCs) will decrease and the number of intense hurricanes will increase, changes in North Atlantic TC activity remain uncertain. This is likely because climate models produce differing patterns of tropical SST change and different representations of tropical Atlantic SST relative to the tropical mean SST, which has been suggested to be a strong regulator of Atlantic TC activity (e.g., Latif et al. 2007; Swanson 2008; Vecchi et al. 2008; Wang and Lee 2008; Knutson et al. 2010; Vecchi et al. 2011; Zhao and Held 2012). Past studies using CMIP3-class models have generally indicated that climate projections for the twenty-first century 
at the local and regional levels remain a substantial challenge.

The present study provides a summary of projected twenty-first-century NA climate change in the updated state-of-the-art climate and Earth system models used in CMIP5. The results contained herein are contributed by members of the CMIP5 Task Force of the National Oceanographic and Atmospheric Administration (NOAA) Modeling, Analysis, Predictions and Projections Program (MAPP). Where appropriate, we make reference to individual papers submitted in parallel with this comprehensive study to the Journal of Climate special collection entitled "North American climate in CMIP5 experiments." These individual contributions provide further depth to and physical interpretation of the findings summarized here. The current paper is one of three papers (with Part I and Part II) that synthesize the results and form the core of the special collection, and they represent an initial step toward integrating our understanding of CMIP5 evaluations and projections for North America. We largely focus on RCP8.5 in a core set of 17 CMIP5 models.

Section 2 provides a brief introduction to CMIP5 as well as the primary climate change experiment (RCP8.5). Section 3 presents an assessment of continental climate changes over the twenty-first century, and section 4 assesses regional climate changes. How intraseasonal variability will change in the twenty-first century is assessed in section 5. Changes in Atlantic and east Pacific TC activity are examined in section 6. Multidecadal trends in interannual to decadal hydroclimate variability are analyzed in section 7 . Conclusions and a discussion are presented in section 8 .

\section{CMIP5 models and experiments}

We use CMIP5 multimodel datasets of historical climate and climate change experiments (Taylor et al. 2012). These are long-term century-scale projections of climate based on coupled simulations that include a representation of future atmospheric composition from the RCPs (Meinshausen et al. 2011). Table 1 summarizes information on the models used in this study. As noted in Taylor et al. (2012), in addition to physical improvements made in many models, one advantage provided by the CMIP5 experiments versus the CMIP3 effort is that the horizontal resolution of the atmospheric components of the coupled models has significantly increased. About one-third of the models have atmospheric resolution of approximately $1.5^{\circ}$ latitude or less, an improvement over CMIP3 where only about $10 \%$ of models met this criterion. This higher resolution is of some help in discerning the regional structure of hydroclimate variables over NA. However, in regions of complex topography and coastlines, the resolution of CMIP5 models remains insufficient for resolving important dynamic and thermodynamic features. Where appropriate in the text, we provide contrasts between the current CMIP5 results and those previously derived from CMIP3.

Results based on RCP8.5 will be highlighted here, as it represents one of the core concentration pathways used for the CMIP5 project (Taylor et al. 2012). This experiment represents a high concentration pathway in which radiative forcing due to anthropogenic factors reaches $8.5 \mathrm{~W} \mathrm{~m}^{-2}$ by 2100 (e.g., Meinshausen et al. 2011, Fig. 4) and continues to grow thereafter. Selected analyses also provide a comparison to a more moderate mitigation pathway (RCP4.5) in which stabilization at $4.5 \mathrm{~W} \mathrm{~m}^{-2}$ occurs around 2050, and then forcing remains fixed. In terms of the time evolution and value of globally averaged radiative forcing at $2100, \mathrm{RCP} 8.5$ and $\mathrm{RCP} 4.5 \mathrm{most}$ closely resemble the A2 and B1 scenarios for CMIP3 used in the International Panel on Climate Change (IPCC) Fourth Assessment Report (Solomon et al. 2007, Fig. 10.26), respectively. The projection experiments are compared to historical runs of the same models forced by observed trace gases, natural and anthropogenic aerosols, solar forcing, and other agents from the midnineteenth century onward (Taylor et al. 2012). A more comprehensive analysis of model performance in the historical runs is provided in the companion papers (Part I and Part II), which provide an additional baseline for comparison with the results shown here. No downscaling or bias correction is used before presentation of results. The exception to lack of downscaling is contained within the supplementary material, where a high-resolution model is used to assess future changes in tropical cyclone activity. Further, the use of downscaling in past and potential future studies is referenced at certain other points in the manuscript.

Multimodel ensemble mean (MEM) differences are highlighted for most of the analyses, as the MEM produces demonstrably superior results in historical climate assessment to those from an individual model (e.g., Gleckler et al. 2008; Pierce et al. 2009). We also use intermodel variability about the MEM to assess model consensus, including the likelihood of specific climate changes, with aspects demonstrating lack of model consensus summarized in the conclusions. In places, the methodology used is more diverse than a simple MEM analysis, given that this paper represents a synthesis of ideas from individual papers in the special collection. Ideally, we would like to compare common future and historical base periods among analyses. Unfortunately, from a practical standpoint this was not always possible. 
In the analysis of historical simulations in Part I and Part II, the base periods were often determined by the availability of the observational data to assess the models, which were application specific. Further, we assess projected changes in phenomena that have different time scales that range from synoptic to decadal. For example, assessment of interannual to decadal variability requires a longer record than assessment of tropical intraseasonal variability to assess statistical significance.

For consistency with Part I and Part II, our analysis concentrates on the core set of CMIP5 model highlighted by asterisks in Table 1 . Part I discussed the selection criteria for these models, which meet the need to include contributions from a large and diverse set of modeling groups and model types. The number of models used in a particular analysis shown below is often limited by availability of data at the time of this study or local storage space, although we try to be as comprehensive as possible. For example, for many of the analyses requiring high-resolution data, a smaller subset of models was used because of the lack of RCP8.5 data availability. Further, because of the large number of contributors from different institutions, overall coordination and unified model selection were not always possible. For some analyses, the number of models used was significantly lower than that of the core set, or the RCP4.5 scenario was used rather than RCP8.5. In these cases, while the results are still enlightening, we have placed the details of these analyses into the supplementary material. These include analyses of moisture transport and diurnal temperature range changes, as well as an analysis of tropical cyclone activity change using a downscaling technique with a high-resolution model. We also occasionally include a more expansive set than the core models in an individual analysis, although we comment on how results would differ if a smaller subset including only core models were used.

\section{Continental climate}

\section{a. Temperature and precipitation}

We first examine projected changes on the continental scale at the end of the twenty-first century relative to the twentieth century climate. Part I noted that CMIP5 models have success in capturing the broad-scale features of NA surface temperature and precipitation in current climate, although with some regional-scale biases. Figure 1 shows the 17-member MEM December-February (DJF) and June-August (JJA) precipitation changes during 2070-99 for RCP8.5 relative to a 1961-90 base period. For models that have more than one run with the same forcing, the average is taken over all runs prior to forming the MEM. A two-sided $t$ test comparing the MEM change to a standard error associated with interannual variability is shown at the $95 \%$ confidence level. Note that this tests only the sampling error associated with interannual variability in forming the MEM. Figure 2 shows the model agreement for the precipitation changes, along with two additional criteria for evaluation of significance that are described in the figure caption.

Figures 1 and 2 indicate increases in MEM wintertime precipitation along the west coast of NA from California to Alaska, as well as along the NA east coast from the Mid-Atlantic states northward. Model agreement for these changes is high north of about $40^{\circ} \mathrm{N}$, where all but one or two models agree on the sign of changes for all locations. Comparison to a similar ensemble of 16 CMIP3 models indicates that, while the large-scale pattern of precipitation increases at middle to high latitudes and precipitation decreases in the subtropics are similar between the two intercomparisons, one notable difference is that the boundary between these changes has shifted slightly south. This yields projected precipitation increases over parts of California in CMIP5, passing the binomial test for agreement on sign at levels exceeding $95 \%$ at points seen in Fig. 2. High interannual variance over coastal land points prevents these from passing the stricter Neelin et al. (2006) criterion. Area averages pass significance tests on the model ensemble (Neelin et al. 2013), which points out a relationship between the extension of storm-track-associated precipitation in this region and the regional manifestation of jet stream increases at the steering level. For such differences at the boundaries of precipitation features, it remains an open question whether the CMIP5 ensemble should be given any additional weight in assessment relative to the CMIP3 ensemble.

Summertime MEM precipitation changes are characterized by higher precipitation amounts in Alaska and the Yukon, where the models all agree on the sign of the changes. All models also suggest precipitation increases along the Arctic coast across the entire length of NA. The MEM indicates reduced summertime precipitation in the east Pacific warm pool and the Caribbean, with agreement of all models in the vicinity of major Caribbean islands, the Yucatan, and in southwestern Mexico adjacent to the east Pacific warm pool. The agreement on these changes for the Caribbean and Mexico was high for CMIP3 models (e.g., Neelin et al. 2006) and is reinforced as a region of even higher intermodel agreement in CMIP5. Because of the model disagreement in projections of future tropical cyclone activity for the Atlantic and east Pacific (shown in section 6 below), it is unlikely that changes in tropical cyclone activity are responsible for these precipitation decreases given the strong model agreement in the precipitation change. 
TABLE 1. CMIP5 models evaluated in this study and their attributes.

\begin{tabular}{|c|c|c|c|c|c|}
\hline Model & Expanded name & Center & $\begin{array}{c}\text { Atmospheric } \\
\text { horizontal resolution } \\
\left({ }^{\circ} \text { lon } \times{ }^{\circ} \text { lat }\right)\end{array}$ & $\begin{array}{l}\text { No. of } \\
\text { model } \\
\text { levels }\end{array}$ & Reference \\
\hline ACCESS1.0 & $\begin{array}{l}\text { Australian Community } \\
\text { Climate and Earth- } \\
\text { System Simulator, } \\
\text { version } 1.0\end{array}$ & $\begin{array}{l}\text { Commonwealth Scientific } \\
\text { and Industrial Research } \\
\text { Organization/Bureau of } \\
\text { Meteorology, Australia }\end{array}$ & $1.875 \times 1.25$ & 38 & Bi et al. 2012 \\
\hline BCC_CSM1.1* & $\begin{array}{l}\text { Beijing Climate Center, } \\
\text { Climate System } \\
\text { Model, version } 1.1\end{array}$ & $\begin{array}{l}\text { Beijing Climate Center, } \\
\text { China Meteorological } \\
\text { Administration, China }\end{array}$ & $2.8 \times 2.8$ & 26 & Xin et al. 2013 \\
\hline CanCM4 & $\begin{array}{l}\text { Fourth Generation } \\
\text { Canadian Coupled } \\
\text { Global Climate } \\
\text { Model }\end{array}$ & $\begin{array}{l}\text { Canadian Centre for } \\
\text { Climate Modeling and } \\
\text { Analysis, Canada }\end{array}$ & $2.8 \times 2.8$ & 35 & Chylek et al. 2011 \\
\hline CanESM2* & $\begin{array}{l}\text { Second Generation } \\
\text { Canadian Earth } \\
\text { System Model }\end{array}$ & $\begin{array}{l}\text { Canadian Centre for Climate } \\
\text { Modeling and Analysis, } \\
\text { Canada }\end{array}$ & $2.8 \times 2.8$ & 35 & Arora et al. 2011 \\
\hline CCSM4* & $\begin{array}{l}\text { Community Climate } \\
\text { System Model, } \\
\text { version } 4\end{array}$ & $\begin{array}{l}\text { National Center for } \\
\text { Atmospheric Research, } \\
\text { United States }\end{array}$ & $1.25 \times 1$ & 26 & Gent et al. 2011 \\
\hline CNRM-CM5.1* & $\begin{array}{l}\text { Centre National de } \\
\text { Recherches } \\
\text { Météorologiques Cou- } \\
\text { pled Global } \\
\text { Climate Model, } \\
\text { version 5.1 }\end{array}$ & $\begin{array}{l}\text { National Centre for } \\
\text { Meteorological Research, } \\
\text { France }\end{array}$ & $1.4 \times 1.4$ & 31 & $\begin{array}{l}\text { Voldoire et al. } \\
2013\end{array}$ \\
\hline CSIRO Mk3.6.0* & $\begin{array}{l}\text { Commonwealth } \\
\text { Scientific and } \\
\text { Industrial Research } \\
\text { Organisation Mark, } \\
\text { version 3.6.0 }\end{array}$ & $\begin{array}{l}\text { Commonwealth Scientific } \\
\text { and Industrial Research } \\
\text { Organization/Queensland } \\
\text { Climate Change Centre of } \\
\text { Excellence, Australia }\end{array}$ & $1.8 \times 1.8$ & 18 & $\begin{array}{l}\text { Rotstayn et al. } \\
\quad 2010\end{array}$ \\
\hline EC-EARTH & EC-Earth Consortium & EC-Earth Consortium & $1.125 \times 1.12$ & 62 & $\begin{array}{l}\text { Hazeleger et al. } \\
2010\end{array}$ \\
\hline FGOALS-s2 & $\begin{array}{l}\text { Flexible Global Ocean- } \\
\text { Atmosphere-Land } \\
\text { System Model } \\
\text { gridpoint, second } \\
\text { spectral version }\end{array}$ & $\begin{array}{l}\text { State Key Laboratory of } \\
\text { Numerical Modeling } \\
\text { for Atmospheric } \\
\text { Sciences and Geophysical } \\
\text { Fluid Dynamics (LASG), } \\
\text { Institute of Atmospheric } \\
\text { Physics, Chinese Academy } \\
\text { of Sciences }\end{array}$ & $2.8 \times 1.6$ & 26 & Bao et al. 2013 \\
\hline GFDL CM3* & $\begin{array}{l}\text { Geophysical Fluid } \\
\text { Dynamics Laboratory } \\
\text { Climate Model, } \\
\text { version } 3\end{array}$ & $\begin{array}{l}\text { NOAA/Geophysical Fluid } \\
\text { Dynamics Laboratory, } \\
\text { United States }\end{array}$ & $2.5 \times 2.0$ & 48 & $\begin{array}{l}\text { Donner et al. } \\
2011\end{array}$ \\
\hline GFDL-ESM2G/M* & $\begin{array}{l}\text { Geophysical Fluid } \\
\text { Dynamics Laboratory } \\
\text { Earth System Model } \\
\text { with Generalized } \\
\text { Ocean Layer Dynamics } \\
\text { (GOLD) component } \\
\text { (ESM2G) and with } \\
\text { Modular Ocean } \\
\text { Model } 4 \text { (MOM4) } \\
\text { component (ESM2M) }\end{array}$ & $\begin{array}{l}\text { NOAA/Geophysical Fluid } \\
\text { Dynamics Laboratory, } \\
\text { United States }\end{array}$ & $2.5 \times 2.0$ & 24 & $\begin{array}{l}\text { Donner et al. } \\
2011\end{array}$ \\
\hline
\end{tabular}


TABle 1. (Continued)

\begin{tabular}{|c|c|c|c|c|c|}
\hline Model & Expanded name & Center & $\begin{array}{c}\text { Atmospheric } \\
\text { horizontal resolution } \\
\left({ }^{\circ} \text { lon } \times{ }^{\circ} \text { lat }\right)\end{array}$ & $\begin{array}{l}\text { No. of } \\
\text { model } \\
\text { levels }\end{array}$ & Reference \\
\hline GISS-E2H/-E2-R* & $\begin{array}{l}\text { Goddard Institute for } \\
\text { Space Studies Model E, } \\
\text { coupled with the } \\
\text { HYCOM ocean } \\
\text { model (GISS-E2H) } \\
\text { and coupled with the } \\
\text { Russell ocean model } \\
\text { (GISS-E2-R) }\end{array}$ & $\begin{array}{l}\text { National Aeronautics and } \\
\text { Space Administration } \\
\text { (NASA) Goddard } \\
\text { Institute for Space } \\
\text { Studies, United States }\end{array}$ & $2.5 \times 2.0$ & 40 & Kim et al. 2012 \\
\hline HadCM3* & $\begin{array}{l}\text { Hadley Centre Coupled } \\
\text { Model, version } 3\end{array}$ & $\begin{array}{l}\text { Met Office Hadley } \\
\text { Centre, United Kingdom }\end{array}$ & $3.75 \times 2.5$ & 19 & Collins et al. 2001 \\
\hline HadGEM2-CC & $\begin{array}{l}\text { Hadley Centre Global } \\
\text { Environment Model, } \\
\text { version 2-Carbon Cycle }\end{array}$ & $\begin{array}{l}\text { Met Office Hadley } \\
\text { Centre, United } \\
\text { Kingdom }\end{array}$ & $1.8 \times 1.25$ & 60 & Jones et al. 2011 \\
\hline HadGEM2-ES* & $\begin{array}{l}\text { Hadley Centre Global } \\
\text { Environment Model, } \\
\text { version 2-Earth } \\
\text { System }\end{array}$ & $\begin{array}{l}\text { Met Office Hadley } \\
\text { Centre, United } \\
\text { Kingdom }\end{array}$ & $1.8 \times 1.25$ & 60 & Jones et al. 2011 \\
\hline INM-CM4.0* & $\begin{array}{l}\text { Institute of Numerical } \\
\text { Mathematics Coupled } \\
\text { Model, version } 4.0\end{array}$ & $\begin{array}{l}\text { Institute of Numerical } \\
\text { Mathematics, Russia }\end{array}$ & $2 \times 1.5$ & 21 & Volodin et al. 2010 \\
\hline IPSL-CM5A-LR* & $\begin{array}{l}\text { L'Institut Pierre-Simon } \\
\text { Laplace Coupled } \\
\text { Model, version 5, } \\
\text { coupled with NEMO, } \\
\text { low resolution }\end{array}$ & $\begin{array}{l}\text { L'Institut Pierre-Simon } \\
\text { Laplace, France }\end{array}$ & $3.75 \times 1.8$ & 39 & $\begin{array}{l}\text { Dufresne et al. } \\
2013\end{array}$ \\
\hline IPSL-CM5A-MR & $\begin{array}{l}\text { L'Institut Pierre-Simon } \\
\text { Laplace Coupled } \\
\text { Model, version 5, } \\
\text { coupled with NEMO, } \\
\text { mid resolution }\end{array}$ & $\begin{array}{l}\text { L'Institut Pierre-Simon } \\
\text { Laplace, France }\end{array}$ & $2.5 \times 1.25$ & 39 & $\begin{array}{l}\text { Dufresne et al. } \\
2013\end{array}$ \\
\hline MIROC5* & $\begin{array}{l}\text { Model for Interdisciplinary } \\
\text { Research on Climate, } \\
\text { version } 5\end{array}$ & $\begin{array}{l}\text { Atmosphere and Ocean } \\
\text { Research Institute (The } \\
\text { University of Tokyo), } \\
\text { National Institute for } \\
\text { Environmental Studies, } \\
\text { and Japan Agency for } \\
\text { Marine-Earth Science } \\
\text { and Technology, Japan }\end{array}$ & $1.4 \times 1.4$ & 40 & $\begin{array}{l}\text { Watanabe et al. } \\
2010\end{array}$ \\
\hline MIROC-ESM* & $\begin{array}{l}\text { Model for Interdisciplinary } \\
\text { Research on Climate, } \\
\text { Earth System Model }\end{array}$ & $\begin{array}{l}\text { Japan Agency for } \\
\text { Marine-Earth Science and } \\
\text { Technology, } \\
\text { Atmosphere and Ocean } \\
\text { Research Institute (The } \\
\text { University of Tokyo), } \\
\text { and National Institute } \\
\text { for Environmental } \\
\text { Studies, Japan }\end{array}$ & $2.8 \times 2.8$ & 80 & $\begin{array}{l}\text { Watanabe et al. } \\
2011\end{array}$ \\
\hline MIROC-ESM-CHEM & $\begin{array}{l}\text { Model for Interdisciplinary } \\
\text { Research on Climate, } \\
\text { Earth System Model, } \\
\text { Chemistry Coupled }\end{array}$ & $\begin{array}{l}\text { Japan Agency for } \\
\text { Marine-Earth Science } \\
\text { and Technology, } \\
\text { Atmosphere and Ocean } \\
\text { Research Institute (The } \\
\text { University of Tokyo), } \\
\text { and National Institute } \\
\text { for Environmental } \\
\text { Studies, Japan }\end{array}$ & $2.8 \times 2.8$ & 80 & $\begin{array}{l}\text { Watanabe et al. } \\
2011\end{array}$ \\
\hline
\end{tabular}


TABLE 1. (Continued)

\begin{tabular}{|c|c|c|c|c|c|}
\hline Model & Expanded name & Center & $\begin{array}{c}\text { Atmospheric } \\
\text { horizontal resolution } \\
\left({ }^{\circ} \text { lon } \times{ }^{\circ} \text { lat }\right)\end{array}$ & $\begin{array}{l}\text { No. of } \\
\text { model } \\
\text { levels }\end{array}$ & Reference \\
\hline MPI-ESM-LR* & $\begin{array}{l}\text { Max Planck Institute } \\
\text { Earth System Model, } \\
\text { low resolution }\end{array}$ & $\begin{array}{l}\text { Max Planck Institute for } \\
\text { Meteorology, Germany }\end{array}$ & $1.9 \times 1.9$ & 47 & $\begin{array}{l}\text { Jungclaus et al. } \\
\text { 2006; Zanchettin } \\
\text { et al. } 2012\end{array}$ \\
\hline MRI-CGCM3* & $\begin{array}{l}\text { Meteorological } \\
\text { Research Institute } \\
\text { Coupled Atmosphere- } \\
\text { Ocean General } \\
\text { Circulation Model, } \\
\text { version } 3\end{array}$ & $\begin{array}{l}\text { Meteorological Research } \\
\text { Institute, Japan }\end{array}$ & $1.1 \times 1.1$ & 48 & Yukimoto et al. 2012 \\
\hline $\begin{array}{l}\text { NorESM1-M* and } \\
\text { NorESM1-ME }\end{array}$ & $\begin{array}{l}\text { Norwegian Earth System } \\
\text { Model, version } 1 \\
\text { (intermediate } \\
\text { resolution) and with } \\
\text { carbon cycle }\end{array}$ & $\begin{array}{l}\text { Norwegian Climate } \\
\text { Center, Norway }\end{array}$ & $2.5 \times 1.9$ & 26 & Zhang et al. 2012 \\
\hline
\end{tabular}

* Core model.

Figure S1 (in the supplemental material) provides maps of the MEM percentage precipitation change and its corresponding multimodel standard deviation for the core models used here.

Figure 3 shows the comparable MEM changes for surface air temperature (2-m level) during JJA and DJF. As expected, warming is projected across all regions of $\mathrm{NA}$, with the greatest warming concentrated during wintertime at high latitude regions, where the MEM temperature increase peaks near $15^{\circ} \mathrm{C}$ in the vicinity of Hudson Bay. Land regions warm more than ocean regions, associated in part with ocean heat storage causing a lag relative to the ongoing greenhouse gas increase, as in the CMIP3-based assessments (Meehl et al. 2007). Over the lower 48 United States and most of Canada, the MEM warming exceeds $5^{\circ} \mathrm{C}$ in $\mathrm{JJA}$, with an intermodel standard deviation slightly over $1^{\circ} \mathrm{C}$ in the United States increasing to $2^{\circ} \mathrm{C}$ in northern Canada. In DJF, both the ensemble mean warming and the intermodel standard deviation have a strong poleward gradient, with warming around $4^{\circ} \mathrm{C}$ (standard deviation of $1^{\circ} \mathrm{C}$ ) in the southern United States, increasing to over $12^{\circ} \mathrm{C}$ (standard deviation of over $3^{\circ} \mathrm{C}$ ) in far northern Canada.

While we cannot provide extensive detail on all aspects of projected regional precipitation and temperature change here, Tables S1-S10 (in the supplemental material) provide the MEM and multimodel standard deviation of precipitation and temperature changes as a function of season for the regions defined in Fig. 4. Comparing the individual models or the standard deviation of the model ensemble provides additional information regarding how much confidence should be placed in the MEM mean for a particular region. For instance, in central North America in JJA (Table S9), the intermodel standard deviation is roughly double the MEM value, indicating low confidence that this should be interpreted as significantly different from zero. This is consistent with the summary statistics in Fig. 2, in which only a small portion of this region passes either the binomial test for agreement on sign or the Neelin et al. (2006) criterion that includes a model-by-model $t$ test for significance with respect to interannual variability.

\section{b. Evapotranspiration and runoff}

Future changes in precipitation and how it is partitioned into evaporation and runoff have implications for water availability and the occurrence of extreme hydrological events such as floods and droughts. CMIP3 projections indicated that changes in precipitation coupled with increased potential for evaporation from higher atmospheric moisture holding capacity leads to the drying of subtropical regions including Central America and the southwestern United States (Wang 2005; Seager et al. 2007; Sheffield and Wood 2008) and an increased potential for flooding because of more frequent and intense precipitation events, changes in snow accumulation and melt timing, and changes in antecedent soil moisture conditions (e.g., Hamlet and Lettenmaier 2007; Das et al. 2011). Here we analyze changes in the terrestrial water budget on a regional basis by calculating $30-\mathrm{yr}$ averages in annual mean precipitation, evapotranspiration, and runoff between 1971-2000 and 2071-2100 for 15 core models for six regions of NA (Fig. 4). Changes in water storage (i.e., surface water, soil moisture, groundwater, etc.) over the 30-yr periods are assumed to be small compared to the other terms. Thus, precipitation should equal the sum of evapotranspiration and runoff. 

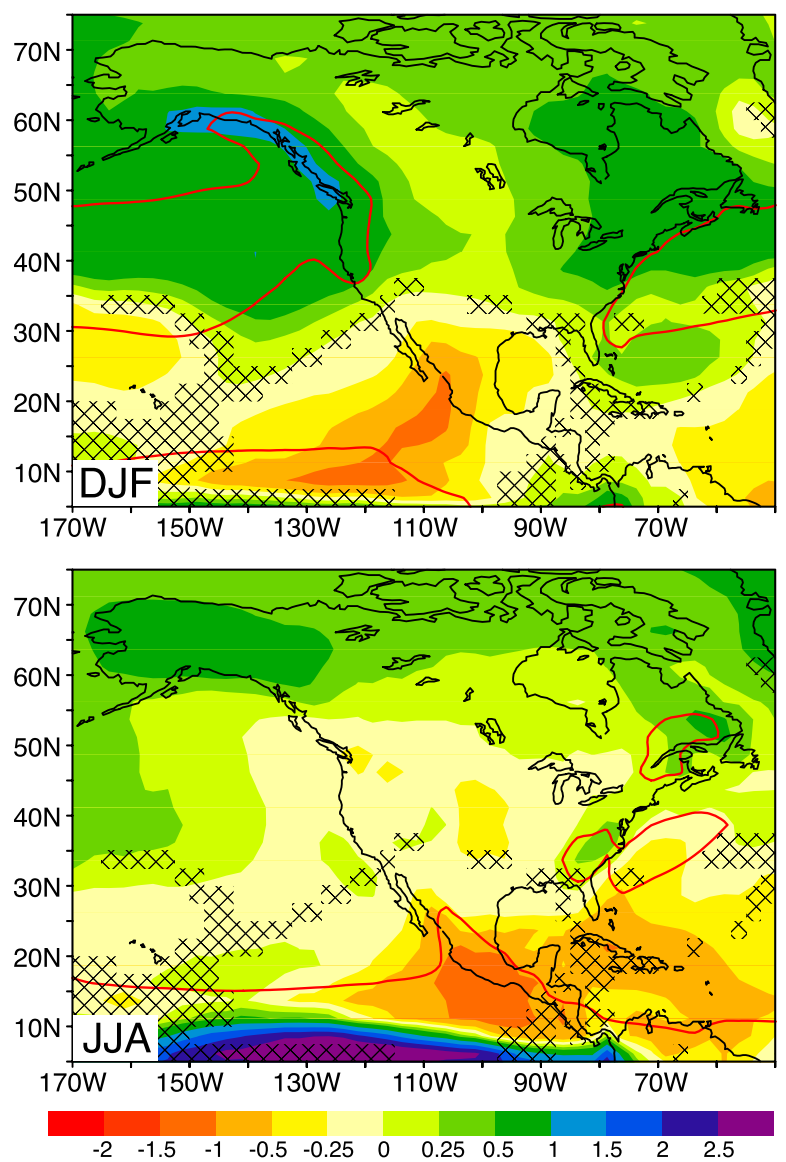

FIG. 1. CMIP5 17-member multimodel, multirun ensemble-mean precipitation change $\left(\mathrm{mm} \mathrm{day}^{-1}\right)$ for RCP8.5 for 2070-99 relative to 1961-90 base period for (top) DJF and (bottom) JJA. Models used: BCC_CSM1.1, CanESM2, CCSM4, CNRM-CM5.1, CSIRO Mk3.6.0, FGOALS-s2, GFDL CM3, GFDL-ESM2M, GISS-E2-R, HadGEM2-CC, INM-CM4.0, IPSL-CM5A, MIROC5, MIROCESM, MPI-ESM-LR, MRI-CGCM3, and NorESM1-M (see Table 1). The red line is the $4 \mathrm{~mm} \mathrm{day}^{-1}$ contour of the $1961-90$ climatology. Grid points are cross hatched where the MEM does not pass a two-sided $t$ test for differences of the mean with respect to interannual variability at the $95 \%$ level (see text). All models are interpolated to a common $2.5^{\circ}$ by $2.5^{\circ}$ latitude-longitude grid as in the corresponding climatology figure in Part I (Fig. 1).

For western and eastern NA regions, an increase in MEM annual precipitation is projected, consistent with Fig. 1. The precipitation increases in these regions are apportioned more to evapotranspiration than to runoff (which is important for understanding changes in the availability of water), although models tend to overestimate evapotranspiration in historical simulations (Part I). In the central region, annual mean precipitation increases are more modest. In high latitudes (Alaskanorthwest Canada and northeast Canada) the MEM precipitation is projected to increase, consistent with Fig. 1, and is mostly partitioned into increases in runoff,
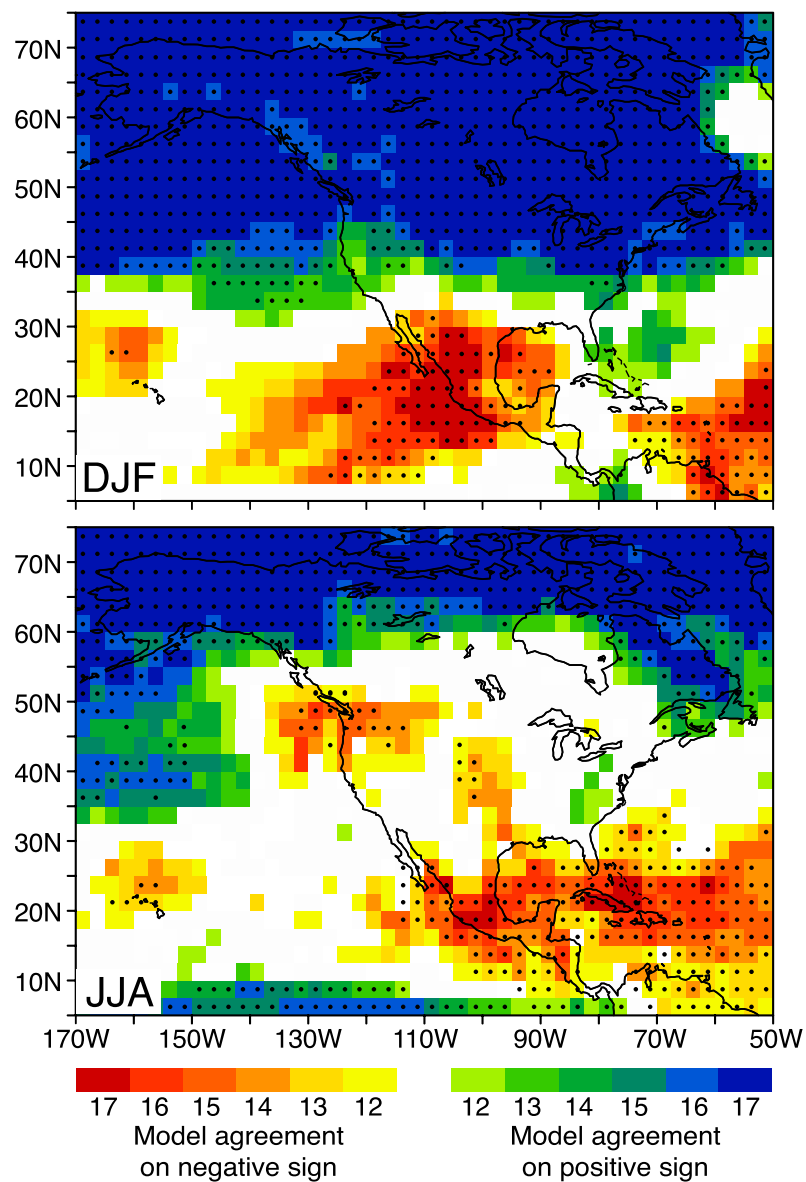

FIG. 2. The (top) DJF and (bottom) JJA plots of model agreement on sign of end-of-century precipitation change for the CMIP5 RCP8.5 scenario for the years 2070-99, relative to a base period of 1961-90. Red colors indicate the number of models (out of 17) that agree on a negative precipitation change; blue colors indicate the number of models that agree on a positive precipitation change. The color shaded areas (12 or more models agreeing on sign) pass a binomial test rejecting the hypothesis of $50 \%$ probability of either sign at the $95 \%$ level; areas not passing at this level are left unshaded. Stippled areas use a version of the Neelin et al. (2006) criterion to show grid points where more than half ( 9 or more) of the models both pass a two-tailed $t$ test at the $95 \%$ confidence level and agree on sign. Tebaldi et al. (2011) use a modified version of this test that is effectively the same over the region shown here. Both of these criteria use significance tests on individual models that are more restrictive than the $t$ test in Fig. 1 or the binomial test, which test characteristics of the ensemble rather than individual models (for comparisons of significance tests, see Langenbrunner and Neelin 2013).

rather than increases in evapotranspiration. This is likely because 1) higher temperatures will increase the proportion of rainfall to snowfall and will melt the snowpack earlier and faster in the spring and 2) the increased precipitation will come in more intense events. In Central America, precipitation is projected to decrease with most of the decrease manifesting in decreasing runoff. 


\section{c. Snow}

Reductions in snow cover extent and amount are expected in the future as a result of increasing temperatures modified by changes in precipitation and their seasonal interactions. This has important implications for water supply, hydropower generation, and ecosystems and feedbacks with the underlying soil and permafrost (Lawrence and Slater 2010) and to the climate system through changes in albedo (Qu and Hall 2007). CMIP3 projections (Räisänen 2008) indicated that warming reduces the snow season length from both ends across NA, but midwinter snow water equivalent (SWE) is expected to increase in high latitude colder regions because of increased winter snowfall but decrease in regions to the south, where temperature effects on precipitation phase and melting dominate any changes in precipitation amount.

Changes in snow are calculated using the CMIP5 model SWE values. Figure 5 (top) shows the seasonal cycle of changes between 2070-99 and 1971-2000 in monthly mean SWE averaged over NA for 15 core models. All models project a decrease in SWE throughout the year with maximum changes during the peak of the snow season in January-April. The MEM decrease in SWE averaged over NA is about $-30 \mathrm{~mm}$ (with models ranging from -80 to $-10 \mathrm{~mm}$ ) in the spring and about $-10 \mathrm{~mm}$ in the summer (ranging from 0 to $-65 \mathrm{~mm}$ ). Spatially, the majority of NA (south of $70^{\circ} \mathrm{N}$ ) is projected to experience a decline in SWE where increasing temperatures have a dominant effect by reducing the ratio of snowfall to rainfall and accelerating melting (Fig. 5, bottom). These reductions are concentrated in the Rocky Mountains to southern Alaska, in the eastern provinces of Canada, and with lower magnitude in the Canadian Prairies. North of $70^{\circ} \mathrm{N}$, SWE is projected to increase in places because of increasing precipitation, which outweighs the effects of increasing temperature. Uncertainties across models are likely associated with differences in the temperature projections, to which modeled snow is highly sensitive (Räisänen 2008). At higher latitudes, the sign of the change is uncertain in transitional regions because of the competing effects of increasing snowfall and warming temperatures and in regions of increasing SWE where the magnitude of the precipitation increase is also quite uncertain.

\section{d. Growing season length}

Projected warming will likely impact temperaturesensitive flora and fauna, as well as agriculture. We calculate changes in biophysically relevant temperature thresholds including the last spring freeze, the first
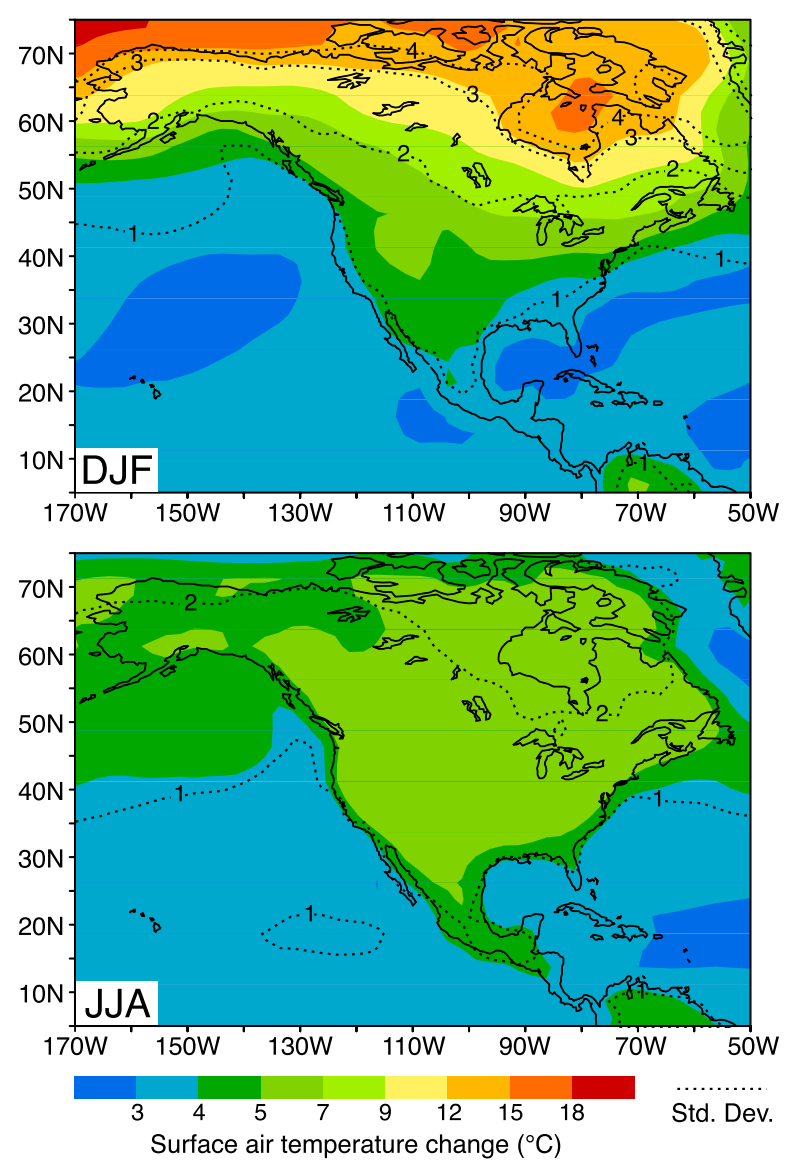

FIG. 3. CMIP5 17-member multimodel, multirun ensemblemean surface air temperature $\left(2-\mathrm{m}\right.$ level) change $\left({ }^{\circ} \mathrm{C}\right.$; contour interval shown on color bar) for RCP8.5 for 2070-99 relative to the 1901-60 base period for (top) DJF and (bottom) JJA. All grid points pass the two-tailed $t$ test for the multimodel ensemble mean at the $95 \%$ level. Contours for the standard deviation among individual ensemble member surface temperature change are superimposed (contour interval of $1^{\circ} \mathrm{C}$ ).

autumn freeze, and the growing season length at 20712100. The growing season length is defined as the number of days between the last spring freeze and the first autumn freeze in the same year. A hard freeze occurs when the daily maximum temperature drops below $-2^{\circ} \mathrm{C}$. (Schwartz et al. 2006). An analysis of 14 core models (Fig. 6) indicates that the growing season will increase across the NA continent by the end of the century, although substantial variability in the magnitude of these changes exists on a regional basis. All changes are statistically significant at the $95 \%$ level relative to interannual variability in the observations (see Part I) with implications for impacts on agriculture and natural vegetation. The largest changes occur over the western United States and northern Mexico, where MEM increases of 40 days or more are projected. It 

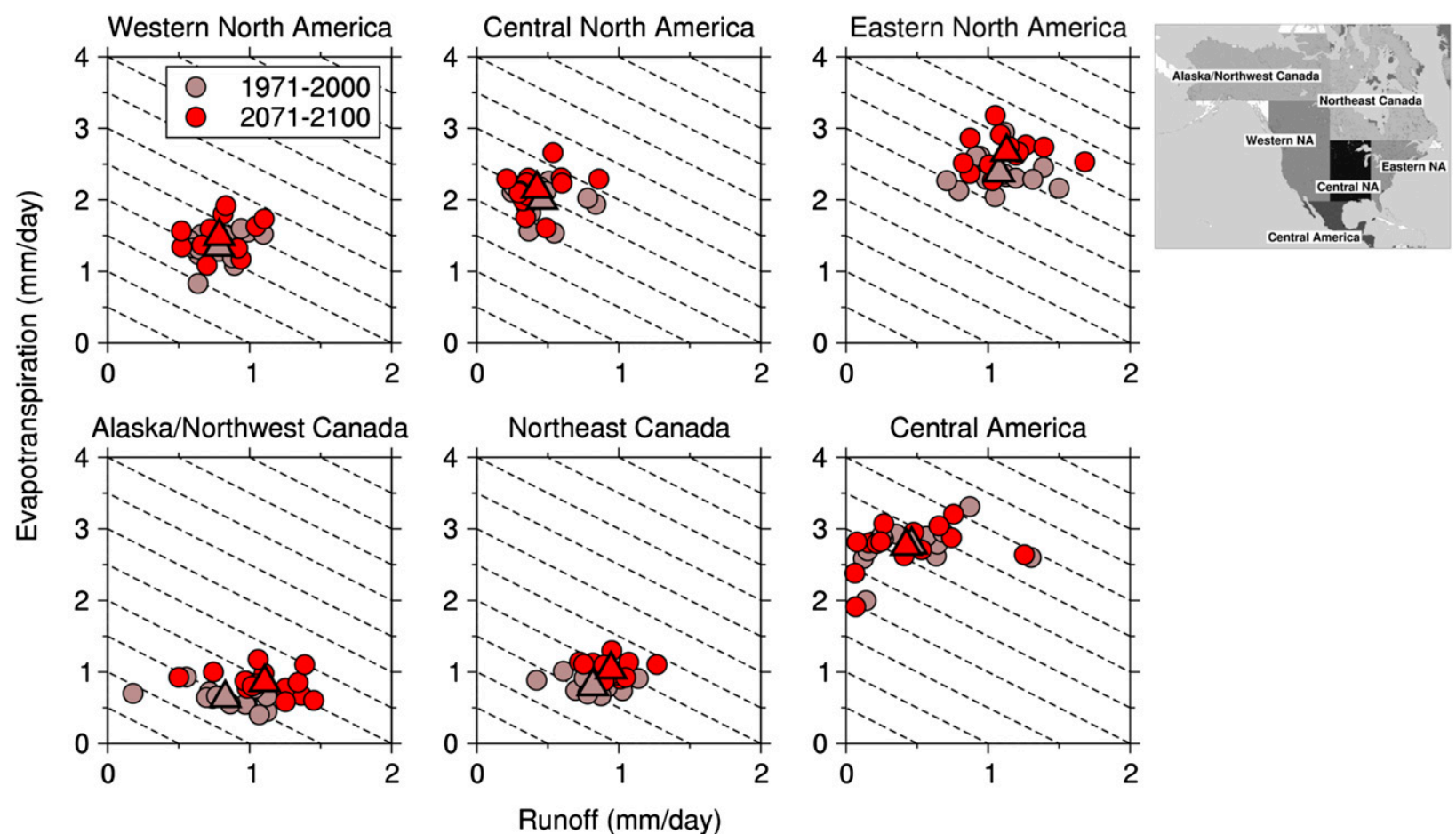

FIG. 4. The 30-yr means from the historical (1971-2000) and RCP8.5 experiment (2071-2100) for regionally averaged runoff and evapotranspiration $\left(\mathrm{mm} \mathrm{day}^{-1}\right)$. Six regions were defined for the NA continent: Central America (CAM), western North America (WNA), central North America (CNA), eastern North America (ENA), Alaska/northwest Canada (ALA), and northeast Canada (NEC). The circles represent individual climate models. The triangles represent the MEM values. Precipitation balances runoff plus evapotranspiration over decadal time scales by assuming no change in water storage. The diagonal lines represent contours of precipitation. A shift in the MEM toward the top right indicates an increase in precipitation. Values are calculated for 15 core models (BCC_CSM1.1, CanESM2, CCSM4, CNRM-CM5.1, GFDL CM3, GFDL-ESM2G, GISS-E2-R, INM-CM4.0, IPSL-CM5A-LR, MIROC5, MIROCESM, MPI-ESM-LR, MRI-CGCM3, and NorESM1-M) using one ensemble member each.

should be noted that these same regions have complex terrain and are characterized by some of the largest negative biases in historical simulations (Part I), as well as the largest multimodel standard deviation in growing season length change of up to 8 days. In the central United States and Canada, increases of about 3-5 weeks are projected. The lengthening of the growing season is caused by both last spring freezes that are earlier and first autumn freezes that are later (not shown), but the change in the former is generally larger. A complementary analysis detailing changes in frost days is shown in the supplementary material.

\section{e. Extreme events}

To assess the projected changes in the frequency of occurrence (FOC) of extreme persistent dry-wet events over NA, we use the eight core models that contain three or more runs for both the historical and RCP8.5 experiments (see caption). Because these events are rare, three runs from each model are needed in order to produce enough events for meaningful statistics. The methodology used to define extreme events is the same as in Part I and repeated in the Fig. 7 caption. Note that because these calculations account for only liquid precipitation, results in the coldest northern regions are questionable and not discussed.

We first calculated the difference in FOC of extreme precipitation events using each experiment's own climatology as a baseline for that experiment. Therefore, the historical climatology is from 1850 to 2005 and the RCP8.5 climatology is from 2006 to 2100 . Each model shows little difference in the FOCs for both positive (wet) and negative (dry) events (not shown). The MEM difference between the positive and negative events (Fig. 7j) also shows no robust change between the model projections and historical data when the different climatologies are used. When the historical climatology is used as a baseline for the RCP8.5 experiment instead of the RCP8.5 climatology, all models but HadGEM2-ES show a decrease in the number of positive events in Mexico and the southwest United States and an increase in such events in the northeastern United States. The opposite is true for negative (dry) events. This shows the impact of the changing climatology between the 

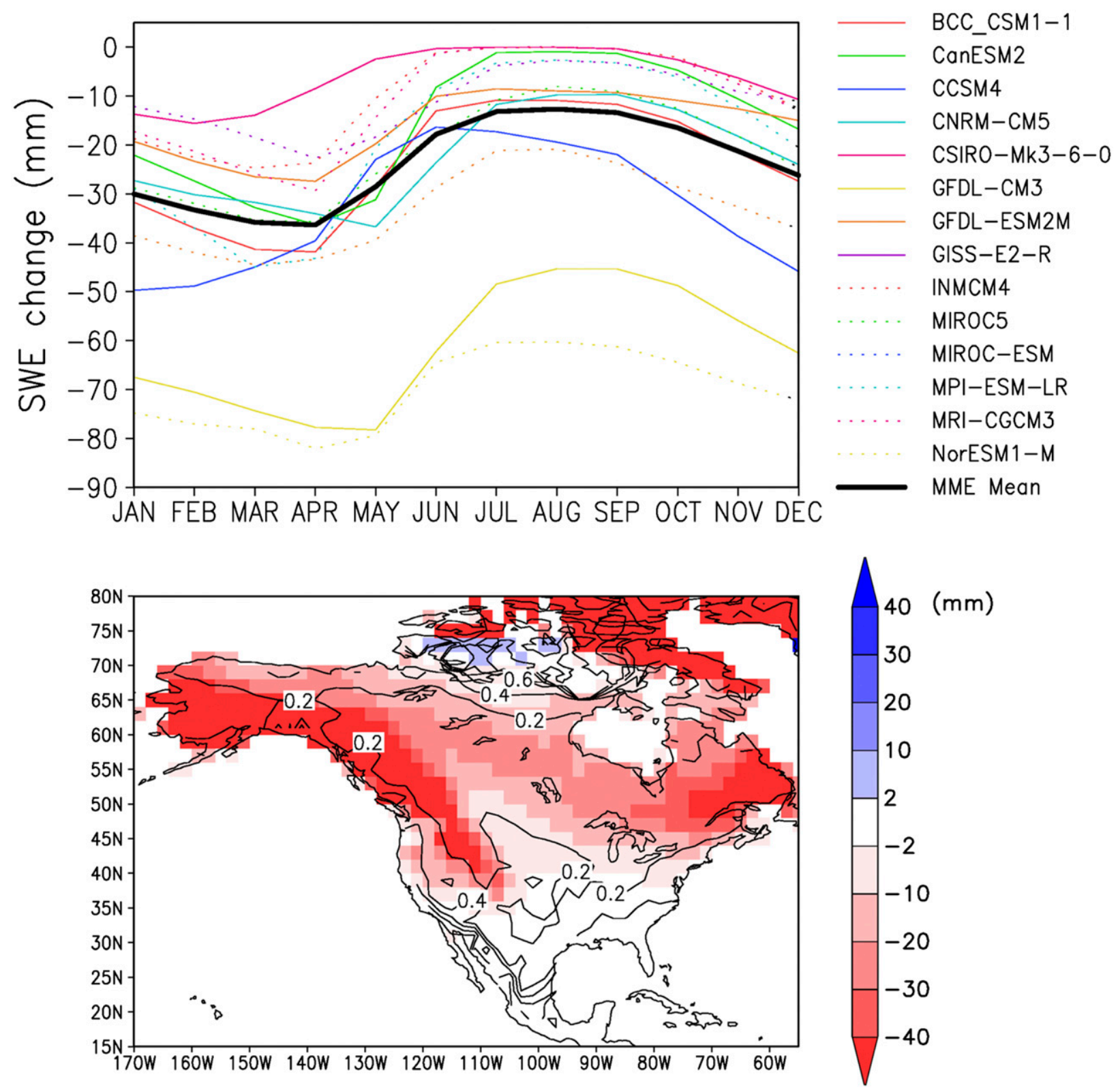

FIG. 5. Changes in SWE (mm) from 14 CMIP5 core models (one ensemble member each) from 1971-2000 to 2071-2100 for the RCP8.5 scenario. (top) Mean monthly change in SWE averaged over North America $\left(25^{\circ}-80^{\circ} \mathrm{N}, 170^{\circ}-65^{\circ} \mathrm{W}\right)$ and (bottom) spatial distribution of change in winter-spring [November-May (NDJFMAM)] SWE (shading) and coefficient of variation (CV) of changes in SWE across models (contours). Some of the models have spuriously high snow accumulations at isolated grid cells and these are filtered out. The models are as follows: BCC_CSM1.1, CanESM2, CCSM4, CNRM-CM5.1, CSIRO Mk3.6.0, GFDL CM3, GFDL-ESM2M, GISS-E2-R, INM-CM4.0, MIROC5, MIROC-ESM, MPI-ESM-LR, MRI-CGCM3, and NorESM1-M.

experiments. These results are illustrated in Figs. 7a-h for individual models and in Fig. 7i for the MEM. The patterns among the models are similar, but they differ in magnitude and the precise location of the zero line. For example, IPSL-CM5A-LR shows an increase in dry events over the southern United States and Mexico, but the CCSM4 indicates that only Mexico is impacted. A metric showing the difference between area averages of the northeast quadrant $\left(94^{\circ}-75^{\circ} \mathrm{W}, 35^{\circ}-48^{\circ} \mathrm{N}\right)$ and the southwest quadrant $\left(123^{\circ}-95^{\circ} \mathrm{W}, 15^{\circ}-35^{\circ} \mathrm{N}\right)$ of NA is also given (Table 2). The metric values also have a small range between 0.31 and 0.48 when HadGEM2-ES is removed. With the spread taken into consideration, we conclude that more droughts are projected over Mexico and more persistent wet spells are projected over the northeast United States (Fig. 7i). 
The projected changes of extreme surface temperature during 2081-2100 relative to 1981-2000 are shown in Fig. 8, calculated using one ensemble member from each of the 11 models described in the caption (10 are core models). Daily maximum surface temperatures $T_{\max }$ are used to compute the number of days per year that exceed $90^{\circ}$ (Fig. 8a) and $100^{\circ} \mathrm{F}$ (Fig. 8b), respectively. The MEM projections show an increase of $60 \%-$ $300 \%$ (50-80 days) annually with $T_{\max }$ warmer than $90^{\circ} \mathrm{F}$ in the southern United States and northern Mexico. In the southeastern United States, southern Texas, and northern Mexico, the number of days with $T_{\max }$ warmer than $90^{\circ} \mathrm{F}$ is projected to increase to nearly 80 . The MEM projections also show that the number of days with $T_{\max }$ warmer than $100^{\circ} \mathrm{F}$ will increase $80 \%-400 \%$ (40-80 days) in parts of the south-central and southwestern United States. Across the southern United States and northern Mexico, the change in frequency of extreme surface temperatures are robust, suggested by the MEM projections having greater difference than the intermodel spread of the changes. However, greater uncertainty exists in other areas where MEM increases have the same magnitude as the standard deviation, in particular increases of $90^{\circ} \mathrm{F}$ days in the northeastern United States and northern Rockies and $100^{\circ} \mathrm{F}$ day changes across the northern half of the United States.

\section{Regional climate}

\section{a. North Pacific and North Atlantic storm tracks}

The projected change in Northern Hemisphere stormtrack (ST) activity is examined based on 6-hourly data provided by 15 of the 17 core models (Fig. 9). Here, ST activity is defined based on meridional wind and SLP variance statistics computed using a 24-h difference filter (Wallace et al. 1988) that highlights the synoptic time scale (1.2-6 days).

Near the tropopause $(250 \mathrm{hPa})$, the models project a strengthening of ST activity on the poleward flank of the historical ST peak and a slight weakening on the equatorward flank during winter. In summer, the models project a significant decrease in upper-tropospheric ST activity south of the ST peak and weak increase north of it. These results are consistent with previous studies based on CMIP3 (e.g., Yin 2005; Teng et al. 2008) that indicate a poleward shift of the ST under global warming. In the midtroposphere $(500 \mathrm{hPa})$ and near the surface, the models generally project a significant decrease in ST activity extending from the Pacific across North America into the Atlantic in both seasons. This contrasting upper-level and near-surface change in winter
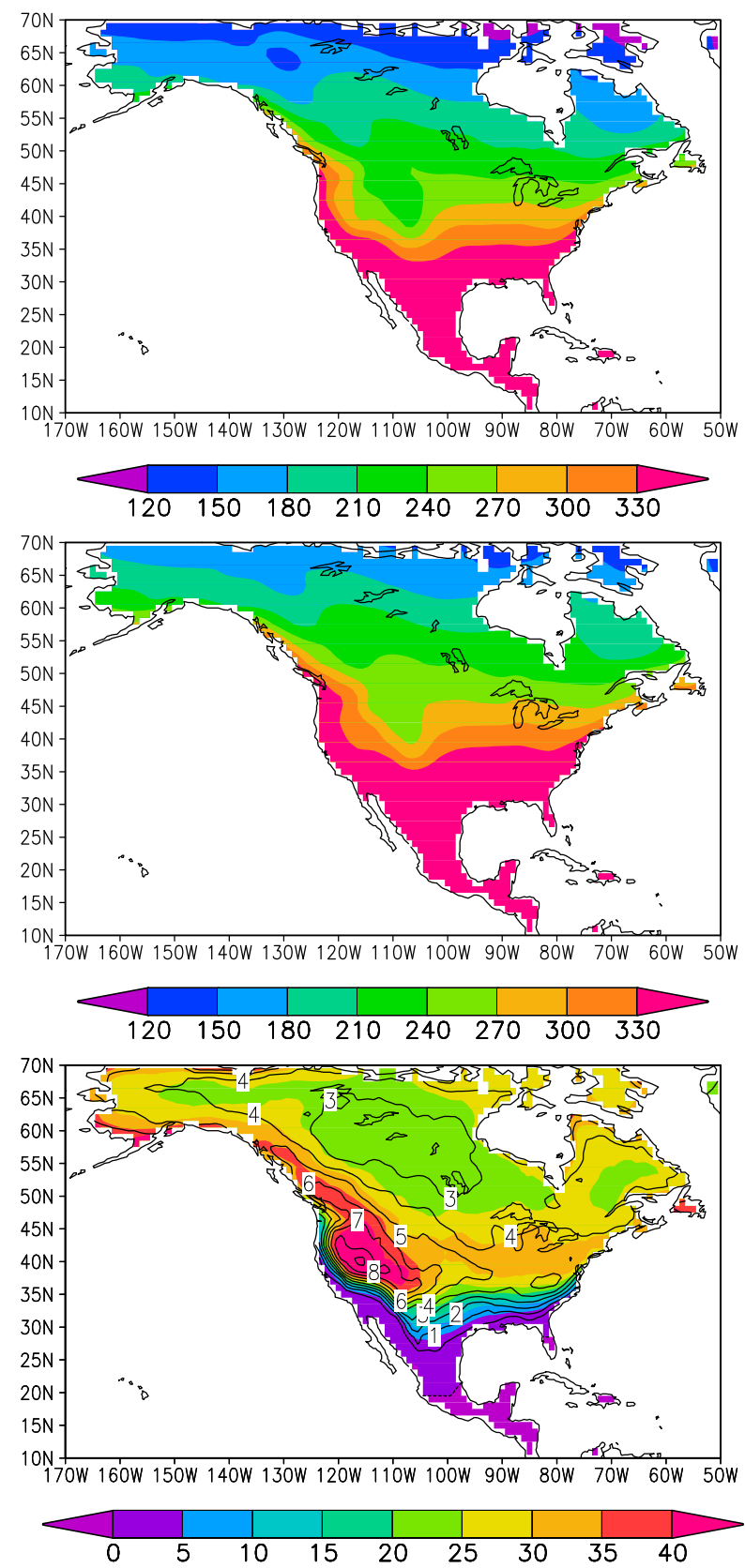

FIG. 6. (bottom) Projected changes in growing season length for 14 core CMIP5 models (BCC_CSM1.1, CanESM2, CCSM4, CSIRO Mk3.6.0, GFDL CM3, GFDL-ESM2M, HadGEM2-ES, INMCM4.0, IPSL-CM5A-LR, MIROC5, MIROC-ESM, MRI-CGCM3, MPI-ESM-LR, and NorESM1-M; all for the first ensemble member) for RCP8.5. Multimodel standard deviations are also shown as contours. Also shown, are the multimodel ensemble growing season lengths for (top) the historical runs (1971-2000) and (middle) RCP8.5 (2071-2100). Changes are calculated as the difference between the mean for 2071-2100 and 1971-2000. We define the growing season length following Schwartz et al. (2006), which is the number of days between the last spring freeze of the year and the first hard freeze of the autumn in the same year. A hard freeze is defined when the daily maximum temperature drops below $-2^{\circ} \mathrm{C}$. Values were calculated on the model grid, interpolated to $2.0^{\circ}$ resolution, and then averaged over 1971-2000 for the historical and 2071-2100 for the RCP8.5 scenario. 
a) CanESM2

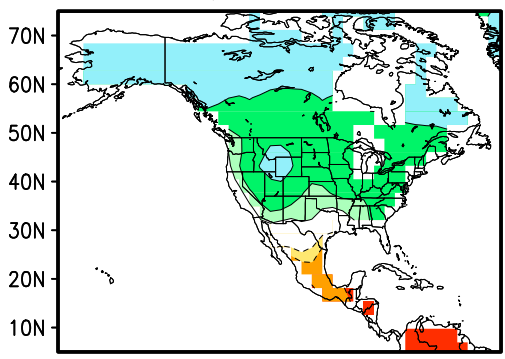

b) $\operatorname{ccsm} 4$

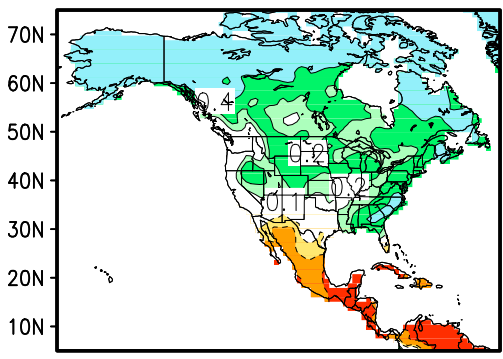

c) CNRM-CM5.1

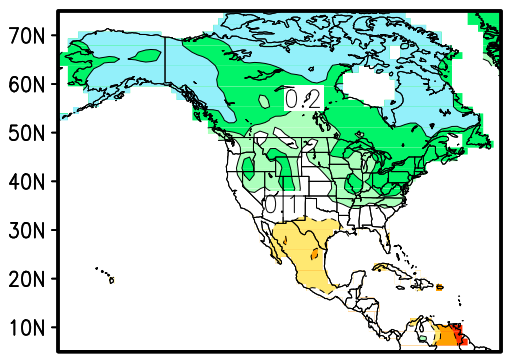

d) $\operatorname{CSIRO}-M k 3.6 .0$

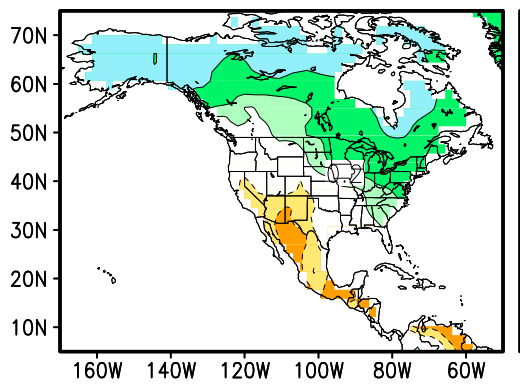

e) HadGEM2-ES

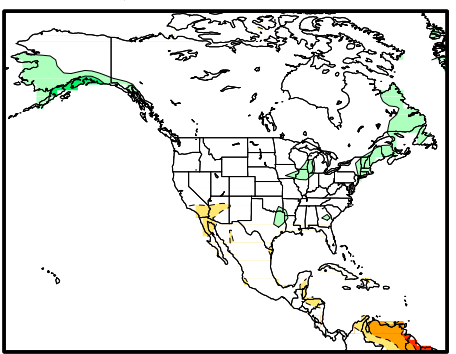

f) IPSL-CM5A-LR

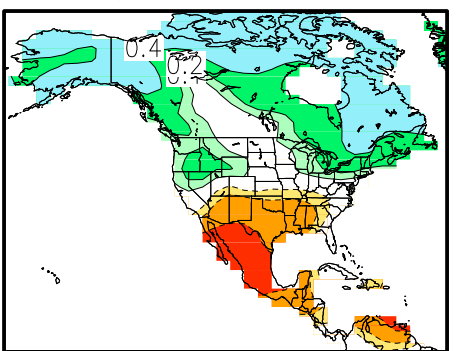

g) MIROC5

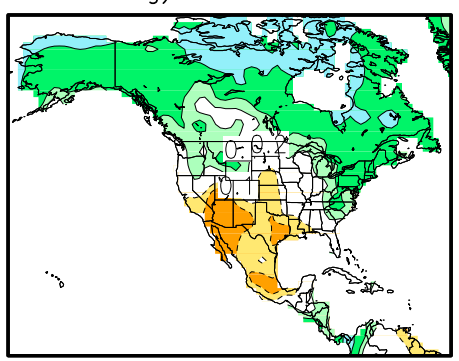

h) $M P \mid-E S M-L R$

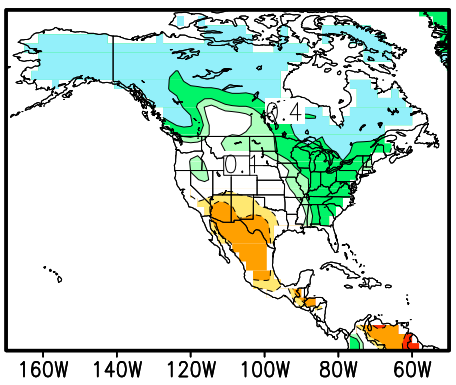

i) Ens Mean

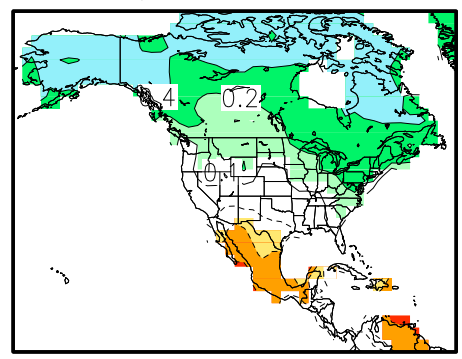

j) Ens Mean - RCP 8.5 Clim*

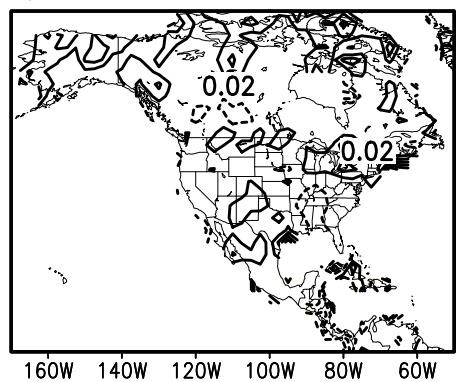

* RCP8.5(RCP8.5 Clim) - Hist(Hist Clim)

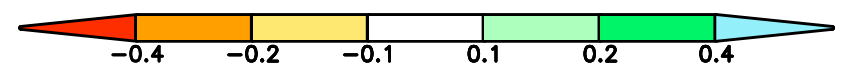

FIG. 7. The difference in FOC for RCP8.5 projection runs minus historical runs both calculated using the historical climatology defined by the 6-month standardized precipitation index (SPI6) averaged over positive (wet) events minus negative (dry) events for (a) CanESM2, (b) CCSM4, (c) CNRM-CM5.1, (d) CSIRO Mk3.6.0, (e) HadGEM2-ES, (f) IPSL-CM5A-LR, (g) MIROC5, (h) MPI-ESM-LR, and (i) the equally weighted ensemble mean. In (a)-(i), contours are shown at $-0.4,-0.2,-0.1,0.1,0.2$, and 0.4 . Negative values are dashed. Values that are statistically significant at the $5 \%$ level are color shaded. (j) As in (i), but anomalies are computed with respect to the RCP8.5 projected climatology and the contour interval is 0.02 . Meteorological drought is measured by precipitation $(P)$ deficit, and the index used to classify drought is the SPI6. The SPI6 is computed by following the method outlined by McKee et al. (1993, 1995). The FOC is the number of extreme events that last at least 9 months divided by the total number of events. An event is defined as extreme if the SPI6 reaches the threshold of \pm 0.8 . Statistics are calculated during 1850-2005 for the historical period and 2006-2100 for RCP8.5. 
TABLE 2. Metric showing the difference between the area average of the northeast quadrant $\left(94^{\circ}-75^{\circ} \mathrm{W}, 35^{\circ}-48^{\circ} \mathrm{N}\right)$ and the southwest quadrant $\left(123^{\circ}-95^{\circ} \mathrm{W}, 15^{\circ}-35^{\circ} \mathrm{N}\right)$ of North America in Fig. 7, which shows the FOC differences between projection and historical experiments for positive minus negative events.

\begin{tabular}{lc}
\hline \multicolumn{1}{c}{ Model } & FOC difference \\
\hline CanESM2 & 0.35 \\
CCSM4 & 0.40 \\
CNRM-CM5.1 & 0.31 \\
CSIRO Mk3.6.0 & 0.40 \\
HadGEM2-ES & 0.12 \\
IPSL-CM5A-LR & 0.48 \\
MIROC5 & 0.34 \\
MPI-ESM-LR & 0.48 \\
Mean & 0.36 \\
Std dev & 0.12 \\
\hline
\end{tabular}

can be related to contrasting projected change in the meridional temperature gradient. Near the surface, the temperature gradient is projected to significantly decrease because of greater warming at high latitudes, while the temperature gradient near the tropopause is projected to increase because of warming in the tropical upper troposphere and cooling in the polar lower stratosphere due to increases in greenhouse gases. The general decrease in ST activity in summer can be related to a projected decrease in mean available potential energy because of a decrease in the midlatitude temperature gradient and an increase in static stability.

As discussed in Chang et al. (2012), the significant near-surface ST activity decrease over NA represents one of the largest differences between CMIP5 and CMIP3 ST projections over the globe. As seen in Table 3, during winter (DJF), CMIP5 models project a $-9.9 \% \pm 3.6 \%$ MEM change in sea level pressure (SLP) variance in winter over the region roughly covering the contiguous United States and $-19.8 \% \pm 6.9 \%$ change in summer (JJA), with 14 out of 15 models projecting a decrease in winter and all 15 models projecting a decrease in summer. On the other hand, 11 CMIP3 models project $-0.4 \% \pm 4.0 \%$ change in the same quantity in winter [based on the Special Report on Emissions Scenarios (SRES) A2 scenario] and $-9.2 \% \pm 6.3 \%$ change in summer, with 7 out of 11 models projecting a decrease in winter and 10 of 11 models projecting a decrease in summer. We have also examined 8 other CMIP5 models not listed in Table 3, and all of them showed a decrease for both seasons. More details are given in Chang (2013), who showed that models projecting a larger decrease in ST activity over North America also project a more northward intrusion of the decrease in subtropical precipitation into southern United States.

We now provide a complementary analysis to that above using the Hodges $(1994,1995)$ cyclone-tracking

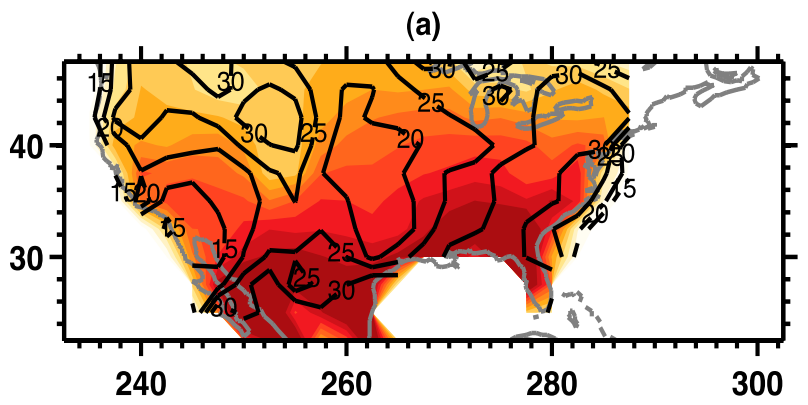

(b)

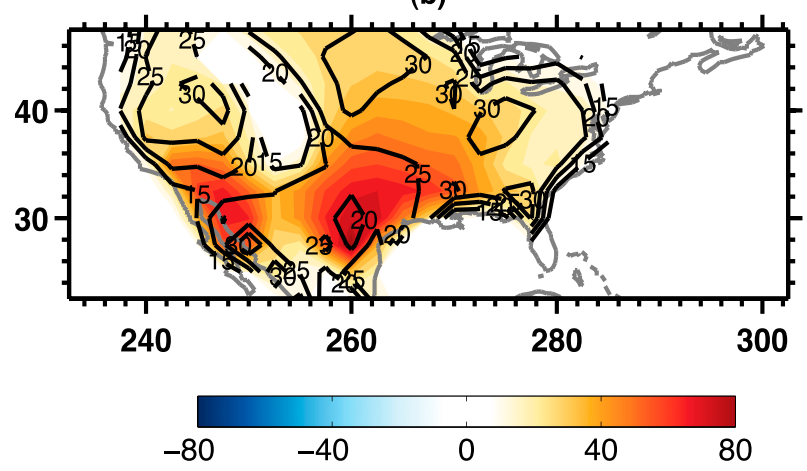

FIG. 8. The MEM changes (color shading) of (a) $T_{\max }>90^{\circ} \mathrm{F}$ and (b) $T_{\max }>100^{\circ} \mathrm{F}$ between RCP8.5 for the period $2081-2100$ and historical simulations for the period 1981-2000 and its standard deviation (contours) across 11 CMIP5 models; the units are number of days. The 11 models we used are CanESM2, CCSM4, GFDL CM3, GFDL-ESM2G, GFDL-ESM2M, HadGEM2-CC, HadGEM2-ES, IPSL-CM5A-LR, MIROC5, MPI-ESM-LR, and MRI-CGCM3.

scheme on 6-hourly mean SLP data to assess changes in extratropical cyclone activity along the U.S. East Coast. Part I presented the historical (1979-2004) predictions of western Atlantic extratropical cyclones during the cool season (November-March), which show substantial skill at simulating the distribution of cyclone activity, although with modest underprediction of amplitude. Colle et al. (2013) highlighted the details of this historical cyclone analysis and the twenty-first-century predictions in this region using these 15 CMIP5 models. Figures 10b-d show the MEM difference in cool season cyclone-track density for each of the three separate 30-yr future periods in RCP8.5 (2009-38, 2038-69, and 2069-98) and the historical period (1979-2004; Fig. 10a). Only a slight decrease in cyclone activity is projected over parts of the western Atlantic storm track for 2009-38 (Fig. 10b); however, Colle et al. (2013) show that this reduction may be more widespread if only the highest-resolution CMIP5 models are considered. The MEM reduction in cyclone density is more apparent for the 2038-69 period, with a reduction of $5 \%-15 \%$, primarily along the southern half of the cyclone storm track, which is near 
a)

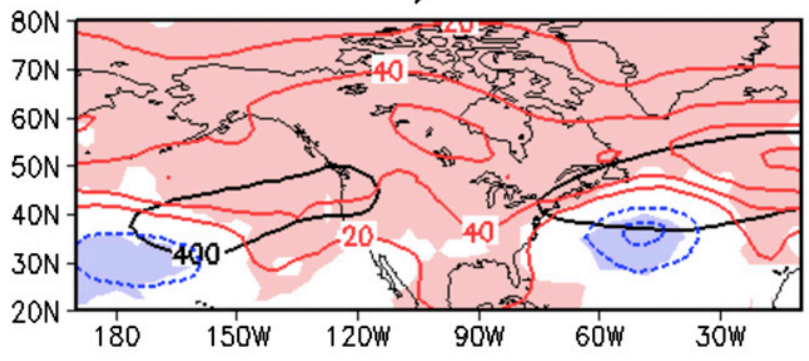

c)

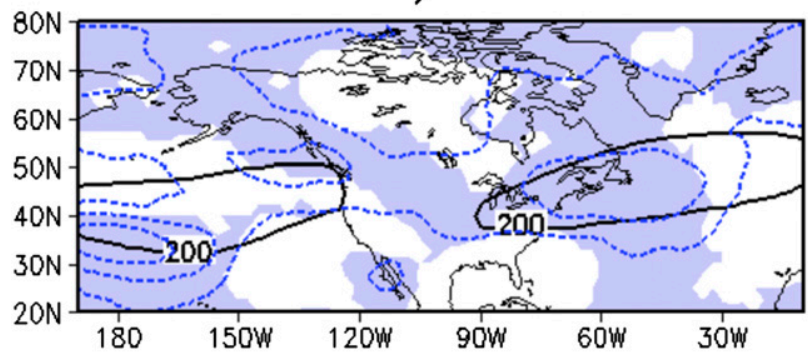

e)

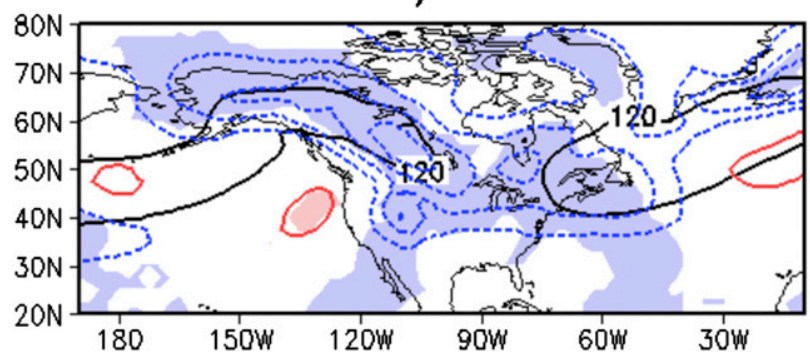

b)

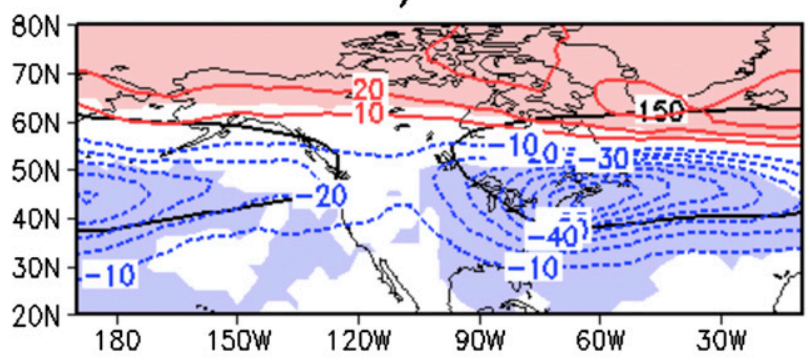

d)

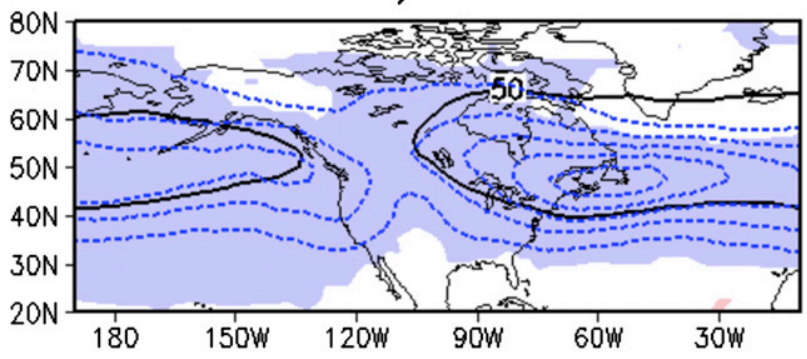

f)

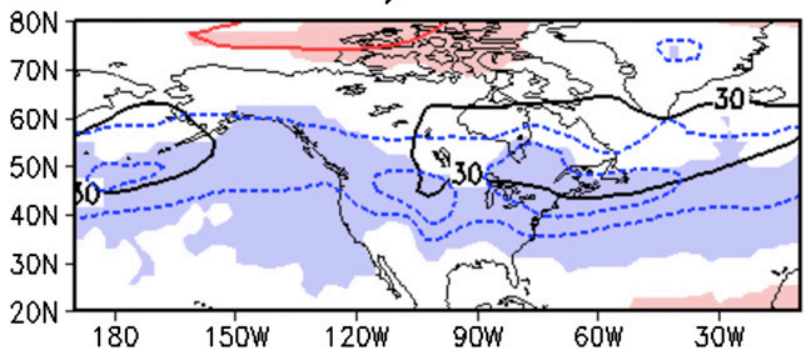

FIG. 9. (a) Black solid contour: winter (DJF) climatological (1980-99) storm-track activity, as indicated by the variance of 24-h difference bandpass-filtered meridional wind $v$ at $250-\mathrm{hPa}$ level (contour level of $400 \mathrm{~m}^{2} \mathrm{~s}^{-2}$ ), based on the MEM of 15 CMIP5 models (core models in Table 1 except GISS-E2-R and HadCM3). The filter used is the 24-h difference filter (Wallace et al. 1988), which highlights synoptic variability with periods of 1.2-6 days. Colored lines: projected change (2081-2100 mean minus 1980-99 mean) based on RCP8.5 (contour interval of $20 \mathrm{~m}^{2} \mathrm{~s}^{-2}$ ) with solid (dashed) lines for positive (negative) values. Color shading: grid boxes over which more than $80 \%$ of CMIP5 models agree on the sign of the projected change. (b) As in (a), but for summer (JJA; contour level of $150 \mathrm{~m}^{2} \mathrm{~s}^{-2}$ and interval of $10 \mathrm{~m}^{2} \mathrm{~s}^{-2}$ ). (c) As in (a), but for 500-hPa level (contour level of $200 \mathrm{~m}^{2} \mathrm{~s}^{-2}$ and interval of $10 \mathrm{~m}^{2} \mathrm{~s}^{-2}$ ). (d) As in (c), but for JJA (contour level of $50 \mathrm{~m}^{2} \mathrm{~s}^{-2}$ and interval of $5 \mathrm{~m}^{2} \mathrm{~s}^{-2}$ ). (e) As in (a), but for variance of SLP (contour level of $120 \mathrm{hPa}^{2}$ and interval of $5 \mathrm{hPa}^{2}$ ). (f) As in (e), but for JJA (contour level of $30 \mathrm{hPa}^{2}$ and interval of $\left.2.5 \mathrm{hPa}^{2}\right)$.

the Gulf Stream boundary. Meanwhile, a slight increase in cyclone density is projected to the north over parts of northern New England and Nova Scotia, enhanced in the highest-resolution models (not shown). Future changes relative to the historical period continue to increase in size and amplitude $(10 \%-20 \%)$ for the 2069 98 period. The results above are very similar if only the 12 of 15 models contained in the core model list (Table 1) are used. Figure S5 provides a commentary analysis of changes in cyclone intensity.

\section{b. Northeast United States and western Atlantic precipitation}

In Part I, 14 of the 17 core CMIP5 models in Table 1 were evaluated to determine how well they can simulate precipitation over the northeast United States and western Atlantic during the cool season (November-March) in the historical period (1979-2004). Figure 11 shows the MEM CMIP5 precipitation for this historical period, as well as the precipitation difference (in $\mathrm{mm}$ season ${ }^{-1}$ 
TABLE 3. Projected percentage change in 24-h difference filtered SLP variance for DJF and JJA over the region $120^{\circ}-60^{\circ} \mathrm{W}, 30^{\circ}-$ $50^{\circ} \mathrm{N}$. Difference is between $2081-2100$ from the RCP8.5 experiment and 1980-99 from the historical experiment.

\begin{tabular}{lrr}
\hline \multicolumn{1}{c}{ Model } & DJF & JJA \\
\hline BCC_CSM1.1 & -17.4 & -8.6 \\
CanESM2 & -15.8 & -25.9 \\
CCSM4 & -11.5 & -14.4 \\
CNRM-CM5.1 & -15.5 & -14.0 \\
CSIRO Mk3.6.0 & -3.2 & -9.0 \\
GFDL CM3 & 3.7 & -51.6 \\
GFDL-ESM2M & -4.3 & -9.3 \\
HadGEM2-ES & -10.7 & -28.3 \\
INM-CM4.0 & -8.3 & -0.1 \\
IPSL-CM5A-LR & -15.5 & -29.3 \\
MIROC5 & -15.1 & -17.1 \\
MIROC-ESM & -18.1 & -32.1 \\
MPI-ESM-LR & -3.9 & -21.0 \\
MRI-CGCM3 & -4.1 & -15.2 \\
NorESM1-M & -8.6 & -20.8 \\
Mean & -9.9 & -19.8 \\
Std dev & 6.5 & 12.5 \\
\hline
\end{tabular}

and percent change) for the early twenty-first century (2009-38) minus historical and late twenty-first century (2069-98) minus historical for these same models. For the early twenty-first century (Fig. 11b), the precipitation increases $5 \%-10 \%(10-30 \mathrm{~mm})$ over the northeast United States. Less than a 5\% increase occurs over the western Atlantic associated with the midlatitude storm track, while the largest percentage increase is over northeastern Canada (10\%-20\%). By the late twentyfirst century (Fig. 11c), the largest increase of 35\%$80 \%\left(40-100 \mathrm{~mm}\right.$ season $\left.^{-1}\right)$ occurs in eastern Canada. Over the northeast United States, the mean precipitation increases by $15 \%-25 \%$ by the late twenty-first century. The number of relatively heavy precipitation events $\left(>25 \mathrm{~mm} \mathrm{day}^{-1}\right)$ over the northeast United States increases by $50 \%$ by the early twenty-first century and increases by $4-5$ times by the late twenty-first century (Fig. 11d). These results suggest that the potential exists for a dramatic increase in the number of extreme rainfall events over the northeast United States during the next 50-75 yr.

\section{c. Western water}

Changes in snow are important in western regions of the United States because of the implications for water resources and winter tourism. Figure 12 shows changes in April SWE over the western United States from 15 core CMIP5 models for RCP8.5. April SWE is an indicator of total snow accumulation over the winter and the potential water resource availability for the coming year, which is especially important in California and the upper Colorado River basin (Fassnacht 2006). A MEM decrease in April SWE of up to $80 \mathrm{~mm}$ or greater is projected for the central Rockies and Canadian Rockies, with general decreases of smaller amplitude indicated elsewhere. The spatial resolution of the models is generally too coarse to represent snow-related processes throughout western North America because of the smoothed topography. For example, the details of the Sierra Nevada range on the California-Nevada border are absent. Nevertheless, this broad decline projected by the models is supported by high-resolution hydrological changes using downscaled projections (Hayhoe et al. 2004). The decrease in SWE is driven by higher temperatures that increase the ratio of rainfall to snowfall (wintertime precipitation is projected to remain the same or increase slightly; see Fig. 1) and increased melt efficiency, therefore moving the spring melt earlier in the season. The shift in snowmelt timing may also have consequences because water rights can be month dependent (Hayhoe et al. 2004).

\section{d. North American monsoon}

In Part I, the seasonal cycle of precipitation in 21 CMIP5 models over the historical period (1979-2005) was evaluated to identify models that have a reasonable precipitation climatology over the core NA monsoon (NAM) region $\left(24^{\circ}-29^{\circ} \mathrm{N}, 105^{\circ}-109^{\circ} \mathrm{W}\right)$. The results of this analysis indicate that 9 of the 21 models have small $(\mathrm{lag}=0)$ phase errors with respect to the observations. Here we present the projected behavior at 2070-99 for this subset of models that best simulate the historical precipitation climatology in this region.

The RMS difference of the future minus historical monthly rainfall climatology and the annual mean rainfall percent differences over the core NAM region are shown in Table 4 for these nine models. The results suggest that even for models correctly capturing the timing of the seasonal cycle of precipitation in the region, large differences exist in what these models project for the change in the monthly mean magnitude (range of $0.4-0.8 \mathrm{~mm} \mathrm{day}^{-1}$ ) and the relative change in the overall annual mean (range from $-34 \%$ to $3.7 \%$ ) in precipitation for the monsoon region. However, seven out of nine models project that conditions for the NAM will be drier in the future under the RCP8.5 warming scenario suggesting some consistency in the sign of the change. Using a larger set of 16 core models that provided daily RCP8.5 rainfall, which include those with nonzero phase errors in the historical period, the change in the monthly mean magnitude of rainfall in the core monsoon region is somewhat greater, with a mean of $0.72 \mathrm{~mm} \mathrm{day}^{-1}$ (range of $0.40-1.35 \mathrm{~mm} \mathrm{day}^{-1}$ ), and the change in the annual mean rainfall indicates more drying, with a mean of $-22.2 \%$ (range from $-72.3 \%$ to $3.7 \%$ ) compared to the 

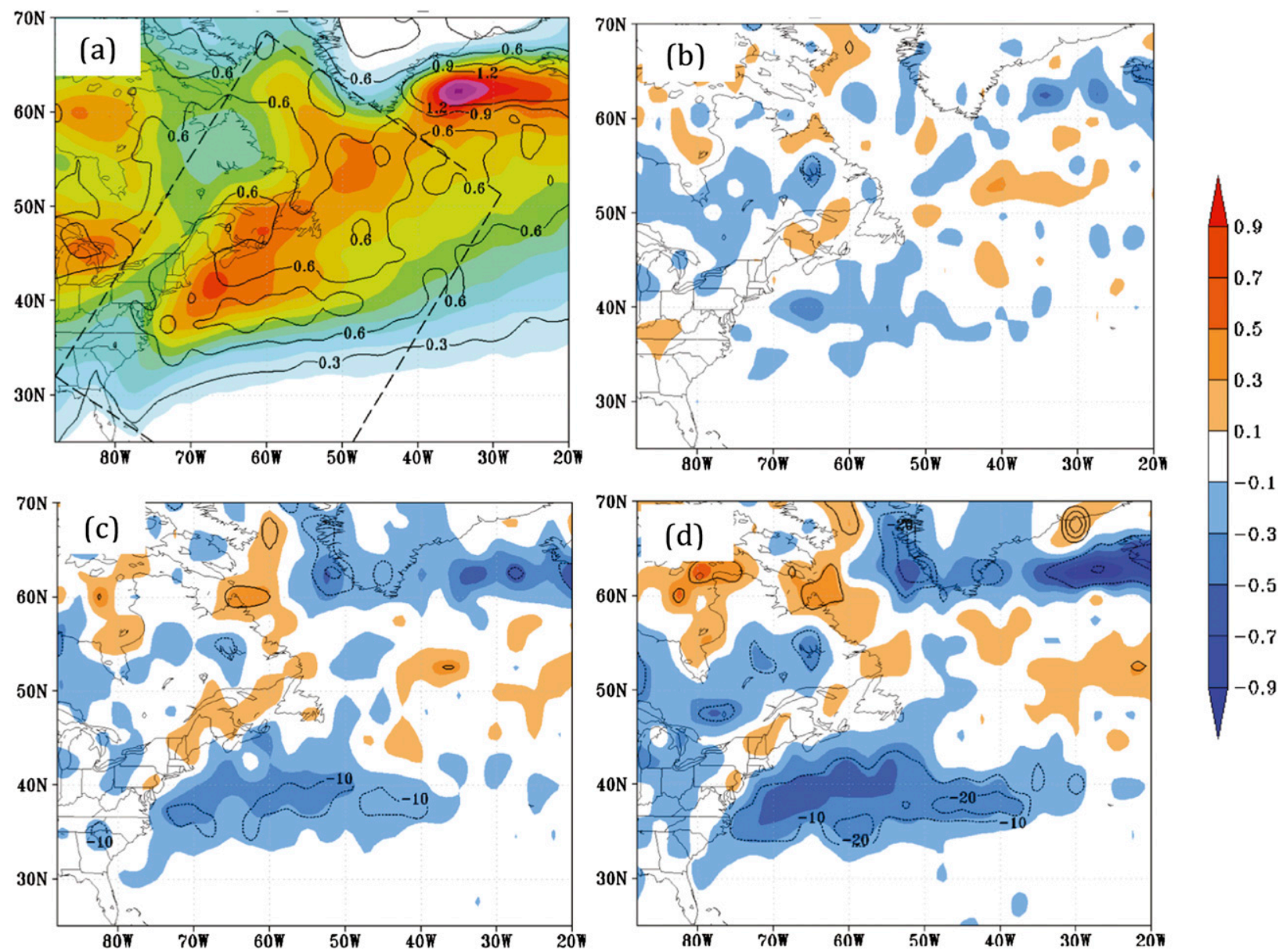

FIG. 10. (a) Cyclone-track density for the MEM (color shaded) and spread (contoured every 0.3 ) for 15 CMIP5 models showing the number of cyclones per cool season (November-March) per $50000 \mathrm{~km}^{2}$ for 1979-2004. (b)-(d) As in (a), but the difference in cyclone density (future minus historical) and percentage change between (b) 2009-38, (c) 2038-68, and (d) 2069-98 and the historical 1979-2004 period. The dashed box in (a) is an averaging region used in the supplemental information to assess changes in cyclone intensity. The 15 models used are BCC_CSM1.1, CanESM2, CNRM-CM5.1, EC-EARTH, GFDL-ESM2M, HadGEM2-ES, HadGEM2-CC, INM-CM4.0, IPSL-CM5A-LR, IPSL-CM5A-MR, MIROC5, MIROC-ESM-CHEM, MRI-CGCM3, MPI-ESM-LR, and NorESM1-M.

$-15.4 \%$ for the better performing models shown in Table 4.

In Fig. 13, MEM monthly precipitation from 16 core models are analyzed for a longitudinal belt $\left(102.5^{\circ}-\right.$ $115^{\circ} \mathrm{W}$ ) from $7.5^{\circ}$ to $35^{\circ} \mathrm{N}$ to assess the seasonal migration of precipitation in the NAM and ITCZ regions. These models capture the northward migration of precipitation between the ITCZ and the NAM region (north of $20^{\circ} \mathrm{N}$ ) during the warm season, although the migration within the NAM region is less evident. The models' historical precipitation (Fig. 13b) begins later and is stronger than the observed (Fig. 13a) in the NAM region but is weaker than the observed south of this region. Model projections from RCP8.5 (Fig. 13d) are consistent with the CMIP3 results (see introduction) and show reduced precipitation from $10^{\circ}$ to $25^{\circ} \mathrm{N}$ through the cold season and extending into June and July, with increased precipitation in September and October. The monthly mean precipitation response from the individual models indicates strong model agreement on reduced December-July rainfall and a weaker consensus on increased late summer rainfall (Fig. 13c). These reductions in precipitation from $10^{\circ}$ to $25^{\circ} \mathrm{N}$ in June and July are also consistent with reduced Mexico and $\mathrm{Ca}-$ ribbean precipitation in this latitude band seen in Figs. 1 and 2 for JJA.

\section{e. Great Plains low-level jet}

The Great Plains (GP) low-level jet (LLJ) is a basic component of the warm season circulation in NA that provides a moisture source for GP precipitation. It emerges in April, strengthens and peaks in June and 

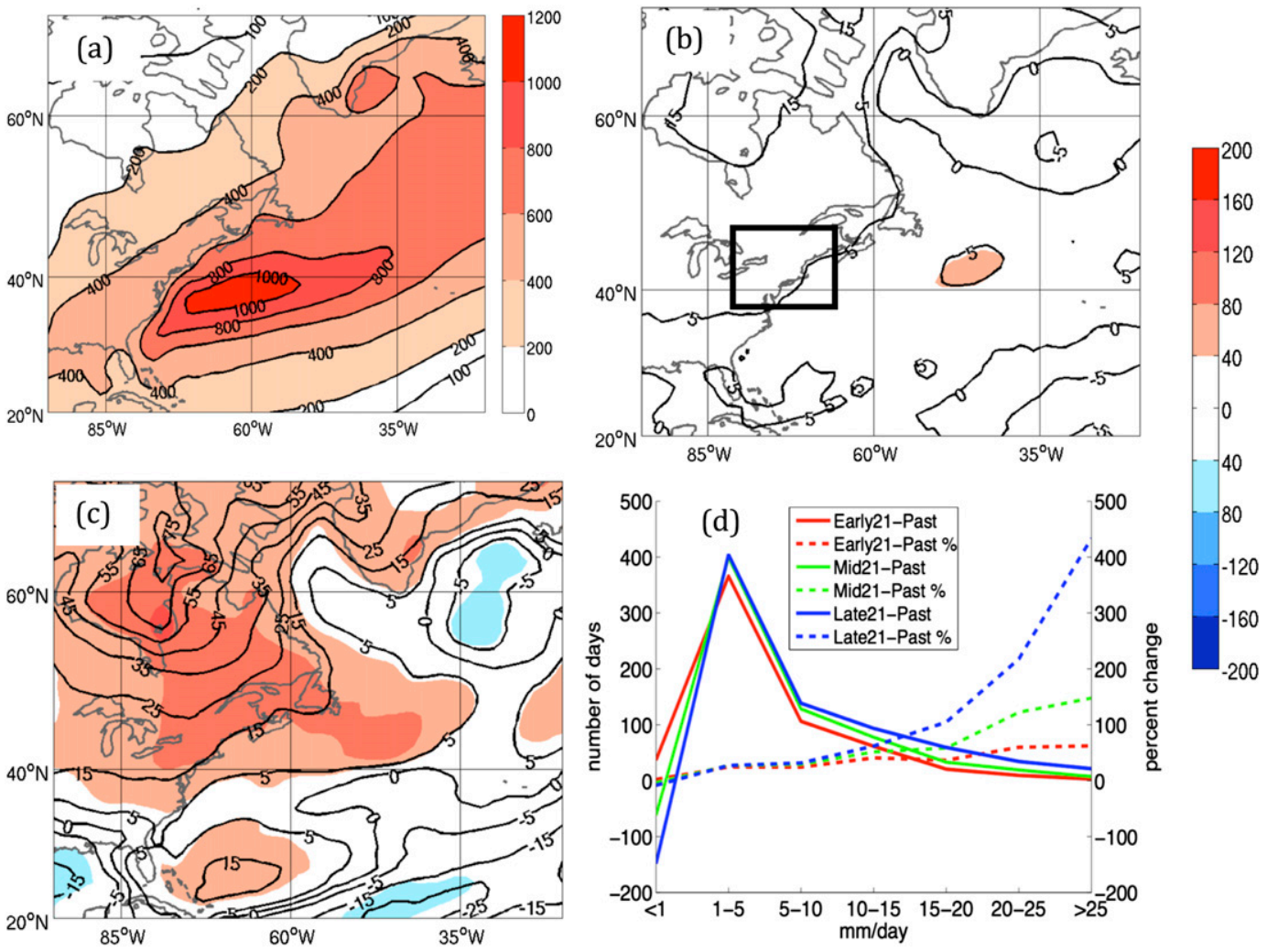

FIG. 11. (a) MEM daily precipitation (mm season ${ }^{-1}$ ) for 14 of the CMIP5 models listed in Table 1 for the historical (1979-2004) period during the cool season (November-March). (b) Precipitation difference (color shaded in mm season ${ }^{-1}$ starting at $40 \mathrm{~mm}$ ) and the percentage change (solid contours every $10 \%$ ) between the 2009-38 and the historical 1979-2004 period for the cool season (November-March). (c) As in (b), but for the 2069-98 period. (d) Difference in the number of precipitation days and percentage change for each amount bin between 2009-38, 2038-68, and 2069-98 and the historical 1979-2004 period for the land area only in the black box in (b). The 14 CMIP5 models include BCC_CSM1.1, CanESM2, CCSM4, CNRM-CM5.1, CSIRO Mk3.6.0, GFDL CM3, GFDL-ESM2M, HadGEM2-ES, INM-CM4.0, IPSL-CM5A-LR, MIROC5, MIROC-ESM, MRICGCM3, and NorESM1-M.

July, and vanishes in late September (e.g., Part I). Figure 14a reviews the ability of 16 of the core models (excluding HadCM3) to capture the intensity and seasonal cycle of meridional flow in the LLJ region. The MEM is best able to capture the amplitude of the LLJ during boreal summer, and vertical cross sections and horizontal maps of the jet verify this behavior (not shown). Figures 14b-e show how the jet strength evolves for the core models in the MEM and \pm 1 standard deviation limits for RCP4.5 and RCP8.5. The MEM projection indicates a strengthening of the LLJ by about $10 \%-20 \%$ during boreal summer by $2071-2100$ in RCP8.5, with modest increases during 2035-64 and in RCP4.5. Notably, the lower one standard deviation bound is separable from zero in RCP8.5 for 2071-2100 during MarchJuly. When the same analysis is applied to only models that produce the best simulation of the LLJ in current climate (Part I), the results are generally consistent.
The development of warm season precipitation anomalies or extreme wet and dry conditions in the GP and the Midwest is largely a result of the weather/ precipitation systems that develop and depend strongly on the dynamic stability of the large-scale circulation (e.g., Moore et al. 2012; Veres and Hu 2013) and is not only a function of the strength of the LLJ. In fact, Klein et al. (2006) show that models that produce a reasonable LLJ may have trouble reproducing an accurate GP mean summertime rainfall distribution if they cannot correctly simulate eastward-propagating convective systems that develop over terrain during the diurnal cycle, since such systems produce $50 \%$ of summertime GP rainfall. This notion might explain the apparent discrepancy between the predicted strengthening LLJ shown in Fig. 14 and the decrease in summer precipitation in the GP shown in Figs. 1 and 2. This discrepancy suggests changes in the future summer circulation regime that would produce 
(a)

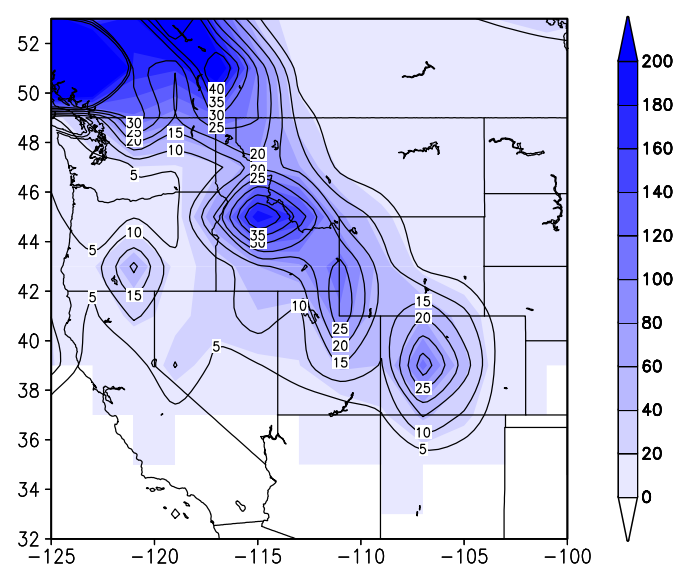

(b)

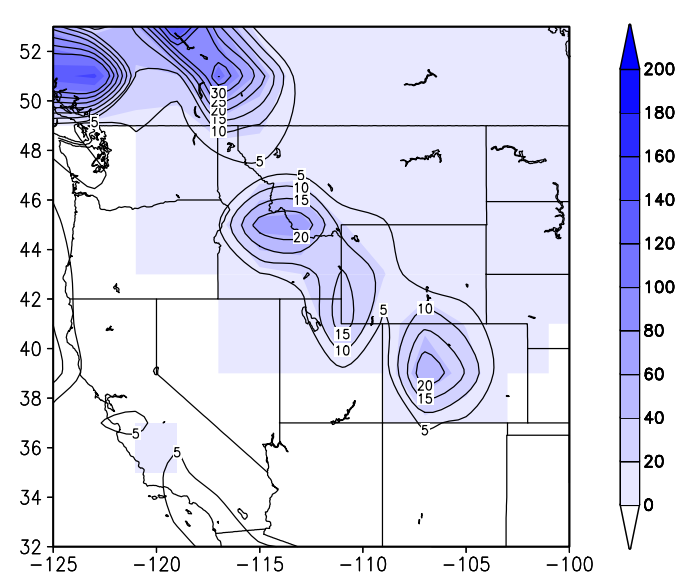

(c)

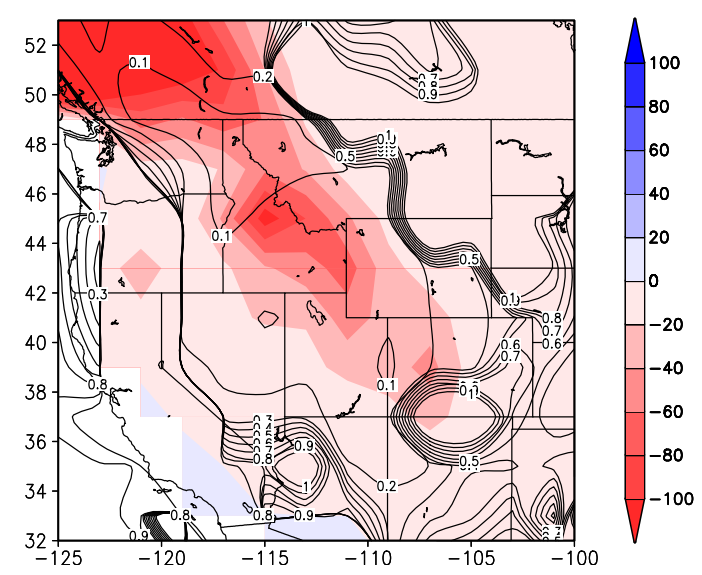

FIG. 12. Average April SWE (mm) from 15 core CMIP5 models for (a) 1971-2000 and (b) 2071-2100 (RCP85) and (c) their difference (color shading) and ratio (contours). For (a),(b) the color shading represents the multimodel mean and the contours represent the intermodel standard deviation. The models are as follows: BCC_CSM1.1, CanESM2, CCSM4, CNRM-CM5.1, CSIRO Mk3.6.0, GFDL CM3, GFDL-ESM2M, GISS-E2-R, HadGEM2-ES, INMCM4.0, MIROC5, MIROC-ESM, MPI-ESM-LR, MRI-CGCM3, and NorESM1-M.
TABLE 4. The RMS of the future minus historical monthly rainfall climatology and the annual mean rainfall differences for nine high performing models for the core NAM region $\left(24^{\circ}-29^{\circ} \mathrm{N}\right.$, $\left.105^{\circ}-109^{\circ} \mathrm{W}\right)$. The last row provides results for an expanded set of 16 core models.

\begin{tabular}{lcc}
\hline \hline \multicolumn{1}{c}{ Model } & $\begin{array}{c}\text { Future-historical } \\
\text { RMS difference } \\
\left(\mathrm{mm} \mathrm{day}^{-1}\right)\end{array}$ & $\begin{array}{c}\text { Future-historical } \\
\text { precipitation } \\
\text { difference }(\%)\end{array}$ \\
\hline BCC_CSM1.1 & 0.79 & 3.4 \\
CanESM2 & 0.40 & 3.7 \\
CCSM4 & 0.67 & -32.0 \\
CNRM-CM5.1 & 0.50 & -12.8 \\
CSIRO Mk3.6.0 & 0.78 & -34.0 \\
HadGEM2-ES & 0.53 & -5.3 \\
MIROC5 & 0.65 & -19.9 \\
MPI-ESM-LR & 0.74 & -30.9 \\
MRI-CGCM3 & 0.57 & -10.5 \\
Median & 0.65 & -12.8 \\
Mean & 0.63 & -15.4 \\
Median (core) & 0.64 & -16.9 \\
Mean (core) & 0.72 & -22.2 \\
\hline
\end{tabular}

less precipitation in a moister environment with possibly a different intensity distribution of precipitation events in the GP, similar to what is observed in the northeast United States presented in section $4 \mathrm{~b}$.

\section{f. Arctic sea ice}

Significant reductions in the extent and thickness of the Arctic sea ice cover have occurred during the past several decades (e.g., Stroeve et al. 2012a,b; Kwok and Rothrock 2009), with wide-ranging impacts on marine ecosystems, coastal communities, prospects for resource extraction, and weather conditions in the Arctic and beyond (e.g., Francis and Vavrus 2012). While negative trends are observed in all calendar months, the largest reductions are observed in September at the end of the summer melt season. Through 2013, the rate of decline in September sea ice extent since 1979 has been $-14.0 \%$ per decade, representing a reduction of more than $40 \%$ in the amount of sea ice covering the Arctic Ocean.

All models participating in CMIP5 correctly simulate a declining Arctic sea ice cover over the period of observations (Stroeve et al. 2012a). However, trends from most models remain smaller than observed. Figure 15 shows the CMIP5 MEM and \pm 1 standard deviation of the historical (gray line and shading) and future evolution of the sea ice cover under RCP4.5 (blue line and shading) and RCP8.5 (red line and shading). Observations based on a combination of satellite data and ship and aircraft observations (Meier et al. 2012) are shown in black. In constructing the MEM, the same criteria as used in Stroeve et al. (2012a) was applied, such that models that had more than $75 \%$ of their extents outside the observed range from 1953 to 1995 

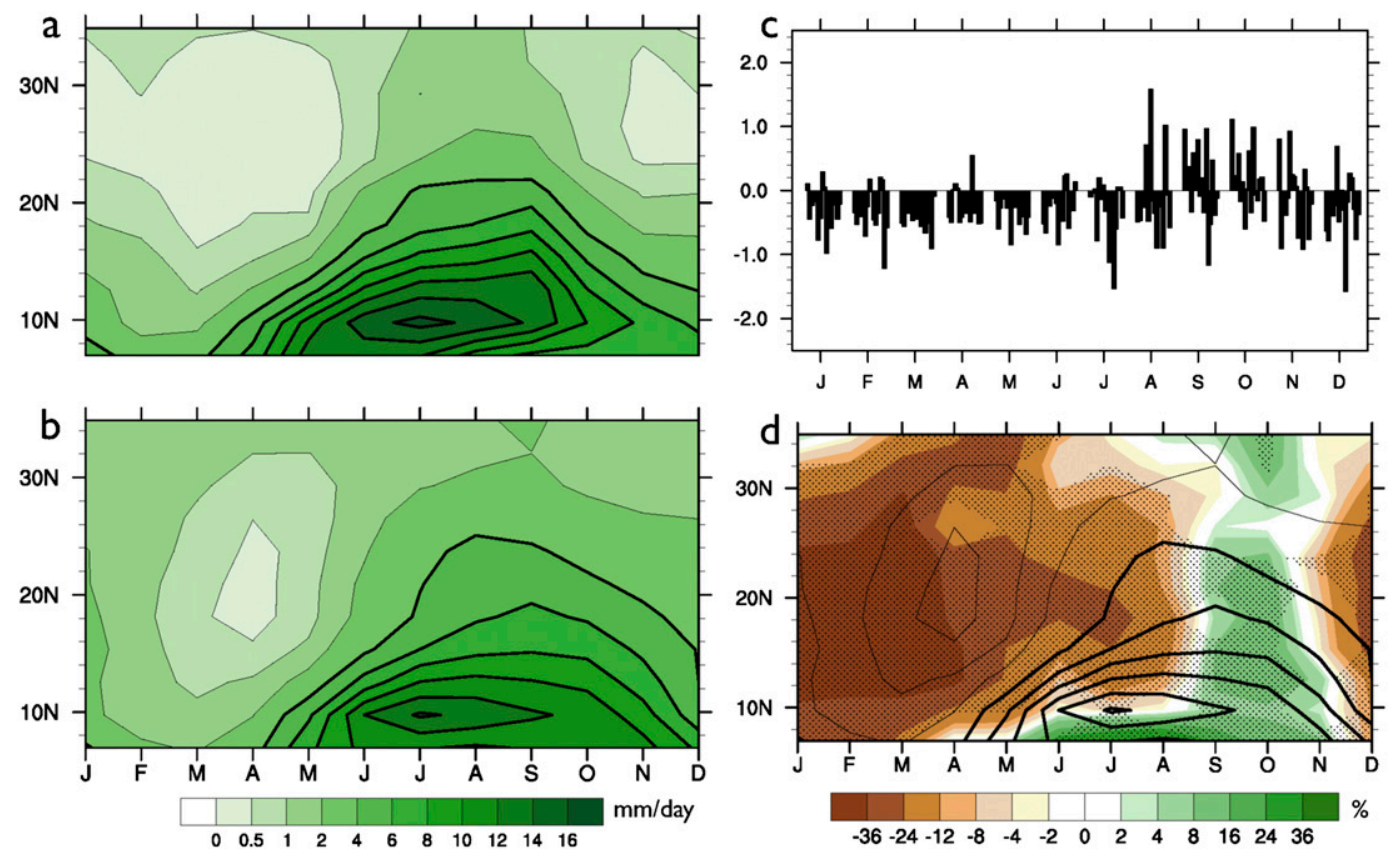

FIG. 13. Precipitation annual cycle averaged for longitudes representing the North American monsoon (102.5 $115.0^{\circ} \mathrm{W}$ ) for the 1986-2005 climatological period from (a) Climate Prediction Center (CPC) Merged Analysis of Precipitation (CMAP), version 2 from Xie and Arkin (1997) and (b) the MEM of 16 CMIP5 models (mm day ${ }^{-1}$ ) with thick black lines identifying contours $>4 \mathrm{~mm} \mathrm{day}^{-1}$. (c) Individual monthly model (in order specified below) precipitation differences (mm day ${ }^{-1}$ for RCP8.5; 2081-2100 minus 1986-2005) shown as bars (averaged from $20^{\circ}$ to $35^{\circ} \mathrm{N}$ ). (d) Multimodel climatology contours (black lines) from (b) and MEM precipitation percent difference from the historical simulations (color shading). Areas of significant change are stippled. The models employed in the analysis are BCC_CSM1.1, CCSM4, CNRM-CM5.1, CSIRO Mk3.6.0, CanESM2, GFDL CM3, GFDL-ESM2M, GISS-E2-R, HadGEM2-ES, IPSLCM5A-LR, MIROC-ESM, MIROC5, MPI-ESM-LR, MRI-CGCM3, NorESM1-M, and INM-CM4.0.

were excluded. Based on the extent criteria, seven models were excluded (CanCM4, CanESM2, CSIRO Mk3.6.0, EC-EARTH, FGOALS-s2, GISS-E2-R, and HadGEM2-AO). This resulted in 19 models retained for RCP4.5 and 18 models for RCP8.5. If we include only the core models in Table 1 without using the selection criterion applied above, conclusions do not significantly change from those described below.

Under RCP4.5, the MEM does not reach ice-free conditions by 2100 , though the -1 standard deviation bound reaches nearly ice-free conditions (defined as less than $1 \times$ $10^{6} \mathrm{~km}^{2}$ ) around 2050. In contrast, the MEM ice extent drops below $1 \times 10^{6} \mathrm{~km}^{2}$ around 2060 for the RCP8.5 emission scenario, with the -1 standard deviation bound dropping below $1 \times 10^{6} \mathrm{~km}^{2}$ in 2030 and showing completely ice-free conditions by 2050 . Note however that a large spread exists among CMIP5 models as to when a seasonally ice-free Arctic state may be realized. CMIP3 models were found to be very conservative with regards to Arctic sea ice loss (Stroeve et al. 2007, 2012a) despite having a realistic representation of the seasonal cycle in the ice cover. However, despite better overall agreement in CMIP5 with the historical observations, the spread in projected extent through the twenty-first century remains about the same between both modeling efforts, with an equivalent number of models showing summer ice-free conditions at the end of the century. While constraining future projections based on model performance does not significantly change the date when seasonally ice-free conditions will be reached, it does help reduce the spread in the projections.

Spatially, significant reductions in sea ice concentration off the coast of North America are expected during summer, even under the RCP4.5 emission scenario (Fig. 16). MEM mean sea ice concentrations for three decades are shown (2000-09, 2040-49, and 2090-99) together with a measure of the spread of the MEM, defined as the percentage of models that had more than $15 \%$ sea ice concentration for each grid cell. This measure conveys model agreement and, while the selection of a $15 \%$ sea ice concentration threshold is somewhat arbitrary, it is a useful metric for marine shipping and is generally used as a cutoff for sea ice extent calculations.

As early as the middle of the century, MEM sea ice concentrations decrease to less than $10 \%$ compared to 


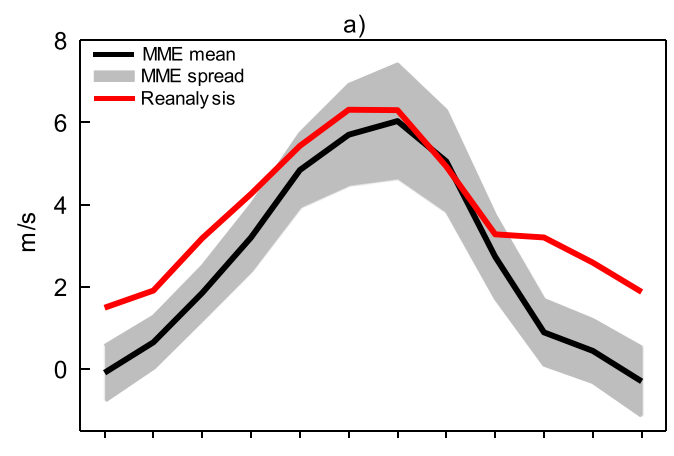

Jan Feb Mar Apr May Jun Jul Aug Sep Oct NovDec

b)

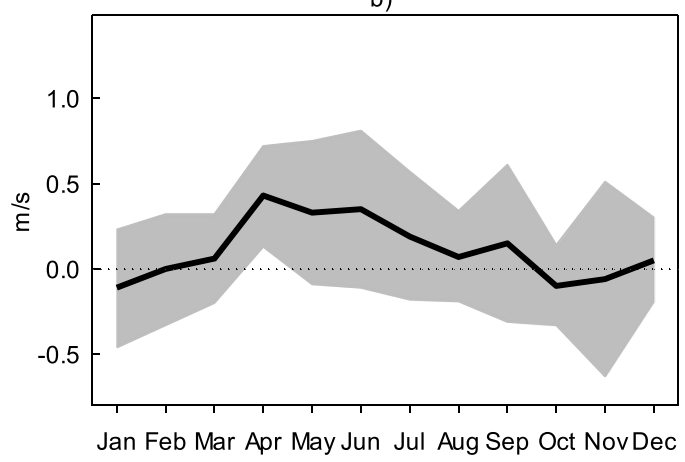

d)

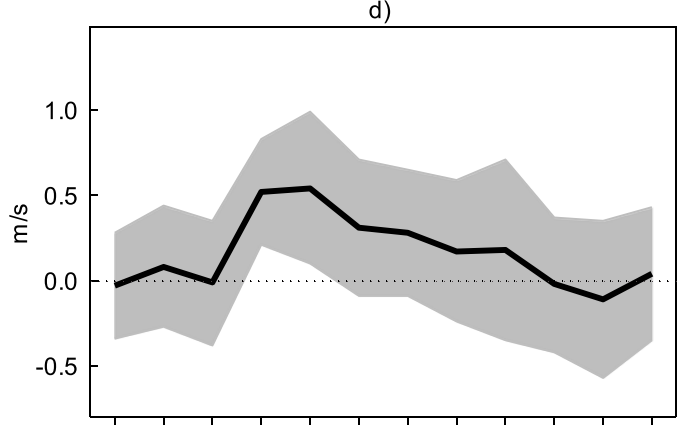

Jan Feb Mar Apr May Jun Jul Aug Sep Oct NovDec

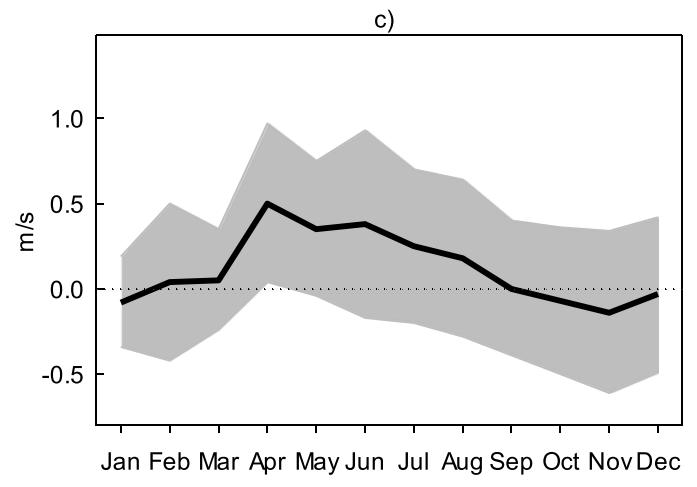

e)

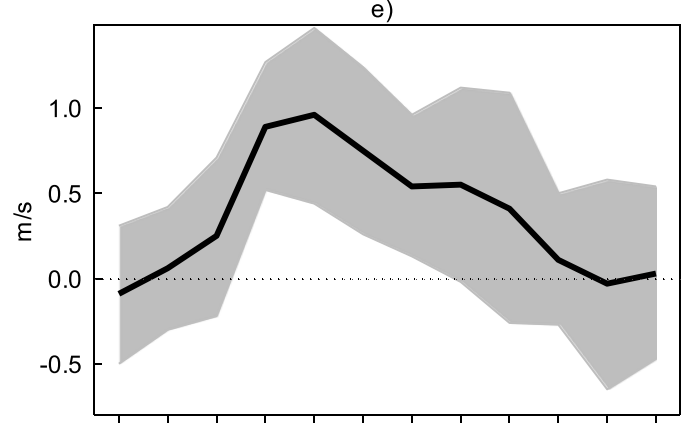

Jan Feb Mar Apr May Jun Jul Aug Sep Oct NovDec

FIG. 14. The (a) 1971-2000 LLJ climatology based on the National Centers for Environmental Prediction-National Center for Atmospheric Research (NCEP-NCAR) reanalysis and the MEM for the core models of Table 1. Multimodel ensemble spread is shown by the gray shading. Deviations of the MEM (black line with the spread shaded gray) for (b) 2035-64 and (c) 2071-2100 from simulations with emission scenario RCP4.5 from that for 19712000 shown in (a). (d),(e) As in (b),(c), but from simulations with emission scenario RCP8.5. The LLJ was computed as the $925-\mathrm{hPa}$ meridional wind averaged over the region $27.5^{\circ}-32.5^{\circ} \mathrm{N}, 95^{\circ}-100^{\circ} \mathrm{W}$.

somewhat higher sea ice concentrations of $10 \%-20 \%$ during the most recent decade. More importantly is that fewer models suggest sea ice concentrations in excess of $15 \%$ in the region. By the end of the century, the region with less than $10 \%$ sea ice concentration has grown and even fewer models suggest there will be ice with concentrations in excess of $15 \%$. North of Greenland and the Canadian Archipelago, the last refuges of old thick ice, MEM ice concentrations in September are less than $50 \%$ by the end of the century. In contrast, during winter (e.g., March), no change in sea ice concentrations along coastal North America is expected under the RCP4.5 emission scenario (Fig. 17). The same is true for most of the Arctic, though the number of models indicating at least $15 \%$ sea ice concentration in the North Atlantic declines throughout the century.

\section{g. Warming hole in the eastern United States}

During the second half of the twentieth century, the central-eastern United States experienced cooling trends 


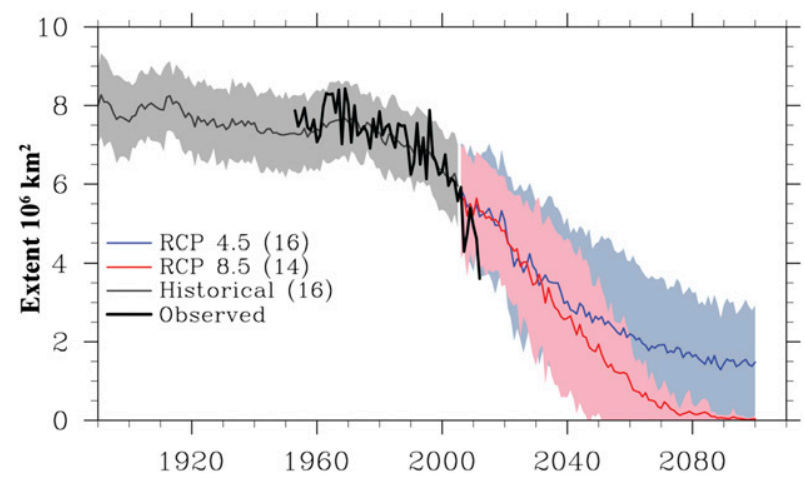

FIG. 15. CMIP5 MEM September Northern Hemisphere sea ice extent from 1900 to 2100, based on the historical (gray) and future RCP4.5 (blue) and RCP8.5 (red) emission scenarios. The observed ice extent from 1953 to 2011 is shown as a heavy black line and the three different shadings represents \pm 1 standard deviation of the multimodel ensemble means. In deriving the multimodel ensemble mean for each emission scenario, only models that have at least $75 \%$ of their distribution of September ice extent within the observed range of $(6.13-8.43) \times 10^{6} \mathrm{~km}^{2}$ from 1953 to 1995 are included. The rejected models include CanCM4, CanESM2, CSIRO Mk3.6.0, EC-EARTH, FGOALS-s2, GISS-E2$\mathrm{R}$, and HadGEM2-AO, resulting in a total of 20 models for the historical scenario, 19 models for the RCP4.5 scenario, and 18 models for the RCP8.5 scenario.

while global mean temperatures warmed. We refer to this cooling region as a "warming hole" (WH), following Pan et al. (2004). A number of studies have attributed the mechanisms for this abnormal trend to large-scale decadal oscillations such as the Pacific decadal oscillation (PDO) and Atlantic multidecadal oscillation (AMO; Robinson et al. 2002; Kunkel et al. 2006; Wang et al. 2009; Meehl et al. 2012a). Other studies indicate that regional-scale processes such as hydrological cycle (Pan et al. 2004) and land surface interaction (Liang et al. 2006) may contribute to the WH. Leibensperger et al. (2012) have attributed the WH to anthropogenic aerosol forcing. While the atmosphere-ocean coupled simulations do not allow for distinguishing different types of forcings, neither CMIP3 nor CMIP5 twentieth-century simulations show the $\mathrm{WH}$ as an externally forced response signal (Kunkel et al. 2006; Kumar et al. 2013; Pan et al. 2013). Kumar et al. (2013) found that observed temperature trend variability in the eastern United States is significantly correlated with the AMO. In Kumar et al. (2013) and Part II, it was shown that the $95 \%$ uncertainty range of historical CMIP5 simulations brackets the observed negative temperature trend, although the MEM time series has limited skill at reproducing the $\mathrm{WH}$.

Here we assess whether evidence of an eastern United States WH exists in twenty-first-century projections. Figure 18 shows the MEM annual temperature trends during 2015-50 and 2051-98 for RCP4.5 and RCP8.5 in the core models (Table 1; one ensemble member each). The MEM shows a warming trend in all regions of NA. In the first half of the twenty-first century, the warming rate is $28 \%$ higher in $\mathrm{RCP} 8.5\left(0.55^{\circ} \mathrm{C}_{\text {decade }}^{-1}\right)$ than in RCP4.5 $\left(0.43^{\circ} \mathrm{C}\right.$ decade $\left.^{-1}\right)$. In the second half of the twenty-first century (2051-98), the warming rate is more than 4 times higher in RCP8.5 $\left(0.73^{\circ} \mathrm{C} \mathrm{decade}^{-1}\right)$ than in RCP4.5 $\left(0.17^{\circ} \mathrm{Cdecade}^{-1}\right)$. The $50 \%$ reduction in the late-twenty-first-century warming rate compared to the first half of the twenty-first century is consistent with stabilization of $\mathrm{CO}_{2}$ emissions in RCP4.5 (Moss et al. 2010; Meehl et al. 2012b). In both RCP4.5 and RCP8.5 the projected warming rate is significantly higher than the twentieth-century warming rate in CMIP5 simulations $\left(0.07^{\circ} \mathrm{C}_{\text {decade }}{ }^{-1}\right.$; Kumar et al. 2013).

Figures 19a and 19b show time series of 30-yr running trends of eastern United States annual temperature for RCP4.5 and RCP8.5 simulations from the core models including all available ensemble members (a total of 55 ensemble members in RCP4.5 simulations, and 46 ensemble members in RCP8.5 simulations). The multimodel ensemble median of RCP8.5 simulations indicates a continued increase in warming rate from $0.4^{\circ} \mathrm{C}^{\circ}$ ecade $^{-1}$ at the start of the twenty-first century to $0.7^{\circ} \mathrm{Cdecade}^{-1}$ toward the end of the twenty-first century, whereas RCP4.5 simulations indicates a decline in warming rate from $0.3^{\circ}$ to $0.1^{\circ} \mathrm{C} \mathrm{decade}{ }^{-1}$ over the twenty-first century. The entire $95 \%$ uncertainty range in RCP8.5, as well as the majority of the $95 \%$ uncertainty range ( $>90 \%$ ) in RCP4.5, is above the zero line for the 30-yr running annual temperature trend in eastern United States (Figs. 19a,b). Kumar et al. (2013) found similar results for summer (JJA) temperature trends. Hence, the negative temperature trend in eastern United States is shown to disappear under RCP4.5 projections with $90 \%$ probability and to disappear under RCP 8.5 projections with $100 \%$ probability. We did not find a significant difference in trends between the eastern and western United States (defined in Fig. 18) in the twenty-first-century climate projections (not shown).

\section{Tropical intraseasonal variability}

\section{a. Midsummer drought}

For most of Central America and southern Mexico, climatological precipitation has a maximum in June and September, bracketing a period of reduced rainfall during July-August known as the midsummer drought (MSD; Portig 1961; Magaña et al. 1999). Hence, this variability in the annual cycle represents a climatological intraseasonal oscillation, akin to those found in other 


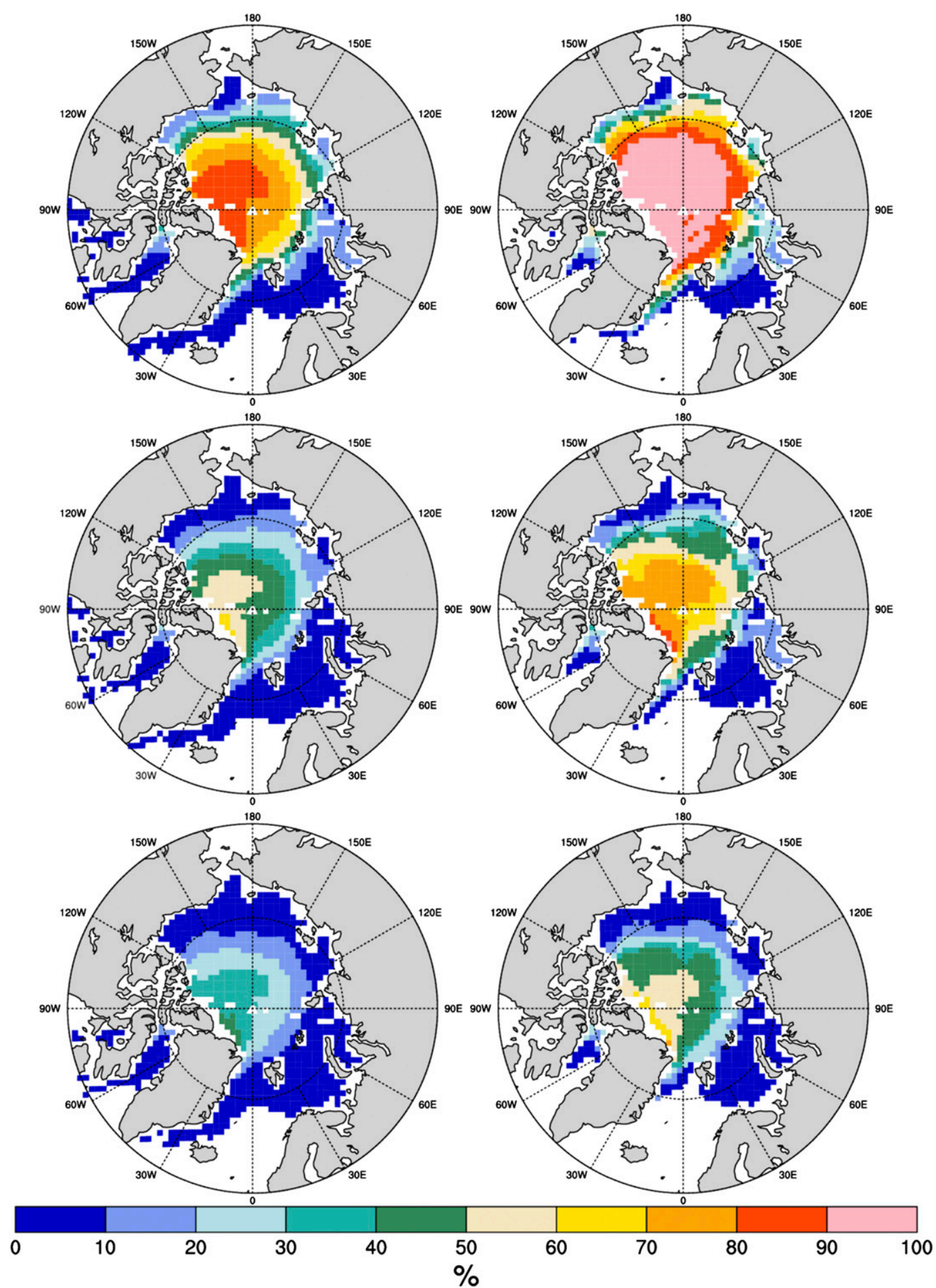

FIG. 16. (left) Decadal averages of multimodel ensemble-mean sea ice concentrations for September under the RCP4.5 emission scenario for three decades: (top) 2000-09, (middle) 2040-49, and (bottom) 2090-99. (right) Corresponding percentage of models having at least $15 \%$ sea ice concentration. 


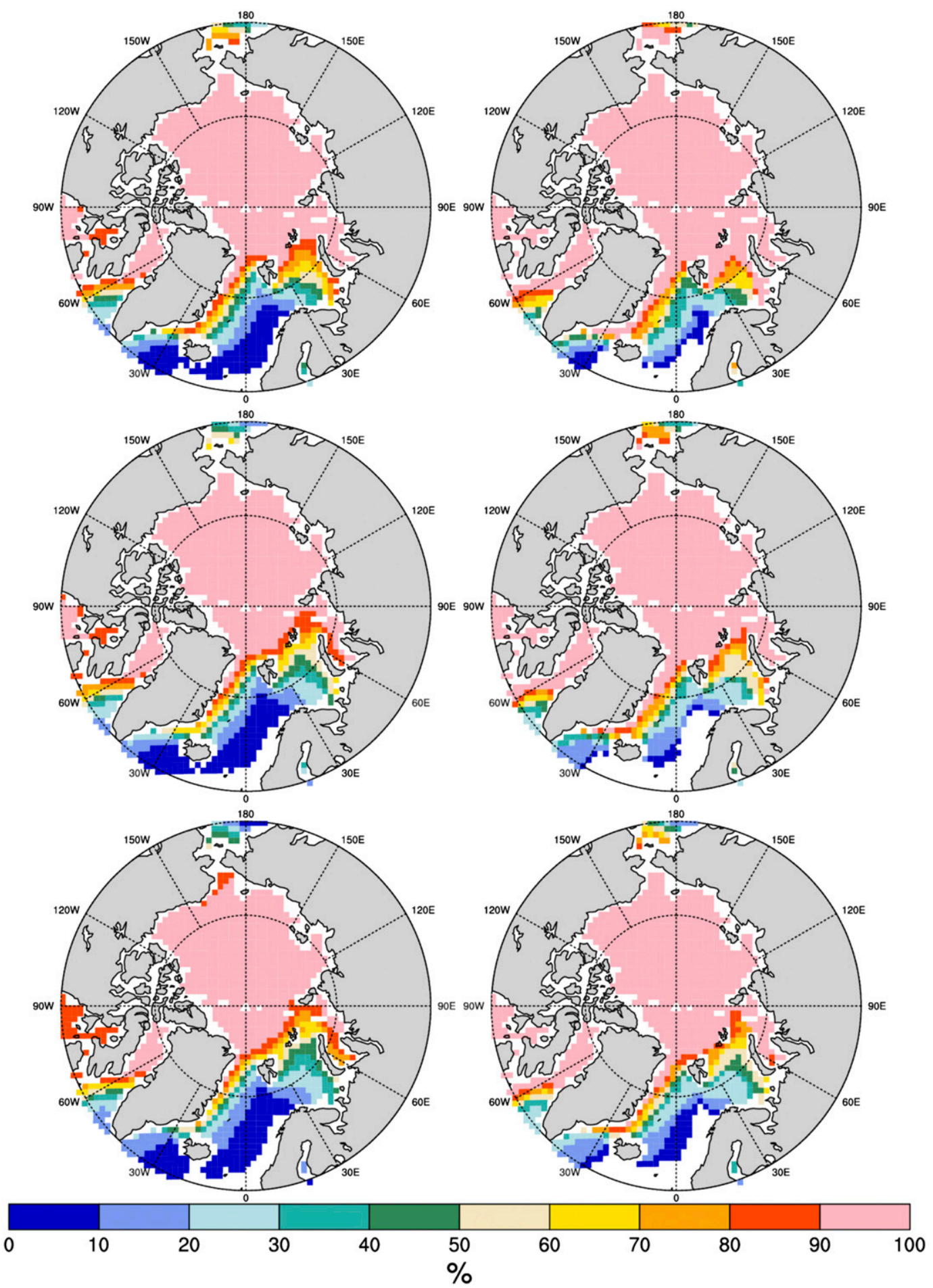

FIG. 17. As in Fig. 16, but for March.

regions of the globe (e.g., Wang and Xu 1997). A previous assessment of CMIP3 model performance at simulating the MSD and future projections (Rauscher et al. 2008) suggested that many CMIP 3 models are capable of simulating the MSD despite an overall dry bias and that the MSD is projected to become stronger with an earlier onset. An updated evaluation of this feature (Part II) indicates that many CMIP5 models are also 
[a]

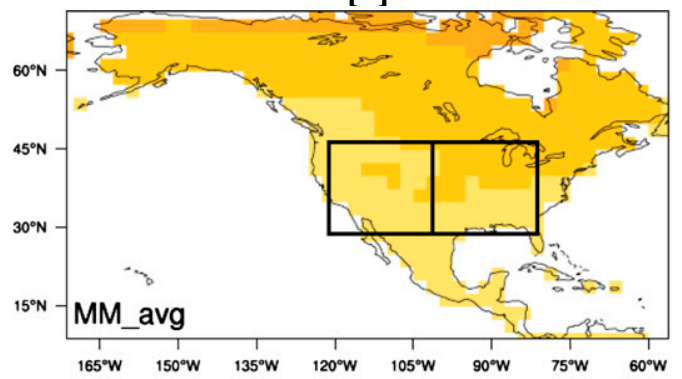

[c]

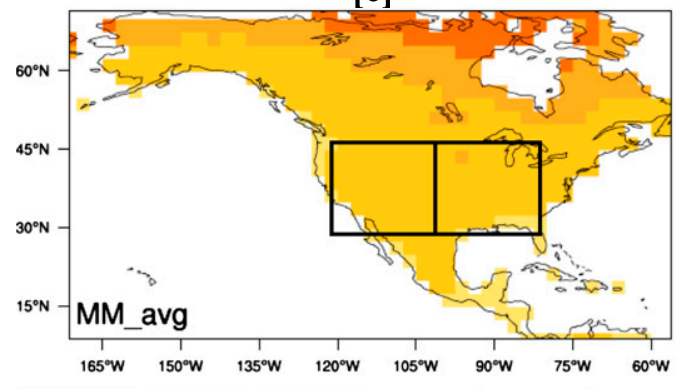

$[$ [b]

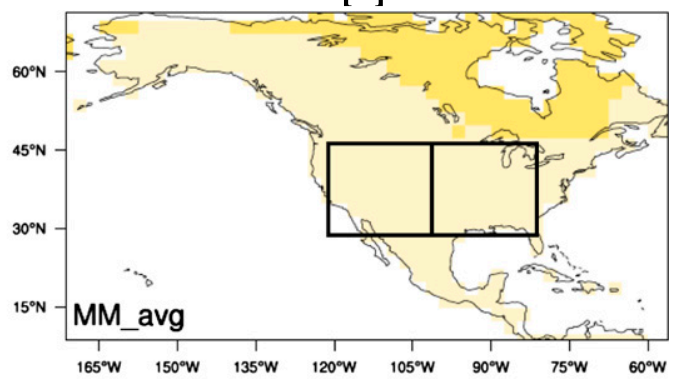

[d]

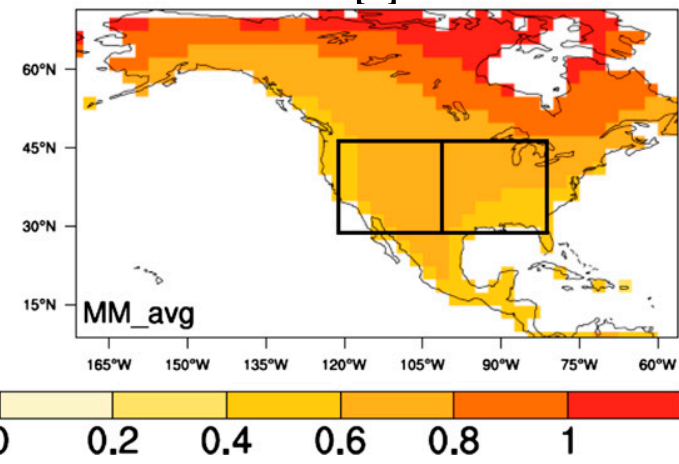

FIG. 18. Annual temperature trends $\left({ }^{\circ} \mathrm{C}\right.$ decade $\left.^{-1}\right)$ in North America during (left) the first half $(2015-50)$ and (right) second half (2051-98) of the twenty-first century for the (a),(b) RCP4.5 and (c),(d) RCP8.5 scenarios. These results are based on 16 core models and one selected ensemble member from each model (Table 1 core models, except for HadCM3). The two boxed regions represent the eastern and western United States, as referenced in section $4 \mathrm{~g}$ and Fig. 19.

able to capture both the spatial and temporal aspects of the MSD. This success is promising, as accurately simulating or including all of the air-sea interaction processes relevant to the MSD is difficult.

The CMIP5 MEM projection for precipitation change during each of the summer months (June through September) is shown in Fig. 20 for the core models in Table 1. During each of the summer months, the east Pacific ITCZ is projected to shift southward in concert with a drying over the east Pacific warm pool (EPWP), Central America/southern Mexico, and the Caribbean with enhanced drying over the Caribbean islands of Cuba, Hispaniola, and Jamaica. The strongest drying is projected to occur during July and August, which are the months when the MSD occurs in many regions throughout the inter-Americas region. The precipitation changes are in general consistent with the JJA average precipitation patterns shown in Fig. 1, although western Mexico is projected to experience wetter conditions in September, consistent with the analysis of Fig. 13.

Next, a simple algorithm for quantifying the MSD strength is used that does not assume a priori which months are climatological maxima and which months constitute the MSD (Karnauskas et al. 2013). Consistent with the month-by-month rainfall projections, the
CMIP5 core MEM provides a very robust projection of a stronger MSD for most regions that experience an MSD today (Fig. 21). The maximum MSD increases from $\sim 2.5 \mathrm{~mm} \mathrm{day}^{-1}$ to $\sim(3-4) \mathrm{mm} \mathrm{day}^{-1}$ in the RCP4.5 forcing experiment. The peak amplitude increases slightly more in the RCP 8.5 forcing experiment, and areas of amplitude greater than $3 \mathrm{~mm} \mathrm{day}^{-1}$ substantially increase in spatial extent. The projection in each of the CMIP5 models that best replicates the observed MSD is qualitatively consistent with the MEM projection (Part II). The stronger MSD is a result of early and midsummer rainfall being reduced relative to the late summer peak (see also Fig. 13). The extension of the MSD northward along the Gulf coast of Mexico and into the United States is projected to strengthen in both RCP4.5 and RCP8.5 experiments. Some regions that did not previously exhibit a MSD (e.g., Panama) develop a moderate MSD under both forcing experiments.

\section{b. Transient intraseasonal oscillations}

Some have argued that the leading mode of intraseasonal variability (ISV) in the east Pacific warm pool is a regional manifestation of the Madden-Julian oscillation (Maloney et al. 2008). Jiang et al. (2013) and Part II documented the ability of CMIP5 models 


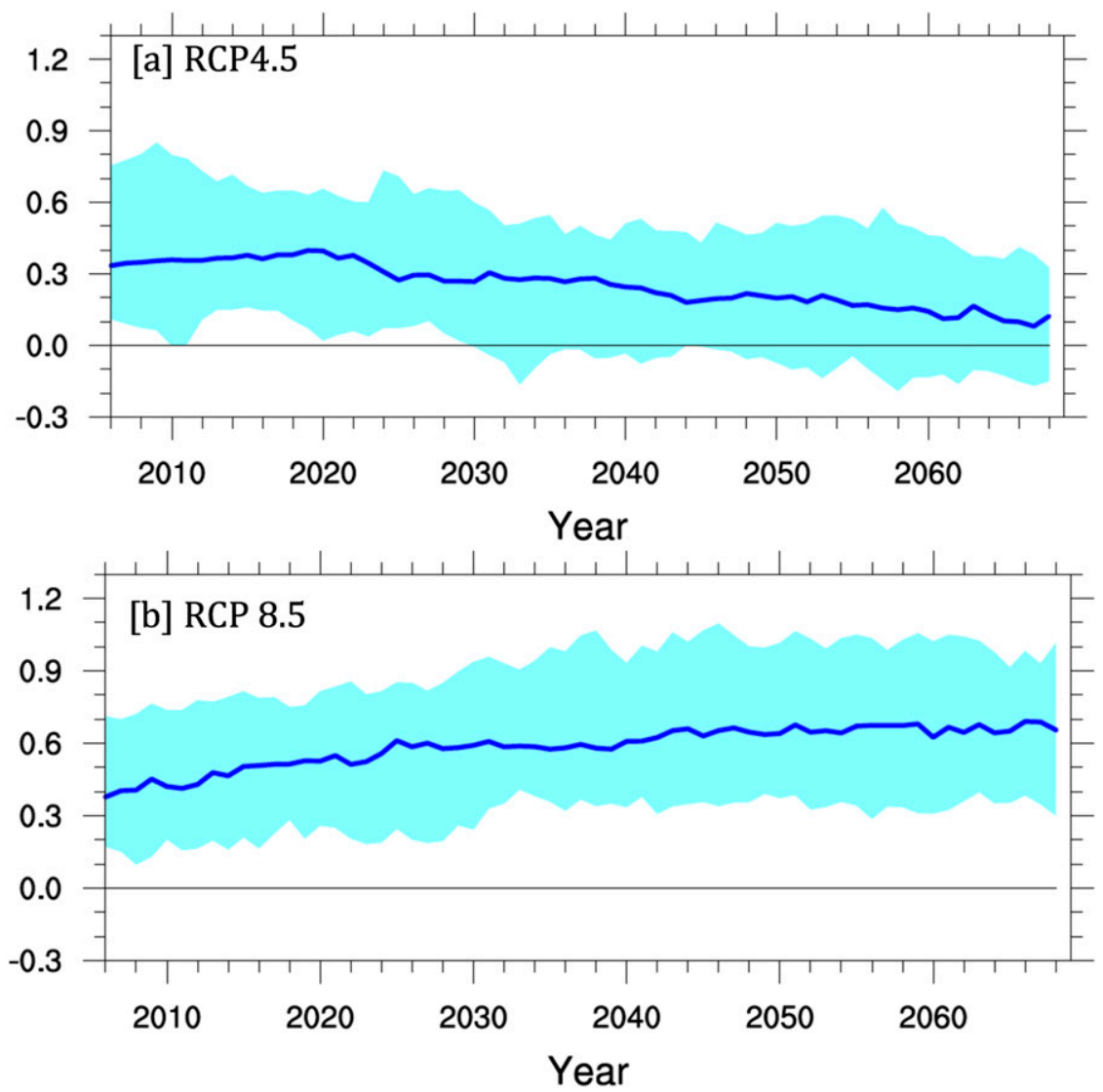

FIG. 19. The 30-yr running temperature trends $\left({ }^{\circ} \mathrm{Cdecade}^{-1}\right)$ in the eastern United States in the twenty-first century for (a) RCP4.5 and (b) RCP8.5. The eastern United States is defined in Fig. 18. The blue line shows the multimodel ensemble median and shaded regions show the $95 \%$ range based on 16 core models including all available ensemble members (Table 1 core models, except for HadCM3). There are a total of 55 ensemble members in the RCP4.5 scenario and a total of 46 ensemble members in the RCP8.5 scenario. The $x$ axis represents the start of the 30-yr period. For example, the trend corresponding to 2030 represents the trend from 2030 to 2059 .

to capture this leading mode of 30-90-day precipitation variability over the east Pacific and adjacent regions of Mexico, Central America, and the Caribbean during June-September. This analysis was done using complex empirical orthogonal function (CEOF; Barnett 1983; Horel 1984) analysis that was previously used to document the leading mode of ISV over the east Pacific during boreal summer (Maloney et al. 2008). Based on a pattern correlation and assessment of amplitude of the leading CEOF as compared to TRMM observations, eight models were judged to produce realistic ISV.

Figure 22 shows a seven-model MEM amplitude of the leading CEOF mode for 1981-2005, the 2076-2100 projection in RCP8.5, and the difference in amplitude relative to present day. As indicated in the caption, these models include six core models that were assessed by Part II to produce realistic ISV, along with one additional core model that produces poor ISV (CCSM4), although results do not differ if only good performing models are used. Stippling on the difference plot (Fig. 22c) shows where amplitude increases are statistically significant from zero at the $95 \%$ confidence level. Robust changes include significantly increased MEM amplitude of the leading CEOF on the southern fringe of the amplitude maximum, with inconsistent changes in amplitude elsewhere. A plot of intraseasonal precipitation variance supports these results (Jiang et al. 2013). These regions of significantly increased variance coincide with areas of mean precipitation increase shown in Figs. 1 and 20, a tendency noted in other studies that have examined projected ISV increases in a warming climate (Maloney and Xie 2013). 

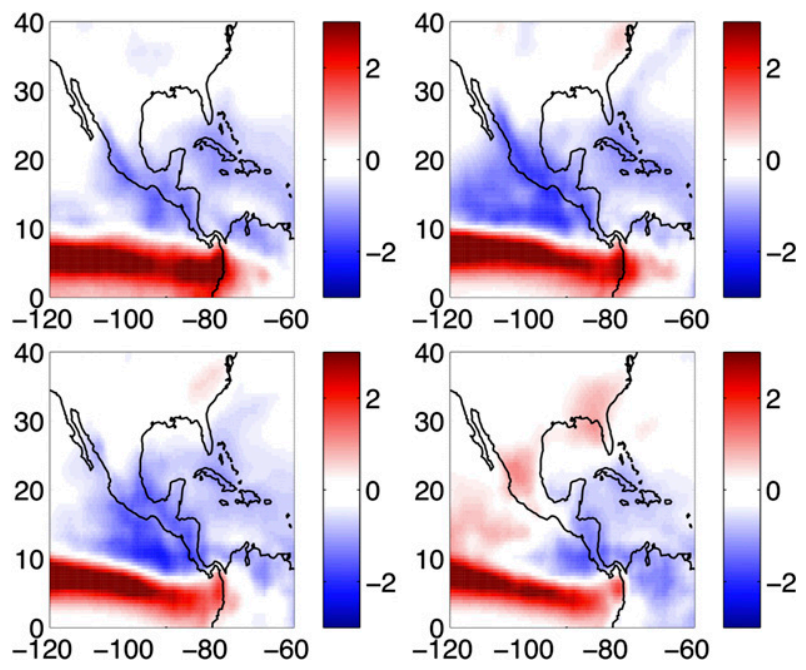

FIG. 20. MEM projection of precipitation change $\left(\mathrm{mm} \mathrm{day}^{-1}\right)$ during each of the summer months-(top left) June and (top right) July; and (bottom left) August and (bottom right) Septemberbased on the mean of the last two decades of the twenty-first century (2080-99) of the RCP8.5 forcing experiment minus the mean over the historical experiment (1860-2005) for the core models in Table 1.

\section{East Pacific and Atlantic tropical storm-track and cyclone activity}

\section{a. Tropical storm track}

Traveling tropical synoptic-scale disturbances found in tropical storm tracks (e.g., Thorncroft and Hodges 2001; Serra et al. 2008, 2010) serve as the precursors to a majority of TCs in the Atlantic and eastern North Pacific. Their frequency at $850 \mathrm{hPa}$ over Africa and the eastern Atlantic has been shown to be positively correlated with Atlantic hurricane activity (Thorncroft and Hodges 2001). Projected changes in the density and strength of these disturbances may therefore contribute to our understanding of how the statistics of TCs may change in the future, with the advantage that these synoptic systems are better resolved by low-resolution global models than the TCs themselves (see section 6b). As described in Part II, storm-track statistics are calculated from smoothed, 6-hourly 850-hPa relative vorticity following the method of Hodges $(1994,1995)$ for nine CMIP5 models. This method tracks 6-hourly $850-\mathrm{hPa}$ positive vorticity centers with a minimum threshold of $0.5 \times 10^{-6} \mathrm{~s}^{-1}$ that persist for at least 2 days and have tracks of at least $1000 \mathrm{~km}$ in length. This method primarily identifies westward moving disturbances such as easterly waves (e.g., Serra et al. 2010), although more intense storms that could potentially reach hurricane intensity are not excluded. Track density is calculated as the number of tracks in a $5^{\circ}$ spherical cap per month while mean track strength is the mean vorticity of those tracks at each location. Comparisons of the CMIP5 track statistics with the European Centre for Medium-Range Weather Forecasts (ECMWF) Interim Re-Analysis (ERA-Interim) for these same models were presented in Part II, which found that the best performing models within this subset are the HadGEM2-ES and CNRMCM5.1 while the worst performing models are the CCSM4, BCC_CSM1.1, and GFDL-ESM2M.

Figure 23 shows the RCP8.5 nine-model MEM and standard deviation of the mean (SDOM) for track density and mean strength for the May-November of 2070-2100 period, as well as the future minus historical period differences in these quantities. Overall, the models indicate a southward shift of the main storm track as well as an increase in track density for the future projections, consistent with results found using CMIP3 models (Bengtsson et al. 2006, 2007; Colbert et al. 2013). This southward shift is also observed in the pattern of mean precipitation change seen in the JJA analysis in
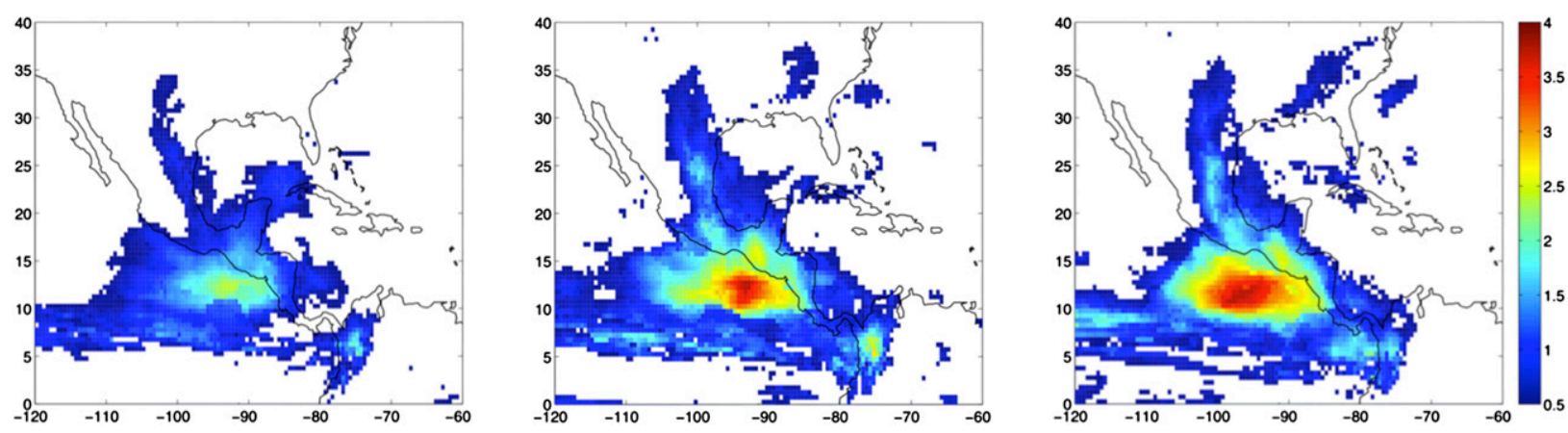

FIG. 21. MEM MSD (mm day ${ }^{-1}$ ) averaged over (left) the historical experiment and (center),(right) 2080-99 of the RCP4.5 and RCP8.5 experiments, respectively, for the core models of Table 1. The MSD for each model is calculated based on the algorithm described in Karnauskas et al. (2013). The algorithm finds minima in the monthly mean precipitation climatology during the warm season at every grid point and then quantifies the strength of the MSD by calculating the difference in precipitation at this minimum from the average of precipitation at the two bracketing maxima. 
a)

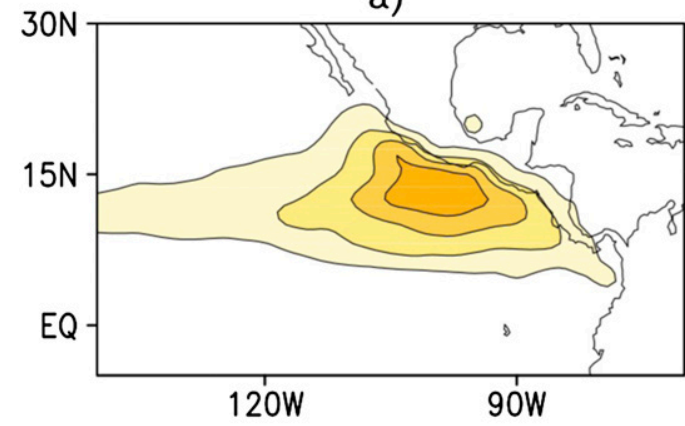

b)

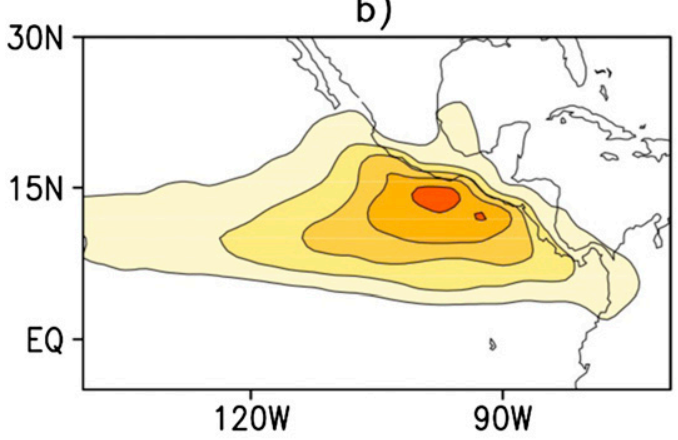

c)
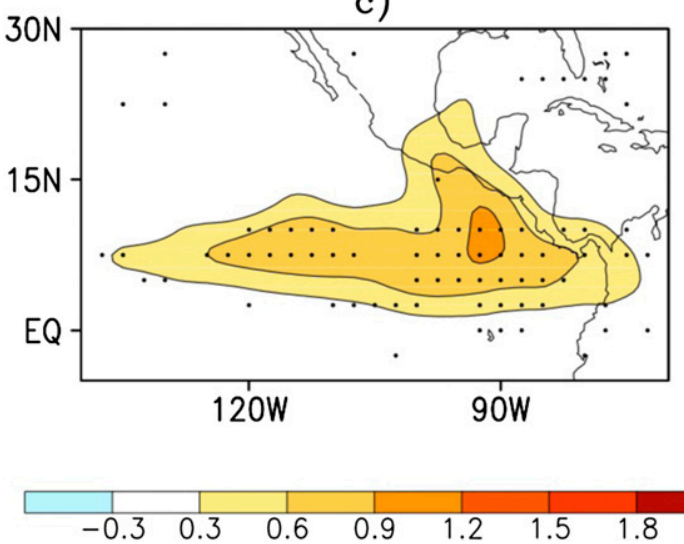

FIG. 22. MEM amplitude of the leading complex EOF of 30-90-day boreal summer precipitation anomalies during (a) 1981-2005, (b) 2076-99 in RCP8.5 and (c) their difference. The models used and total variance explained by the leading CEOF mode for the ends of the twentieth and twenty-first centuries are given as follows for each model: CCSM4 (12.1\% and 14\%), CSIRO Mk3.6.0 (21.3\% and 23.3\%), HadGEM2-CC (22.1\% and 25.7\%), HadGEM2-ES (20.5\% and 21.4\%), MIROC5 (23.2\% and $21.3 \%$ ), MPI-ESM-LR (25.1\% and 26.4\%), and MRI-CGCM3 (12.7\% and $3.9 \%)$. The color bar for the total CEOF amplitude is shown at the right, and the color bar for the difference is shown at the bottom. The time series of the CEOFs were normalized so amplitude information $\left(\mathrm{mm} \mathrm{day}^{-1}\right)$ is contained in the spatial pattern. Regions of amplitude increases that are significant at the $95 \%$ confidence level as determined using the $t$ statistic are dotted.
Figs. 1 and 20. Notably, the two best performing models for the historical period, HadGEM2-ES and CNRMCM5.1, do not show strong agreement on the magnitude of the projected future track density change (not shown). Changes in the mean track strength are less significant, with a small region of decreased strength seen in the west Atlantic and a small region of increased strength seen in the east Pacific.

\section{b. Tropical cyclones}

Using the Camargo and Zebiak (2002) algorithm, we analyzed changes in TC-like vortices in RCP4.5 and RCP8.5 in 14 core CMIP5 models, as shown in the figures of the supplementary material section (e). As discussed in Part II, a subset of these models was shown to produce the best simulation of TC activity in the current climate (GFDL CM3, GFDL-ESM2M, MPI-ESM-LR, MRI-CGCM3, and MIROC5), although all of these models still severely underestimate the number of TCs per year in the Atlantic and east Pacific. The definition of the model TCs includes thresholds for low-level vorticity and wind speed (model and resolution dependent), as well as imposes a constraint of warm core and that the vortex is an SLP minimum. Details of this analysis can be found in Camargo (2013).

Figure 24 shows the mean track density in the North Atlantic for the historical simulations for the period 1951-2000, as well as the difference of the track density between the period 2051-2100 and the historical track density for RCP4.5 and RCP8.5. While the MRI models shows a slight increase in TC track density for the Atlantic north of $25^{\circ} \mathrm{N}$, the MIROC model is characterized by substantial decreases along the U.S. coastline and the GFDL CM3 and the MPI models show a small northward shift in the track density. To be more quantitative, Fig. 25 shows the number of TCs in the Atlantic and eastern north Pacific for these five models in the historical runs, RCP4.5, and RCP8.5. For the North Atlantic, the MRI model exhibits an increase in Atlantic TC numbers in RCP8.5 relative to the historical period, whereas the MIROC5 model exhibits a significant decrease in Atlantic TC numbers in both RCP4.5 and RCP8.5. For the east Pacific, results are also mixed, with significant increases in TC numbers in future climate in the MPI model in both RCP4.5 and RCP8.5 and significant decreases in the MIROC5 model. This inconsistency in future TC changes among models is supported by use of a high-resolution model as a downscaling tool to examine projected changes in hurricane activity, as described in the supplementary material.

In the context of intensity, the CMIP5 models are not able to simulate the most intense TCs due to model resolution. For the seven models that have the highest 
(a)

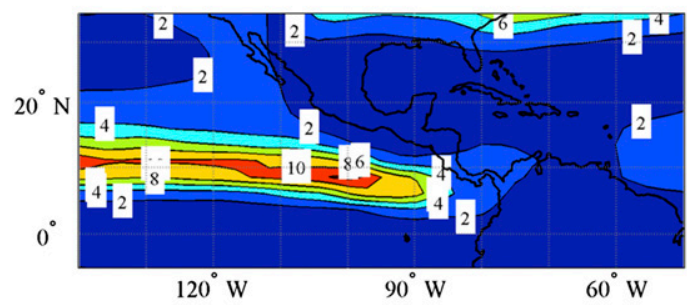

(b)

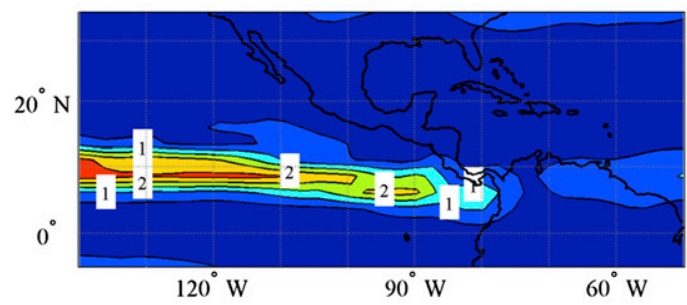

(c)

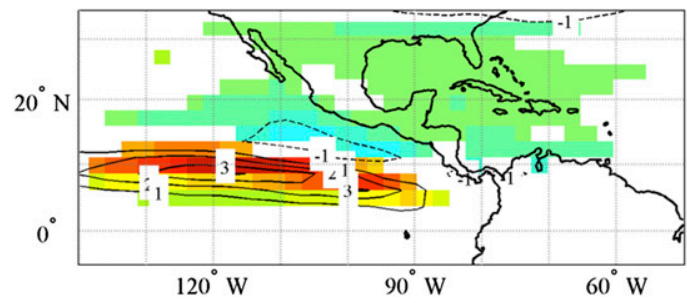

(d)

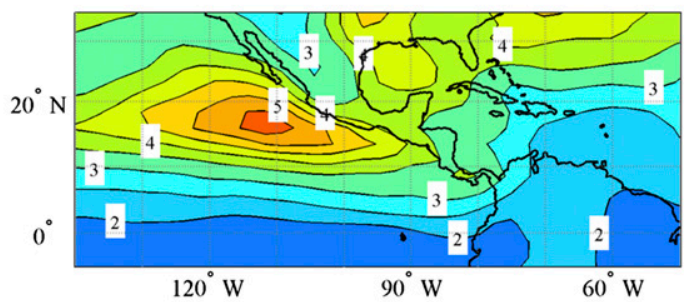

(e)

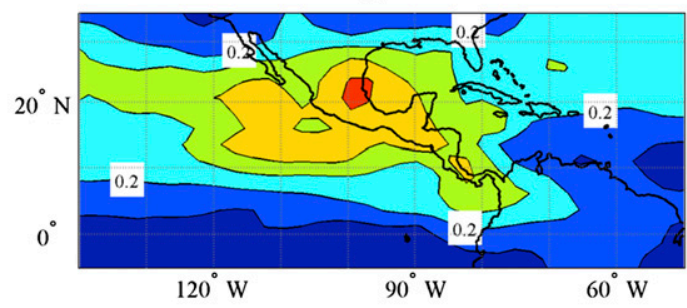

(f)

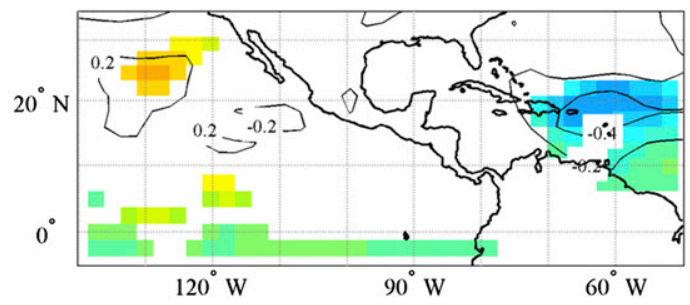

FIG. 23. (a) CMIP5 nine-model MEM, (b) standard deviation of the mean, and (c) future minus historical period differences in track density for the RCP8.5 projections with units of number of tracks per $5^{\circ}$ spherical cap per month. The colors in (a),(b) are used to accentuate the contours. (d)-(f) As in (a)-(c), but for mean track strength $\left(10^{-5} \mathrm{~s}^{-1}\right)$. Colored areas in (c),(f) indicate differences exceeding 1 standard deviation of the historical mean.

global number of TCs, a statistically significant difference is found in the maximum wind speed distributions of the RCP4.5 and RCP8.5 simulations compared with the historical simulation, based on the KolmogorovSmirnov test at the $99 \%$ significance level. For these seven models (CSIRO Mk3.6.0, GFDL CM3, GFDLESM2M, IPSL-CM5A-LR, MIROC5, MPI-ESM-LR, and MRI-CGCM3), increases in the values of the maximum wind speed occur for various percentiles of the wind speed distribution (50th, 75th, and 90th percentiles), with six (five) of the models having increases in the maximum wind speed values in the 95th (99th) percentile.

\section{c. Analysis of Atlantic wind shear and relative SST changes}

We provide further diagnosis here to help explain some of the intermodel inconsistency in Atlantic TC activity in the twenty-first century. Zhao and Held (2012) found that most of the intermodel spread in the North Atlantic TC frequency response among the CMIP3 models can be explained by a simple relative SST (RSST) index defined as the tropical Atlantic SST minus tropical mean SST. Under global warming scenarios the SST difference between the Atlantic main development region (MDR; $85^{\circ}-15^{\circ} \mathrm{W}, 10^{\circ}-20^{\circ} \mathrm{N}$ ) and the other tropical ocean basins varies from model to model with implications for TC activity (Latif et al. 2007; Swanson 2008; Vecchi et al. 2008; Wang and Lee 2008; Xie et al. 2010). Other studies suggest the strong influence of Atlantic vertical shear (VS) variations in future climate on TC activity (e.g., Vecchi and Soden 2007). Here we assess the trends over the twenty-first century in Atlantic MDR RSST and VS in CMIP5 models for RCP8.5.

A scatterplot of the MDR RSST and VS trends in the twenty-first-century CMIP5 simulations is shown in Fig. 26. The conclusions are similar if using only a subset including the core models. The individual models show different responses of the RSST and VS trends, and hence suggest inconsistent changes in TC activity, consistent with the findings in section $6 \mathrm{~b}$. As shown in the supplementary material, similar uncertainty in the sign and magnitude of VS and RSST change is seen in the east Pacific. The linear fit of all models (the solid line in Fig. 26) shows that the VS trend decreases with the RSST trend. That is, if the MDR SST trend under global 

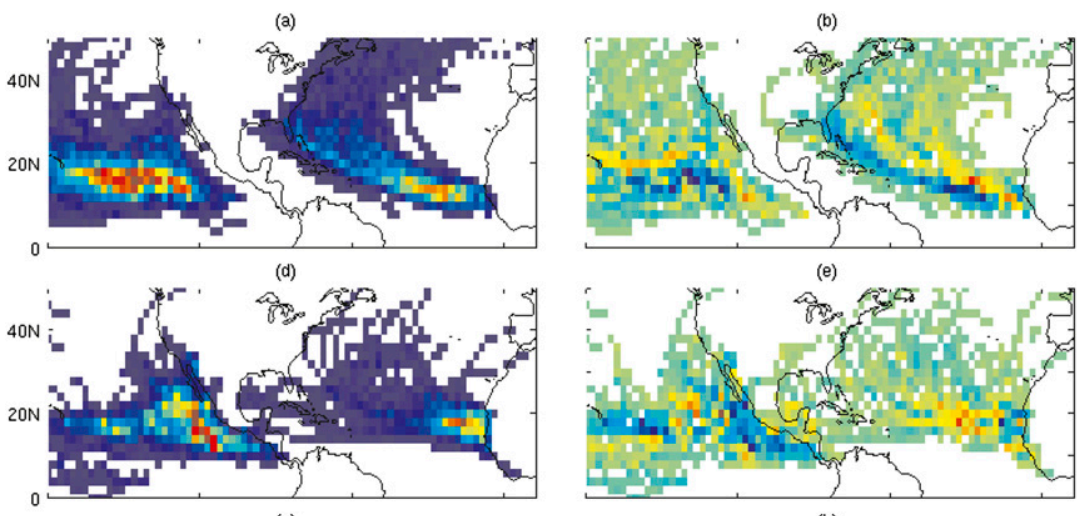

(e)
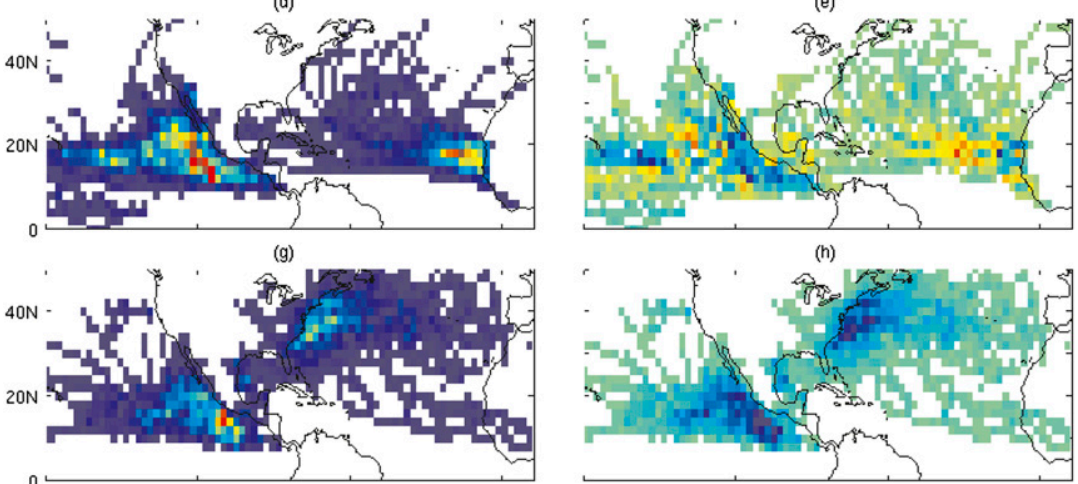

(0)
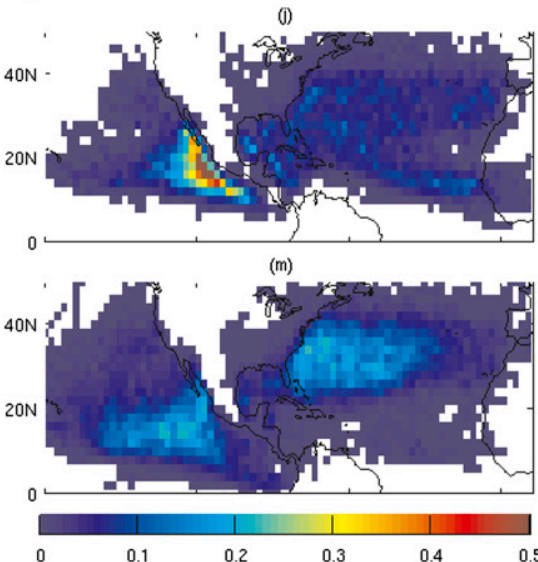

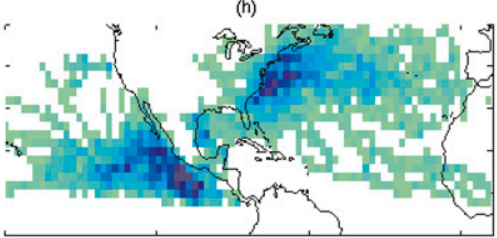

(k)

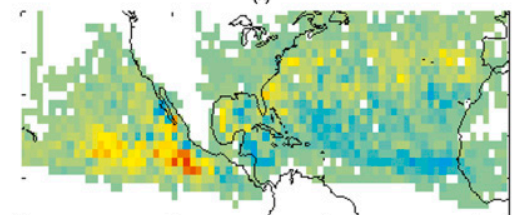

(n)

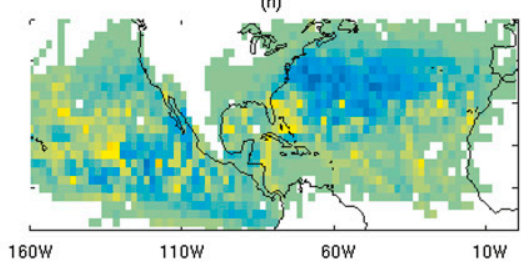

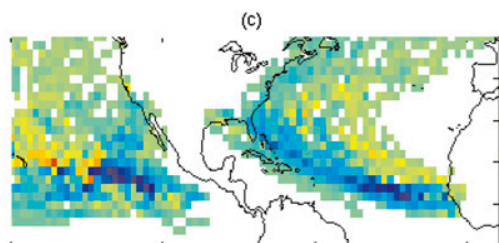
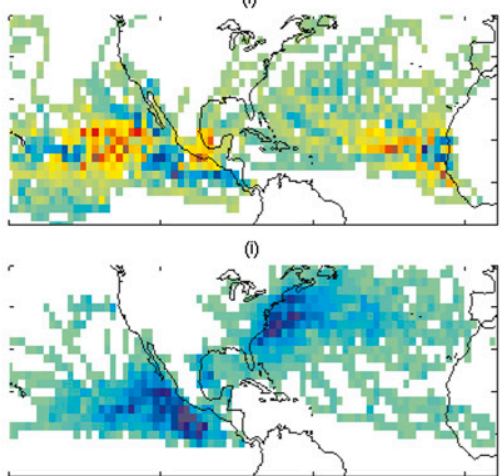

(I)

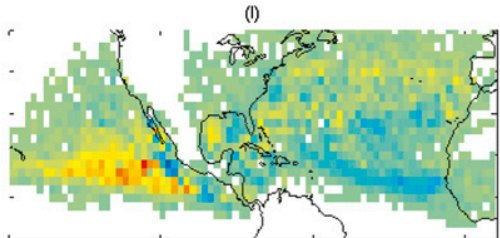

(0)

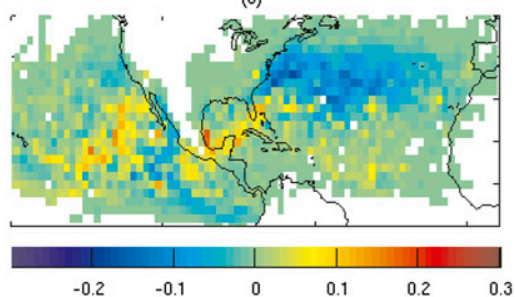

FIG. 24. (left) Mean track density in the North Atlantic for the historical simulation in the period 1951-2000 for models: (top)-(bottom) the GFDL CM3; the GFDL-ESM2M (1 ensemble member: all pathways); the MIROC5 (1 ensemble member: historical; 3 ensemble members: RCP4.5; and 1 ensemble member: RCP8.5); the MPI-ESM-LR (3 ensemble members: all pathways); and the MRI (5 ensemble members: historical and 1 ensemble member: RCP4.5 and RCP8.5).The color bar on the left is used. (center),(right) The difference of the track density in the period 2051-2100 and the historical track density RCP4.5 and RCP8.5, respectively. The color bar on the right is used. The Camargo and Zebiak (2002) method defines the existence of a TC based on low-level vorticity, sea level pressure, definition of a warm core based on temperature anomalies, and surface wind speed. The storms also have to last at least 2 days to be considered in our analysis. Units are storms per year per grid cell.

warming is smaller than that of the global tropical ocean, the VS trend in the MDR is increased and vice versa. This is consistent with a recent modeling study (Lee et al. 2011), showing that a slower warming in the tropical North Atlantic compared with the tropical Indo-Pacific Oceans increases the VS and static stability in the MDR for Atlantic TCs. The preferential warming of the tropical Indo-Pacific Oceans induces a warming of the tropical troposphere over the tropical North Atlantic, via a tropical teleconnection mechanism, and thus increases atmospheric static stability and decreases convection over the tropical North Atlantic. The slower warming (or the relative cooling) of the tropical North
Atlantic induces an increase of the VS in the Atlantic MDR region (Wang et al. 2008). Because of the increased VS and static stability in the MDR, the number of Atlantic TCs in the twenty-first century is projected to decrease in the lower RSST and higher VS conditions predicted by some models.

We note, however, that the projected MIROC5, MRICGCM3, GFDL, and MPI-ESM-LR changes shown in Fig. 25 derived from a direct TC-tracking method do not scale as expected from Fig. 26. This result may highlight the limitations of the direct tracking approach described in section $6 \mathrm{~b}$. Indeed, in the supplementary material we describe results using a high-resolution model as a 
(a)

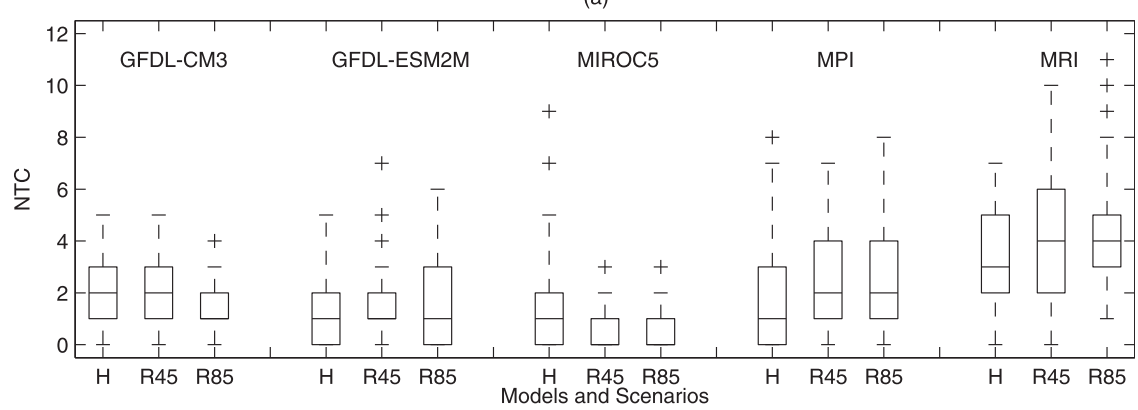

(b)

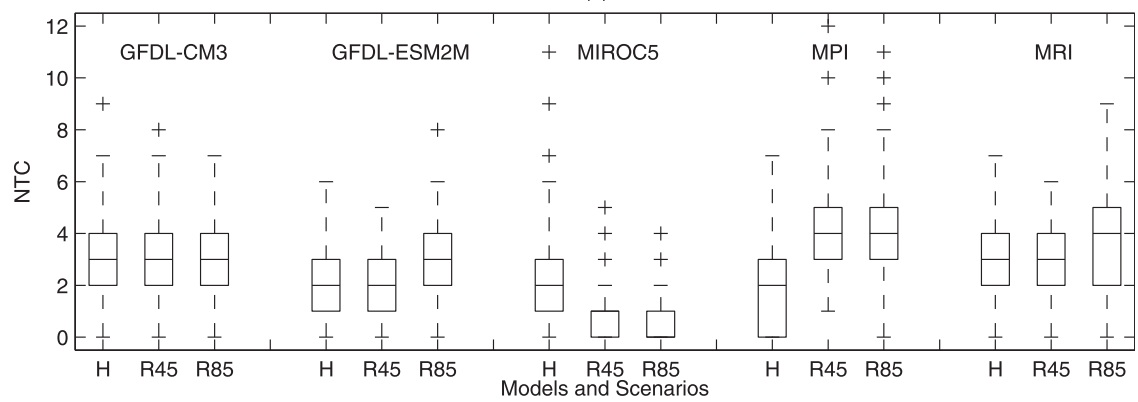

FIG. 25. Box-plots of the number of tropical cyclones (NTCs) per year in five models-from left to right, GFDL CM3, GFDL-ESM2M, MIROC5, MPI-ESM-LR, and MRI-in the three different emission pathways for the last $50 \mathrm{yr}$ in each century: historical (denoted as $\mathrm{H}$; 19512000) and RCP4.5 and RCP8.5 (denoted as R45 and R85; 2051-2100) and for (a) the North Atlantic and (b) eastern North Pacific. The box denotes the range of the 25th and 75th percentiles of the distributions, while the median is marked by the short horizontal line. The values outside of the middle quartile are marked by whiskers and plus symbols. The statistical significance of differences in the distributions of the number of TCs in the present and future was calculated using a Wilcoxon rank sum test for medians.

downscaling tool in which the projected changes in TC activity in the GFDL model come more in line with those suggested by Fig. 26. It is also described in the supplementary material that, at very high greenhouse gas concentrations, the larger direct effect of the atmospheric greenhouse gas concentrations can suppress global and regional TC frequency and thus weaken the relationship between RSST and TC activity (Held and Zhao 2011).

\section{Interannual to decadal hydroclimate}

\section{a. Interannual variability}

The large internal variability of the El Niño-Southern Oscillation (ENSO), a major source of interannual NA hydroclimate variability, makes it difficult to detect changes in ENSO properties over periods of a couple of centuries (Wittenberg 2009; Stevenson et al. 2012). Even without significant changes in ENSO itself, the longterm trend in tropical SST and the associated changes in the midlatitude basic state may result in substantial changes in ENSO-related teleconnections (Meehl et al. 2006; Meehl and Teng 2007; Lau et al. 2008; Kug et al.
2010; Kumar et al. 2010; Stevenson et al. 2012). In this analysis, we evaluate whether the NA seasonal temperature and precipitation patterns associated with ENSO are projected to change significantly in the twenty-first century in CMIP5 models in RCP4.5 and RCP8.5. Performance in accurately simulating ENSO teleconnections in current climate is relatively strong in several of the CMIP5 models and particularly in the MEM (Part II). We do not distinguish different types of ENSO episodes, such as central Pacific from east Pacific El Niño episodes that may change in proportion with climate change (Yeh et al. 2009), but rather consider a single broad class of ENSO events identified by the Niño-3.4 SST index. The Niño-3.4 SST index is defined as the average SST in the region $5^{\circ} \mathrm{N}-5^{\circ} \mathrm{S}, 120^{\circ}-170^{\circ} \mathrm{W}$ (Trenberth 1997). We identify ENSO episodes in the same way as described in the historical analysis (Part II). Because all anomalies are detrended for this analysis, we focus on interannual variability superimposed upon the long-term trend. On the basis of these calculations, we find that the frequency of ENSO episodes in the RCP4.5 and RCP8.5 simulations is approximately the same as in the historical simulations. A hint of increased ENSO amplitude 


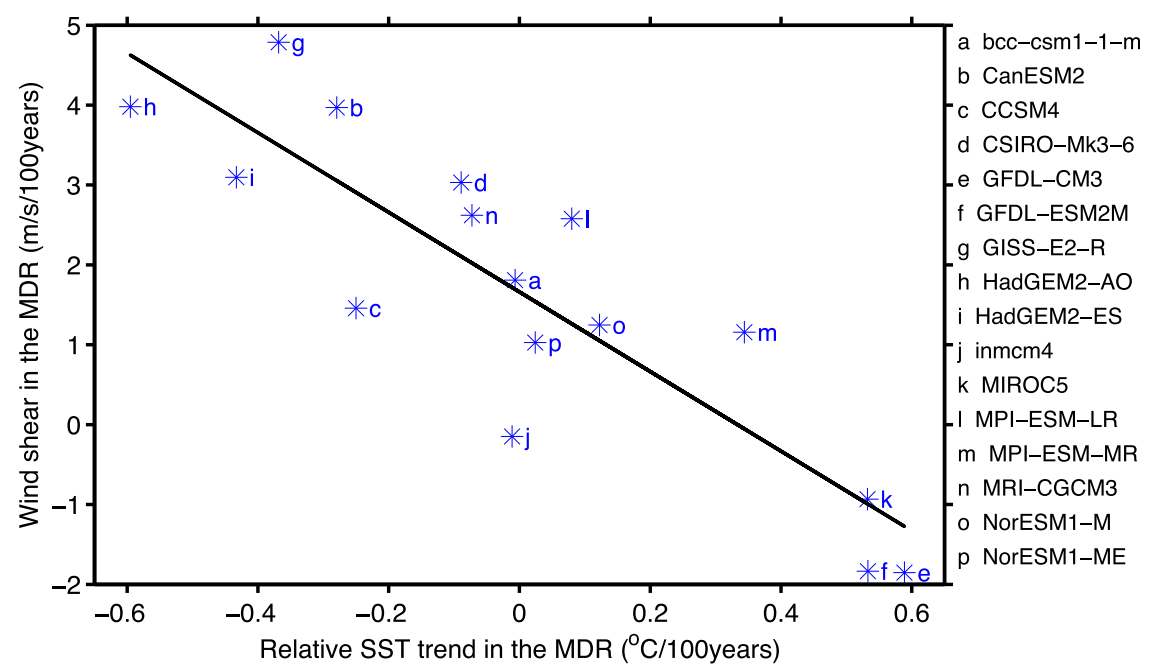

FIG. 26. Scatterplot plot of the vertical wind shear trend over the twenty-first century vs the relative SST trend in the hurricane $\operatorname{MDR}\left(85^{\circ}-15^{\circ} \mathrm{W}, 10^{\circ}-20^{\circ} \mathrm{N}\right)$ during the Atlantic hurricane season of June-November (JJASON) in RCP8.5 for models a-p. The relative MDR SST trend is calculated as the difference between the MDR SST trend and the global tropical $\left(30^{\circ} \mathrm{S}-30^{\circ} \mathrm{N}\right)$ SST trend. SST is taken from the NOAA extended reconstructed SST version 3 (Smith et al. 2008).

exists, as the ensemble and episode mean peak Niño-3.4 SST amplitude of El Niño episodes for the historical, RCP4.5, and RCP8.5 episodes is $1.51^{\circ}, 1.51^{\circ}$, and $1.59^{\circ} \mathrm{C}$, respectively; for La Niña episodes, the mean peak amplitude is $1.39^{\circ}, 1.46^{\circ}$, and $1.57^{\circ} \mathrm{C}$, respectively. However, large intermodel variability exists, so these changes are not robust.

We calculate MEM 300-hPa geopotential height, surface air temperature (SAT), precipitation, and tropical surface temperature composites for RCP8.5 in the same way as in the historical analysis (Part II) and then show the RCP8.5 (2006-2100) minus historical (1850-2005) composite differences in Fig. 27 (see Table 5 for the list of 21 models used that encompass the core set). Comparison of Fig. 27 with the historical composites for El Niño (Fig. 9 in Part II) indicates a projected strengthening and slight northeastward shift of the El Niño and La Niña teleconnection patterns in the twenty-first century. These projected changes include a strengthening of the negative southeastern United States temperature anomalies during El Niño (Fig. 27c), warming over much of NA during La Niña (Fig. 27d), and a strengthening of the precipitation patterns on the west and southeastern coastal regions of the United States (Figs. 27e,f). These strengthened patterns are consistent with significant increases in the tropical convective forcing (Figs. 27i,j). The changes in ENSO SST anomalies are modest (Figs. 27g, $\mathrm{h}$ ), and so the increase in the convection anomalies may relate more strongly to the warming of the climatological SSTs, particularly in the eastern equatorial Pacific.
The projected northeastward shift of the Aleutian anomaly during El Niño has been noted in previous studies (Meehl and Teng 2007; Kug et al. 2010), but not all models exhibit this change. As noted in Stevenson (2012), some models project this northeastward shift whereas others tend to indicate a strengthening in place. This uncertainty is reflected in high ensemble standard deviations of $300-\mathrm{hPa}$ height over the North Pacific (Fig. 27a), which then contributes to the high ensemble standard deviations in projected temperature changes over northwest NA (Fig. 27c). For the La Niña teleconnections, the projected changes in the geopotential height field (Fig. 27b) resemble the response to Indowestern Pacific warming shown in Lau et al. (2008), which suggests that the changes may be a direct response to the increased Indo-western Pacific convection anomalies (Fig. 27j). For both the El Niño and La Niña teleconnection changes, the highest intermodel variance generally corresponds with the regions of highest precipitation change (Figs. 27e,f).

Table 5 provides centered pattern correlations and RMS differences between the historical and twenty-first-century RCP8.5 seasonal composites of SAT and precipitation over the NA region $\left(6^{\circ}-75^{\circ} \mathrm{N}, 180^{\circ}-50^{\circ} \mathrm{W}\right)$ for one run of each CMIP5 model. In addition, we indicate whether the composite patterns are significantly different based on a "false discovery rate" (FDR) (Benjamini and Hochberg 1995; Wilks 2006) field significance test, as discussed in Table 5. Table 5 indicates a large degree of intermodel spread for each seasonal composite, but the total ensemble pattern 

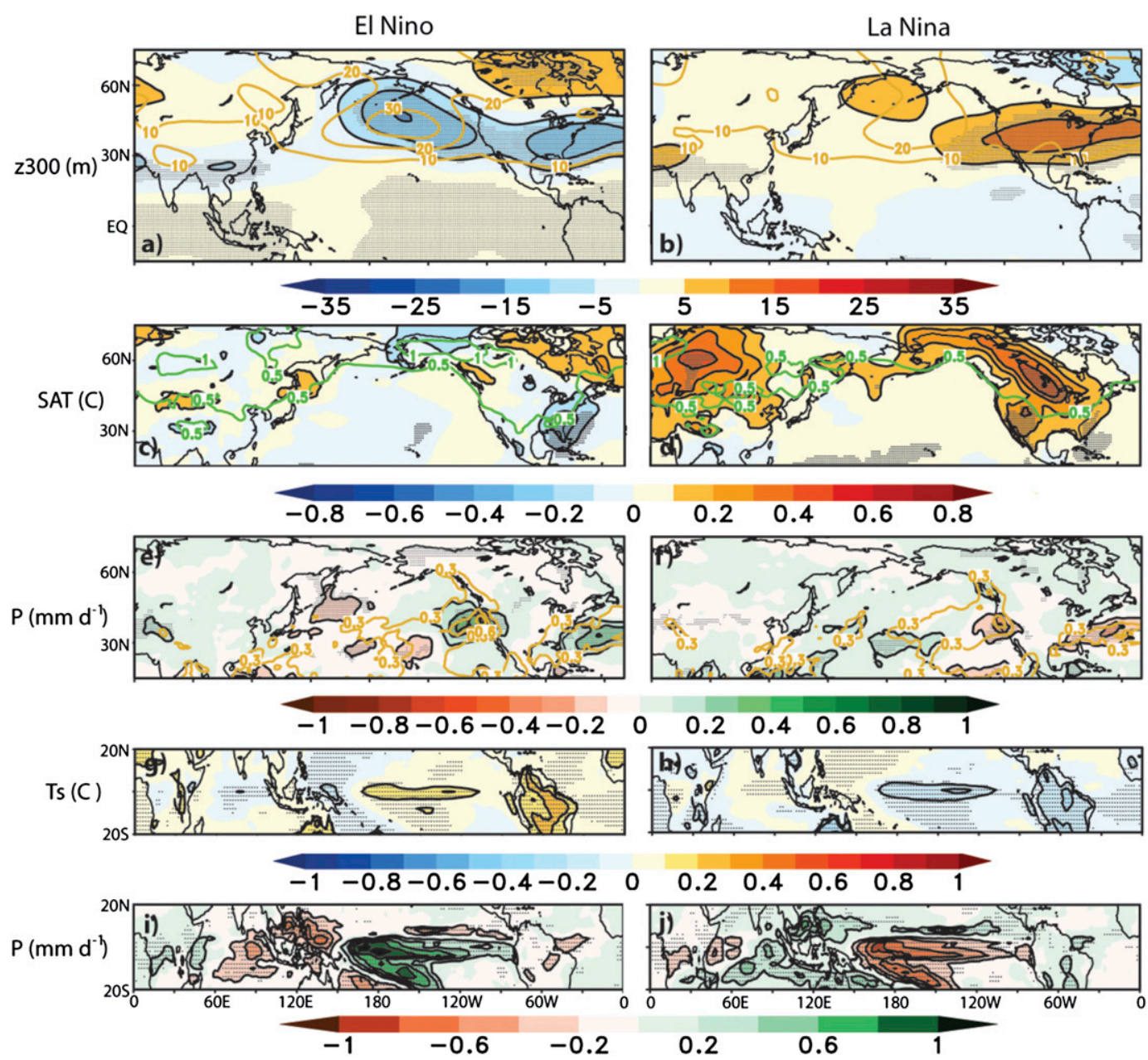

FIG. 27. RCP8.5 twenty-first-century (2006-2100) minus historical (1850-2005) CMIP5 ensemble DJF (left) El Niño and (right) La Niña composite differences of (a),(b) 300-hPa geopotential height (m; color-filled contours); (c),(d) surface air temperature $\left({ }^{\circ} \mathrm{C}\right.$; color-filled contours); (e),(f) precipitation $\left(\mathrm{mm} \mathrm{day}^{-1}\right.$; color-filled contours); (g),(h) surface temperature $\left({ }^{\circ} \mathrm{C}\right.$; color-filled contours); and (i),(j) tropical precipitation (mm day ${ }^{-1}$; color-filled contours). The dark yellow contours in (a),(b),(e),(f) and green contours in (c),(d) indicate the ensemble standard deviations of the individual model composites. The composites in (a)-(f) are normalized by the Niño-3.4 SST amplitude. Stippling indicates composite differences that are statistically significant at the $5 \%$ significance level based on a two-sided $t$ test.

correlations are high for each composite and yet some of the projected changes are statistically significant. This finding reinforces the tendency for projected strengthening of the MEM teleconnections with little change in pattern shape.

\section{b. Decadal variability}

Similar to our analysis for ENSO, we evaluate whether NA temperature and precipitation patterns associated with the PDO are projected to change in the CMIP5 models. We define the PDO as the leading empirical orthogonal function of extended winter (November-April) monthly mean sea surface temperature (SST) anomalies in the North Pacific poleward of $20^{\circ} \mathrm{N}$. We follow the same procedures for calculating SST anomalies, performing the EOF analysis, and calculating the PDO index as described in the historical analysis (Part II), except that we now base the EOF analysis on the period from 2006 to 2090. As in the preceding analysis of ENSO teleconnection changes, we examine changes in decadal variability superimposed on the long-term trend by removing the global mean SST for the PDO EOF calculations and by detrending the NA temperature and precipitation anomalies prior to the regressions. Part II showed that CMIP5 models have success in reproducing the PDO temperature teleconnection pattern but mixed success at capturing the teleconnection pattern in precipitation.

Overall, we find that SAT and precipitation pattern changes for individual models are generally not significant, 
TABLE 5. ENSO North America composites: historical simulations compared with twenty-first-century (2006-2100) RCP8.5 simulations. In each cell, El Niño (La Niña) metrics are located to the left (right) and pattern correlations lie above the RMS difference $\left({ }^{\circ} \mathrm{C}\right.$ for $\mathrm{SAT}$ and $\mathrm{mm} \mathrm{day}^{-1}$ for precipitation). This test identifies local $p$ values that control the FDR at a level $q$, which is the expected proportion of rejected local null hypotheses that are actually true. Most relevant for the present context, if at least one local null hypothesis is rejected at the level $q$, then the patterns are deemed different at a global significance level equal to $q$ (for more details, see Wilks 2006). Missing values indicate that less than two seasons met the criteria for compositing.

\begin{tabular}{|c|c|c|c|c|c|c|c|c|}
\hline Model & DJF SAT & $\begin{array}{c}\text { DJF } \\
\text { precipitation }\end{array}$ & MAM SAT & $\begin{array}{c}\text { MAM } \\
\text { precipitation }\end{array}$ & JJA SAT & $\begin{array}{c}\mathrm{JJA} \\
\text { precipitation }\end{array}$ & SON SAT & $\begin{array}{c}\text { SON } \\
\text { precipitation }\end{array}$ \\
\hline \multirow[t]{2}{*}{ GISS-E2-R } & $-0.11^{\mathrm{a}} / 0.50^{\mathrm{a}}$ & $0.53 / 0.41$ & $-/ 0.44$ & $-/ 0.27$ & $0.05 / 0.13$ & $-0.19 / 0.34$ & $0.73 / 0.48$ & $0.33 / 0.56$ \\
\hline & $0.81^{\mathrm{a}} / 0.52^{\mathrm{a}}$ & $0.51 / 0.43$ & $-/ 0.63$ & $-/ 0.61$ & $0.38 / 0.32$ & $0.79 / 0.42$ & $0.27 / 0.27$ & $0.41 / 0.35$ \\
\hline \multirow[t]{2}{*}{ MPI-ESM-LR } & $0.36 / 0.72$ & $0.74 / 0.75^{\mathrm{a}}$ & $0.69 / 0.75$ & $0.67 / 0.78$ & $0.65 / 0.64$ & $0.77^{\mathrm{b}} / 0.62$ & $0.62 / 0.27$ & $0.58 / 0.73$ \\
\hline & $0.43 / 0.32$ & $0.29 / 0.33^{\mathrm{a}}$ & $0.28 / 0.33$ & $0.32 / 0.35$ & $0.21 / 0.24$ & $0.26^{\mathrm{b}} / 0.32$ & $0.22 / 0.28$ & $0.35 / 0.27$ \\
\hline \multirow[t]{2}{*}{ CCSM4 } & $0.31^{\mathrm{b}} / 0.91$ & $0.59 / 0.86$ & $0.85 / 0.92^{\mathrm{a}}$ & $0.86 / 0.76^{\mathrm{a}}$ & $0.37^{\mathrm{a}} / 0.28$ & $0.69^{\mathrm{a}} / 0.80^{\mathrm{c}}$ & $0.43 / 0.42$ & $0.69^{\mathrm{c}} / 0.74^{\mathrm{c}}$ \\
\hline & $0.48^{\mathrm{b}} / 0.31$ & $0.25 / 0.19$ & $0.31 / 0.28^{\mathrm{a}}$ & $0.22 / 0.22^{\mathrm{a}}$ & $0.23^{\mathrm{a}} / 0.30$ & $0.45^{\mathrm{a}} / 0.37^{\mathrm{c}}$ & $0.20 / 0.20$ & $0.42^{\mathrm{c}} / 0.36^{\mathrm{c}}$ \\
\hline \multirow[t]{2}{*}{ GFDL-ESM2G } & $0.53^{\mathrm{b}} / 0.77$ & $0.64 / 0.72$ & $0.83 / 0.39$ & $0.67 / 0.61$ & $0.52 / 0.49$ & $0.67 / 0.69$ & $0.58 / 0.69$ & $0.72 / 0.78$ \\
\hline & $0.52^{\mathrm{b}} / 0.25$ & $0.32 / 0.26$ & $0.43 / 0.55$ & $0.37 / 0.23$ & $0.25 / 0.24$ & $0.35 / 0.46$ & $0.20 / 0.16$ & $0.31 / 0.31$ \\
\hline \multirow[t]{2}{*}{ GFDL-ESM2M } & $0.86 / 0.85$ & $0.88 / 0.92$ & $0.92 / 0.96$ & $0.91 / 0.79$ & $0.93 / 0.88$ & $0.86 / 0.89$ & $0.43 / 0.35$ & $0.84 / 0.82$ \\
\hline & $0.25 / 0.20$ & $0.17 / 0.14$ & $0.19 / 0.15$ & $0.20 / 0.17$ & $0.16 / 0.14$ & $0.16 / 0.17$ & $0.22 / 0.21$ & $0.26 / 0.28$ \\
\hline \multirow[t]{2}{*}{ GFDL CM3 } & $0.70 / 0.53$ & $0.92 / 0.92$ & $0.92 / 0.88$ & $0.89 / 0.87$ & $0.54 / 0.56$ & $0.75^{\mathrm{a}} / 0.63$ & $0.23 / 0.43$ & $0.27 / 0.62$ \\
\hline & $0.15 / 0.21$ & $0.20 / 0.20$ & $0.21 / 0.21$ & $0.17 / 0.16$ & $0.20 / 0.22$ & $0.39^{\mathrm{a}} / 0.31$ & $0.17 / 0.16$ & $0.28 / 0.23$ \\
\hline \multirow[t]{2}{*}{ BCC_CSM1.1 } & $0.58 / 0.44$ & $0.63 / 0.61$ & $0.20 / 0.78$ & $0.08 / 0.51$ & $0.26 / 0.22$ & $0.12 / 0.41$ & $-0.10 / 0.05$ & $0.42 / 0.21$ \\
\hline & $0.39 / 0.44$ & $0.25 / 0.36$ & $0.56 / 0.35$ & $0.38 / 0.37$ & $0.34 / 0.29$ & $0.49 / 0.49$ & $0.28 / 0.26$ & $0.33 / 0.42$ \\
\hline \multirow[t]{2}{*}{ CanESM2 } & $0.87^{\mathrm{c}} / 0.68^{\mathrm{a}}$ & $0.60^{\mathrm{c}} / 0.75^{\mathrm{c}}$ & $0.91 / 0.88^{\mathrm{b}}$ & $0.82^{\mathrm{c}} / 0.86^{\mathrm{a}}$ & $0.61^{\mathrm{c}} / 0.54$ & $0.81 / 0.71$ & $0.43 / 0.35$ & $0.90 \% / 0.90$ \\
\hline & $0.33^{\mathrm{c}} / 0.35^{\mathrm{a}}$ & $0.36^{\mathrm{c}} / 0.28^{\mathrm{c}}$ & $0.26 / 0.29^{\mathrm{b}}$ & $0.40^{\mathrm{c}} / 0.36^{\mathrm{a}}$ & $0.22^{\mathrm{c}} / 0.24$ & $0.29 / 0.23$ & $0.24 / 0.23$ & $0.26^{\mathrm{a}} / 0.23$ \\
\hline \multirow[t]{2}{*}{ CNRM-CM5.1 } & $0.04 / 0.46^{\mathrm{c}}$ & $0.63 / 0.70$ & $0.64 / 0.83$ & $0.42 / 0.51$ & $0.30 / 0.32$ & $0.81 / 0.72$ & $0.18 / 0.16$ & $0.27 / 0.41$ \\
\hline & $0.45 / 0.32^{c}$ & $0.22 / 0.20$ & $0.36 / 0.28$ & $0.31 / 0.28$ & $0.21 / 0.18$ & $0.22 / 0.25$ & $0.14 / 0.14$ & $0.20 / 0.16$ \\
\hline \multirow[t]{2}{*}{ CSIRO Mk3.6.0 } & $0.75 / 0.84$ & $0.76 / 0.73$ & $0.69 / 0.58$ & $0.88 / 0.83$ & $0.71 / 0.55$ & $0.86 / 0.90$ & $0.72 / 0.60$ & $0.93 / 0.76$ \\
\hline & $0.41 / 0.31$ & $0.35 / 0.33$ & $0.25 / 0.25$ & $0.27 / 0.31$ & $0.24 / 0.23$ & $0.41 / 0.35$ & $0.19 / 0.30$ & $0.39 / 0.50$ \\
\hline \multirow[t]{2}{*}{ HadGEM2-CC } & $0.28^{\mathrm{c}} / 0.66^{\mathrm{c}}$ & $0.05^{\mathrm{c}} / 0.65^{\mathrm{b}}$ & $0.50^{\mathrm{b}} / 0.51^{\mathrm{a}}$ & $0.46^{\mathrm{c}} / 0.53^{\mathrm{c}}$ & $0.03^{\mathrm{c}} / 0.01^{\mathrm{c}}$ & $-0.18^{\mathrm{c}} / 0.29$ & $0.47^{\mathrm{c}} / 0.27^{\mathrm{c}}$ & $-0.06^{\mathrm{c}} /-0.18^{\mathrm{c}}$ \\
\hline & $0.39^{\mathrm{c}} / 0.40^{\mathrm{c}}$ & $0.77^{\mathrm{c}} / 0.61^{\mathrm{b}}$ & $0.58^{\mathrm{b}} / 0.47^{\mathrm{a}}$ & $0.46^{\mathrm{c}} / 0.64^{\mathrm{c}}$ & $0.33^{\mathrm{c}} / 0.38^{\mathrm{c}}$ & $0.79^{c} / 0.61$ & $0.27^{\mathrm{c}} / 0.20^{\mathrm{c}}$ & $0.82^{\mathrm{c}} / 0.65^{\mathrm{c}}$ \\
\hline \multirow[t]{2}{*}{ HadGEM2-ES } & $0.46^{\mathrm{c}} / 0.25^{\mathrm{a}}$ & $0.31^{\mathrm{a}} /-0.10^{\mathrm{a}}$ & $0.59 / 0.18^{c}$ & $0.26^{\mathrm{c}} / 0.37$ & $0.43 / 0.32^{\mathrm{c}}$ & $0.09^{\mathrm{a}} / 0.01^{\mathrm{a}}$ & $-0.14^{\mathrm{a}} / 0.06^{\mathrm{c}}$ & $0.33^{\mathrm{c}} / 0.06^{\mathrm{c}}$ \\
\hline & $0.39^{\mathrm{c}} / 0.47^{\mathrm{a}}$ & $0.65^{\mathrm{a}} / 0.73^{\mathrm{a}}$ & $0.37 / 0.63^{c}$ & $0.44^{\mathrm{c}} / 0.60$ & $0.37 / 0.29^{c}$ & $0.95^{\mathrm{a}} / 0.79^{\mathrm{a}}$ & $0.31^{\mathrm{a}} / 0.23^{\mathrm{c}}$ & $0.84^{\mathrm{c}} / 0.75^{\mathrm{c}}$ \\
\hline HadCM3 & - & - & - & - & - & - & - & - \\
\hline \multirow[t]{2}{*}{ INM-CM4.0 } & $0.40 / 0.43$ & $0.46^{\mathrm{b}} / 0.28$ & $0.33 / 0.43$ & $0.72 / 0.62$ & $0.24 / 0.20$ & $0.28 /-0.04$ & $0.47^{\mathrm{a}} /-0.01$ & $0.59 / 0.51$ \\
\hline & $0.41 / 0.49$ & $0.43^{\mathrm{b}} / 0.29$ & $0.45 / 0.35$ & $0.26 / 0.24$ & $0.28 / 0.37$ & $0.29 / 0.34$ & $0.25^{\mathrm{a}} / 0.30$ & $0.31 / 0.31$ \\
\hline \multirow[t]{2}{*}{ IPSL-CM5A-LR } & $0.33 / 0.68$ & $0.52^{\mathrm{a}} / 0.41$ & $0.82 / 0.63$ & $0.74 / 0.72$ & $0.41 / 0.46$ & $0.39 / 0.62$ & $0.35 / 0.48$ & $0.56 / 0.34$ \\
\hline & $0.40 / 0.39$ & $0.46^{\mathrm{a}} / 0.43$ & $0.42 / 0.45$ & $0.29 / 0.25$ & $0.21 / 0.21$ & $0.31 / 0.32$ & $0.24 / 0.22$ & $0.27 / 0.30$ \\
\hline \multirow[t]{2}{*}{ IPSL-CM5A-MR } & $0.35^{\mathrm{b}} /-0.48$ & $0.58^{\mathrm{b}} / 0.38$ & $0.85^{\mathrm{a}} / 0.85$ & $0.70 / 0.77$ & $0.66 / 0.49$ & $0.67 / 0.59^{c}$ & $0.29 / 0.62$ & $0.59 / 0.35$ \\
\hline & $0.40^{\mathrm{b}} / 0.52$ & $0.45^{\mathrm{b}} / 0.36$ & $0.26^{\mathrm{a}} / 0.30$ & $0.29 / 0.35$ & $0.20 / 0.27$ & $0.33 / 0.35^{\mathrm{c}}$ & $0.25 / 0.22$ & $0.35 / 0.37$ \\
\hline \multirow[t]{2}{*}{ MIROC5 } & $0.69^{\mathrm{a}} / 0.74$ & $0.92^{\mathrm{c}} / 0.92$ & $0.71^{b} / 0.80$ & $0.64^{\mathrm{b}} / 0.76$ & $0.82 / 0.89$ & $0.86^{\mathrm{a}} / 0.86^{\mathrm{c}}$ & $0.71 / 0.76$ & $0.85^{\mathrm{c}} / 0.89$ \\
\hline & $0.35^{\mathrm{a}} / 0.25$ & $0.22^{\mathrm{c}} / 0.23$ & $0.29^{\mathrm{b}} / 0.26$ & $0.24^{\mathrm{b}} / 0.24$ & $0.15 / 0.12$ & $0.27^{\mathrm{a}} / 0.39^{\mathrm{c}}$ & $0.15 / 0.12$ & $0.32 / 0.25$ \\
\hline \multirow[t]{2}{*}{ MIROC-ESM } & $0.29 / 0.37$ & $0.73 / 0.74$ & $0.01 / 0.33$ & $0.49 / 0.32$ & $0.30^{\mathrm{b}} /-0.42^{\mathrm{b}}$ & $0.57 / 0.19$ & $-0.21 /-0.12$ & $0.16 / 0.61$ \\
\hline & $0.56 / 0.57$ & $0.27 / 0.29$ & $0.87 / 0.63$ & $0.47 / 0.42$ & $0.51^{\mathrm{b}} / 0.63^{\mathrm{b}}$ & $0.38 / 0.56$ & $0.40 / 0.47$ & $0.44 / 0.41$ \\
\hline \multirow[t]{2}{*}{ FGOALS-s2 } & $0.84^{\mathrm{c}} / 0.79^{\mathrm{b}}$ & $0.70^{\mathrm{c}} / 0.76$ & $0.74 / 0.69$ & $0.67 / 0.80$ & $0.73 / 0.74^{\mathrm{c}}$ & $0.73 / 0.76$ & $-0.20^{\mathrm{c}} / 0.65^{\mathrm{c}}$ & $0.38^{\mathrm{c}} / 0.32^{\mathrm{a}}$ \\
\hline & $0.18^{\mathrm{c}} / 0.32^{\mathrm{b}}$ & $0.23^{\mathrm{c}} / 0.21$ & $0.37 / 0.38$ & $0.39 / 0.29$ & $0.17 / 0.16^{\mathrm{c}}$ & $0.29 / 0.26$ & $0.18^{\mathrm{c}} / 0.13^{\mathrm{c}}$ & $0.21^{\mathrm{c}} / 0.20^{\mathrm{a}}$ \\
\hline \multirow[t]{2}{*}{ MRI-CGCM3 } & $0.70 / 0.88$ & $0.68 / 0.74$ & $-0.07 / 0.71$ & $0.10 / 0.52$ & $0.72 / 0.17^{\mathrm{b}}$ & $0.61 / 0.44$ & $0.69 / 0.81$ & $0.64 / 0.50$ \\
\hline & $0.44 / 0.48$ & $0.40 / 0.38$ & $0.51 / 0.21$ & $0.36 / 0.30$ & $0.39 / 0.38^{\mathrm{b}}$ & $0.33 / 0.39$ & $0.31 / 0.22$ & $0.38 / 0.38$ \\
\hline \multirow[t]{2}{*}{ NorESM1-M } & $0.92 / 0.87$ & $0.65 / 0.72$ & $0.84 / 0.88$ & $0.59 / 0.71$ & $0.88 / 0.70$ & $0.76 / 0.59$ & $0.82 \% / 0.54$ & $0.19 / 0.45$ \\
\hline & $0.26 / 0.43$ & $0.26 / 0.29$ & $0.40 / 0.44$ & $0.35 / 0.32$ & $0.22 / 0.31$ & $0.32 / 0.29$ & $0.13^{\mathrm{a}} / 0.22$ & $0.26 / 0.22$ \\
\hline \multirow[t]{2}{*}{ Ensemble } & $0.97^{\mathrm{c}} / 0.95$ & $0.90 / 0.94$ & $0.98^{\mathrm{a}} / 0.97^{\mathrm{a}}$ & $0.96 / 0.95$ & $0.96 / 0.92$ & $0.95 / 0.95^{\mathrm{a}}$ & $0.90 / 0.96$ & $0.94^{\mathrm{c}} / 0.95^{\mathrm{c}}$ \\
\hline & $0.08^{c} / 0.09$ & $0.14^{\mathrm{c}} / 0.11$ & $0.12^{\mathrm{a}} / 0.10^{\mathrm{a}}$ & $0.08 / 0.09$ & $0.06 / 0.06$ & $0.11 / 0.10^{\mathrm{a}}$ & $0.06 / 0.04$ & $0.13^{\mathrm{c}} / 0.10^{\mathrm{c}}$ \\
\hline
\end{tabular}

\footnotetext{
${ }^{\text {a }}$ Pattern change is statistically significant at the $5 \%$ level, based on a false discovery rate field significance test.

${ }^{\mathrm{b}}$ Pattern change is statistically significant at the $10 \%$ level, based on a false discovery rate field significance test.

${ }^{\mathrm{c}}$ Pattern change is statistically significant at the $1 \%$ level, based on a false discovery rate field significance test.
}

but some robust changes are apparent in the ensemble mean, particularly for the temperature regressions (Table 6). Table 6 indicates that, although the ensemblemean pattern correlations between the historical and RCP8.5 twenty-first-century temperature regressions are quite high, the projected pattern changes are statistically significant at least at the $5 \%$ significance level for all seasons. Inspection of the regression pattern changes reveals that the PDO-related temperature patterns are projected to weaken in the twenty-first century. Figure 28 
TABLE 6. PDO North America regressions: historical simulations compared with twenty-first-century (2006-2100) RCP8.5 simulations. Pattern correlations lie above the RMS difference $\left({ }^{\circ} \mathrm{C}\right.$ for SAT and $\mathrm{mm}^{\mathrm{Say}}{ }^{-1}$ for precipitation).

\begin{tabular}{|c|c|c|c|c|c|c|c|c|}
\hline Model & DJF SAT & $\begin{array}{c}\text { DJF } \\
\text { precipitation }\end{array}$ & MAM SAT & $\begin{array}{c}\text { MAM } \\
\text { precipitation }\end{array}$ & JJA SAT & $\begin{array}{c}\text { JJA } \\
\text { precipitation }\end{array}$ & SON SAT & $\begin{array}{c}\mathrm{SON} \\
\text { precipitation }\end{array}$ \\
\hline \multirow[t]{2}{*}{ GISS-E2-R } & 0.40 & 0.37 & 0.63 & 0.39 & 0.61 & 0.44 & 0.09 & 0.13 \\
\hline & 0.17 & 0.05 & 0.15 & 0.06 & 0.09 & 0.07 & 0.12 & 0.08 \\
\hline \multirow[t]{2}{*}{ MPI-ESM-LR } & 0.67 & 0.37 & 0.65 & 0.47 & 0.74 & 0.60 & 0.77 & 0.31 \\
\hline & 0.21 & 0.06 & 0.15 & 0.07 & 0.09 & 0.08 & 0.10 & 0.09 \\
\hline \multirow[t]{2}{*}{ CCSM4 } & 0.81 & 0.42 & 0.66 & 0.00 & 0.44 & 0.04 & 0.83 & $0.18^{\mathrm{a}}$ \\
\hline & 0.24 & 0.12 & 0.21 & 0.10 & 0.21 & 0.10 & 0.17 & $0.15^{\mathrm{a}}$ \\
\hline \multirow[t]{2}{*}{ GFDL-ESM2G } & 0.83 & 0.18 & $0.08^{\mathrm{b}}$ & -0.20 & 0.14 & -0.03 & 0.50 & -0.10 \\
\hline & 0.33 & 0.04 & $0.27^{\mathrm{b}}$ & 0.06 & 0.12 & 0.08 & 0.17 & 0.09 \\
\hline \multirow[t]{2}{*}{ GFDL-ESM2M } & 0.78 & 0.43 & 0.72 & 0.53 & 0.25 & 0.59 & 0.29 & -0.14 \\
\hline & 0.24 & 0.06 & 0.14 & 0.05 & 0.13 & 0.08 & 0.12 & 0.09 \\
\hline \multirow[t]{2}{*}{ GFDL CM3 } & -0.15 & 0.48 & 0.08 & -0.02 & 0.47 & -0.05 & 0.64 & 0.14 \\
\hline & 0.13 & 0.04 & 0.13 & 0.04 & 0.09 & 0.04 & 0.12 & 0.04 \\
\hline \multirow[t]{2}{*}{ BCC_CSM1.1 } & 0.86 & 0.44 & 0.36 & -0.14 & 0.17 & 0.15 & 0.34 & -0.15 \\
\hline & 0.20 & 0.08 & 0.18 & 0.12 & 0.17 & 0.13 & 0.25 & 0.14 \\
\hline \multirow[t]{2}{*}{ CanESM2 } & 0.74 & 0.62 & 0.67 & -0.14 & 0.46 & 0.39 & -0.39 & 0.17 \\
\hline & 0.16 & 0.09 & 0.22 & 0.10 & 0.11 & 0.05 & 0.17 & 0.07 \\
\hline \multirow[t]{2}{*}{ CNRM-CM5.1 } & 0.29 & $0.08^{c}$ & 0.36 & 0.09 & 0.35 & -0.03 & -0.15 & -0.14 \\
\hline & 0.40 & $0.38^{\mathrm{c}}$ & 0.36 & 0.16 & 0.27 & 0.20 & 0.29 & 0.20 \\
\hline \multirow[t]{2}{*}{ CSIRO Mk3.6.0 } & -0.27 & 0.13 & $0.15^{\mathrm{a}}$ & 0.56 & $0.31^{\mathrm{b}}$ & 0.56 & 0.75 & 0.82 \\
\hline & 0.26 & 0.04 & $0.22^{\mathrm{a}}$ & 0.11 & $0.14^{\mathrm{b}}$ & 0.17 & 0.15 & 0.09 \\
\hline \multirow[t]{2}{*}{ HadGEM2-CC } & 0.68 & 0.46 & 0.71 & 0.29 & 0.40 & -0.06 & 0.64 & -0.01 \\
\hline & 0.16 & 0.07 & 0.17 & 0.07 & 0.11 & 0.09 & 0.07 & 0.07 \\
\hline \multirow[t]{2}{*}{ HadGEM2-ES } & -0.65 & -0.26 & -0.47 & -0.04 & -0.59 & -0.67 & -0.28 & -0.13 \\
\hline & 0.23 & 0.08 & 0.31 & 0.10 & 0.18 & 0.15 & 0.11 & 0.10 \\
\hline HadCM3 & - & - & - & - & - & - & - & - \\
\hline \multirow[t]{2}{*}{ INM-CM4.0 } & 0.69 & 0.65 & 0.87 & 0.52 & 0.68 & 0.16 & 0.36 & -0.03 \\
\hline & 0.11 & 0.10 & 0.07 & 0.05 & 0.07 & 0.05 & 0.08 & 0.05 \\
\hline \multirow[t]{2}{*}{ IPSL-CM5A-LR } & 0.82 & 0.48 & 0.91 & 0.46 & 0.60 & 0.15 & 0.45 & 0.16 \\
\hline & 0.19 & 0.14 & 0.11 & 0.07 & 0.12 & 0.09 & 0.16 & 0.07 \\
\hline \multirow[t]{2}{*}{ IPSL-CM5A-MR } & 0.30 & 0.66 & 0.73 & 0.30 & -0.07 & -0.07 & -0.68 & -0.01 \\
\hline & 0.14 & 0.05 & 0.12 & 0.04 & 0.10 & 0.06 & 0.15 & 0.05 \\
\hline \multirow[t]{2}{*}{ MIROC5 } & 0.34 & 0.58 & 0.39 & -0.02 & 0.42 & 0.50 & 0.35 & 0.58 \\
\hline & 0.19 & 0.09 & 0.18 & 0.07 & 0.09 & 0.06 & 0.13 & 0.07 \\
\hline \multirow[t]{2}{*}{ MIROC-ESM } & 0.70 & 0.47 & 0.60 & 0.47 & 0.47 & 0.25 & 0.45 & 0.14 \\
\hline & 0.05 & 0.02 & 0.09 & 0.03 & 0.05 & 0.03 & 0.06 & 0.04 \\
\hline \multirow[t]{2}{*}{ FGOALS-s2 } & 0.82 & 0.05 & 0.78 & 0.10 & 0.48 & 0.36 & 0.80 & 0.27 \\
\hline & 0.16 & 0.07 & 0.09 & 0.06 & 0.11 & 0.05 & 0.10 & 0.05 \\
\hline \multirow[t]{2}{*}{ MRI-CGCM3 } & -0.62 & -0.06 & 0.82 & 0.52 & -0.13 & 0.36 & 0.72 & 0.34 \\
\hline & 0.39 & 0.11 & 0.12 & 0.07 & 0.32 & 0.11 & 0.11 & 0.07 \\
\hline \multirow{2}{*}{ NorESM1-M } & 0.70 & 0.45 & 0.69 & 0.40 & 0.56 & 0.05 & 0.18 & -0.06 \\
\hline & 0.27 & 0.06 & 0.14 & 0.04 & 0.08 & 0.05 & 0.14 & 0.05 \\
\hline \multirow{2}{*}{ Ensemble } & $0.94^{\mathrm{b}}$ & 0.78 & $0.97^{\mathrm{c}}$ & 0.75 & $0.86^{\mathrm{c}}$ & 0.78 & $0.90^{\mathrm{c}}$ & 0.44 \\
\hline & $0.10^{\mathrm{b}}$ & 0.02 & $0.09^{c}$ & 0.02 & $0.04^{\mathrm{c}}$ & 0.02 & $0.05^{\mathrm{c}}$ & 0.02 \\
\hline
\end{tabular}

${ }^{a}$ Pattern change is statistically significant at the $10 \%$ level, based on a false discovery rate field significance test.

${ }^{\mathrm{b}}$ Pattern change is statistically significant at the $5 \%$ level, based on a false discovery rate field significance test.

${ }^{\mathrm{c}}$ Pattern change is statistically significant at the $1 \%$ level, based on a false discovery rate field significance test.

shows the projected changes in the RCP8.5 boreal spring SAT regressions, a season that features robust changes under both emissions pathways. This figure indicates a clear weakening of the PDO-related SAT variability in the warmer climate, with largest weakening over western North America. Similar changes are noted in all other seasons and under the RCP4.5 emissions pathway (not shown), although the RCP4.5 changes are weaker in magnitude and statistically significant only in the spring. We find that the PDO-related North Pacific SST variability does not show a similar weakening, however.

\section{Conclusions and discussion}

We have examined twenty-first-century projections of NA climate in CMIP5 models under RCP8.5, including 
a)

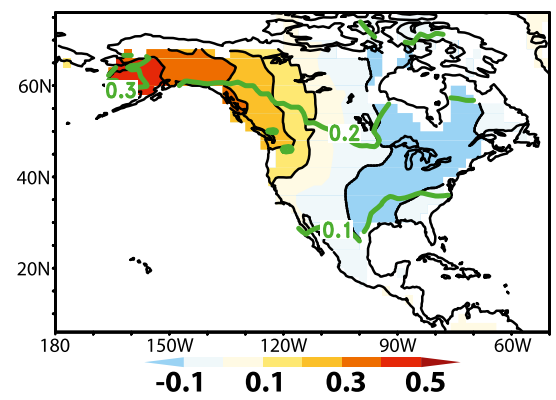

b)

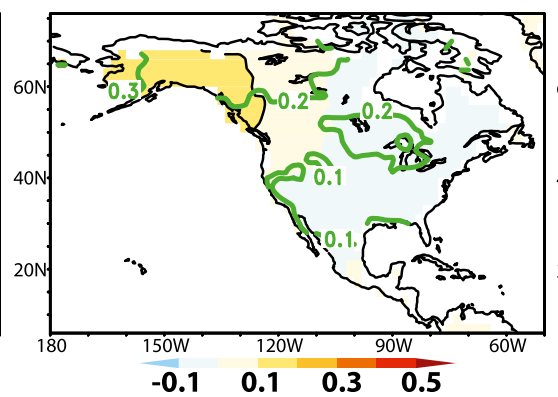

c)

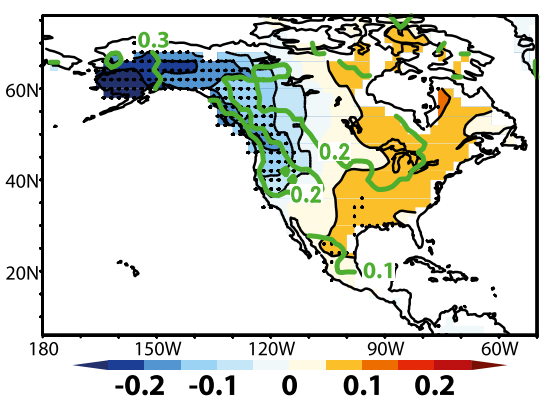

FIG. 28. Changes in spring PDO SAT regressions between historical simulations and the twenty-first century in the RCP8.5 scenario. Ensemble regression of SAT anomalies with the PDO index (color-filled contours) during MAM in (a) historical simulations and (b) RCP8.5 simulations between 2006 and 2100 and (c) the difference between (a) and (b). The contour interval is $0.1^{\circ} \mathrm{C}$ in (a),(b) and $0.05^{\circ} \mathrm{C}$ in (c). Green contours indicate the ensemble standard deviations of individual model regressions. Stippling in (c) indicates where the differences are statistically significant at the $5 \%$ significance level.

RCP4.5 in some cases. In terms of robust projected changes relative to historical runs, models indicate that warming will occur everywhere in NA, with the greatest warming occurring in northern Canada, where MEM temperature increases of $15^{\circ} \mathrm{C}$ can be found during boreal winter at the end of the twenty-first century. Models suggest a very likely disappearance of the negative temperature trend (warming hole) in the eastern United States in the twenty-first century. Models agree that more precipitation will fall north of $40^{\circ} \mathrm{N}$ in winter, with the largest increases along the west coast and northeast United States and Canada. The potential exists for a large increase in the number of extreme rainfall events over the northeast United States, since many of the CMIP5 models suggest a 4-5-fold increase in heavy precipitation events by the late twenty-first century. Model agreement is good on reduced summertime precipitation in the Caribbean and southern Mexico. Projected precipitation increases are robust across models for Alaska and the Arctic rim during boreal summer.

Further robust projected changes include a decrease in snow water equivalent throughout the year, with the greatest decreases in January-April. Especially large decreases are noted in the Rockies and northwest Canada. The growing season is projected to lengthen across NA by the end of the twenty-first century, with the largest changes in the western United States and northern Mexico, where increases of 40 days or more are projected. In the agriculturally important regions of the central United States and Canada, increases of 3-4 weeks are projected. The projections show an increase in the frequency of extended wet periods for the eastern United States and extended dry periods for Mexico. Warm temperature extremes are projected to increase across NA. Particularly notable is an increase of $40-80100^{\circ} \mathrm{F}$ days in parts of the south-central and southwest United States relative to the historical climatology. Models project an increase in Great Plains lower-level jet strength in the twenty-first century. A poleward shift of the Atlantic storm track is indicated in the upper troposphere during all seasons. Near-surface storm-track and cyclone activity are projected to decrease over NA, except along the United States and Canadian east coast. Models agree on a drier early summer (June and July) and wetter fall (September and October) from the Pacific ITCZ north to the NAM region, accompanied by robust strengthening of the midsummer drought in Central America and the greater Caribbean region.

Although many projected changes in NA climate are robust across CMIP5 models, substantial disagreement exists in other areas. The sign of mean precipitation changes across the southern United States is inconsistent among the models, as is the annual mean precipitation change in the core NA monsoon region. Models also disagree on snow water equivalent changes on a regional basis, especially in transitional regions where competing effects occur because of greater snowfall and warming temperatures. The western United States is characterized by large intermodel variability in changes in the number of frost days, where MEM decreases in frost days (greater than 40 days) are also largest. Substantial intermodel spead exists for projections of how ENSO teleconnection changes will affect precipitation and temperature variability in western NA. Projected changes in seasonal mean Atlantic and east Pacific TC activity are inconsistent among models, which disagree on the sign and amplitude of changes in environmental factors that modulate TC activity. For example, changes in Atlantic and east Pacific SSTs relative to the tropical mean differ among models. Xie et al. (2010) imply that differences in model physics that regulate how ocean heat transport and wind-evaporation feedbacks may change in future climate may be partially responsible for different patterns of SST change and hence differing relative SST changes among models. Understanding how and why the 
pattern of SST change varies among models may provide a way to constrain future projections of east Pacific and Atlantic TC activity. It should be noted that even areas of substantial agreement among models may not imply more confidence that projections are correct, as common errors or deficiencies in model parameterizations may provide false confidence in the robustness of future projections.

Model biases in some areas decrease confidence in projections, including changes of the timing of NA monsoon precipitation that exhibits projected changes in the same sense as historical biases. Growing season length is projected to increase most strongly along the West Coast, where models tend to display large negative biases in historical runs. Models have substantial difficulties in simulating the historical distribution of persistent drought and wet spells, which might produce less confidence in the pattern of extreme precipitation event changes in future climate. However, Pierce et al. (2009) found that model success in producing historical climate has little bearing on regional projections. Further, the MEM tends to provide superior performance when compared to an individual model. Hence, MEM statistics were presented for most of the analyses shown here and may provide the best estimate of projected climate changes.

Finally, this paper represents an overview and only first attempt at integrating results for CMIP5 projections of North American climate, and many gaps remain in characterizing NA climate change. Further characterization of changes in projections from CMIP3 to CMIP5 is necessary, including how differences in concentration pathways versus model physical differences dictate projection differences between the two archives. More precise characterization and attribution of regional precipitation changes is also needed, including changes in extremes, as such projections are of particular importance for agricultural and domestic water supplies, hydropower generation, ecosystems, and recreational interests. For this task, it is likely that regional downscaling will provide a useful complement to these CMIP5 results. Further, extended process-oriented diagnosis of climate models is necessary to provide confidence that models are simulating modern climate for the correct reasons, which provides greater confidence in future projections.

Acknowledgments. We acknowledge three reviewers whose insightful comments led to significant improvements in the manuscript. We acknowledge the World Climate Research Programme's Working Group on Coupled Modeling, which is responsible for CMIP, and we thank the climate modeling groups (listed in Table 1 of this paper) for producing and making available their model output. For CMIP, the U.S. Department of Energy's Program for Climate Model Diagnosis and Intercomparison provides coordinating support and led development of software infrastructure in partnership with the Global Organization for Earth System Science Portals. The authors acknowledge the support of NOAA Climate Program Office Modeling, Analysis, Predictions and Projections (MAPP) Program as part of the CMIP5 Task Force. EDM was also supported by the Climate and Large-Scale Dynamics Program of the National Science Foundation under Grant AGS-1025584.

\section{REFERENCES}

Alexander, L. V., and Coauthors, 2006: Global observed changes in daily climate extremes of temperature and precipitation. J. Geophys. Res., 111, D05109, doi:10.1029/2005JD006290.

Arora, V. K., and Coauthors, 2011: Carbon emission limits required to satisfy future representative concentration pathways of greenhouse gases. Geophys. Res. Lett., 38, L05805, doi:10.1029/ 2010GL046270.

Bao, Q., and Coauthors, 2013: The Flexible Global OceanAtmosphere-Land system model, spectral version 2: FGOALS-s2. Adv. Atmos. Sci., 30, 561-576.

Barnett, T. P., 1983: Interaction of the monsoon and Pacific trade wind system at interannual time scales. Part I: The equatorial zone. Mon. Wea. Rev., 111, 756-773.

Bengtsson, L., K. I. Hodges, and E. Roeckner, 2006: Storm tracks and climate change. J. Climate, 19, 3518-3543.

,,-- M. Esch, N. Keenlyside, L. Kornblueh, J.-J. Luo, and T. Yamagata, 2007: How may tropical cyclones change in a warmer climate? Tellus, 59A, 539-561.

Benjamini, Y., and Y. Hochberg, 1995: Controlling the false discovery rate: A practical and powerful approach to multiple testing. J. Roy. Stat. Soc., 57B, 289-300.

Bi, D., and Coauthors, 2012: ACCESS: The Australian Coupled Climate Model for IPCC AR5 and CMIP5. Extended Abstract, AMOS 18th National Conf., Sydney, Australia, AMOS, 123. [Available online at http://www.amos.org.au/documents/item/616.]

Biasutti, M., and A. H. Sobel, 2009: Delayed Sahel rainfall and global seasonal cycle in a warmer climate. Geophys. Res. Lett., 36, L23707, doi:10.1029/2009GL041303.

,-- , S. J. Camargo, and T. T. Creyts, 2012: Projected changes in the physical climate of the Gulf Coast and Caribbean. Climatic Change, 112, 819-845.

Brown, R. D., and P. W. Mote, 2009: The response of Northern Hemisphere snow cover to a changing climate. J. Climate, 22, 2124-2145.

Camargo, S. J., 2013: Global and regional aspects of tropical cyclone activity in the CMIP5 models. J. Climate, 26, 98809902.

— of tropical cyclones in atmospheric general circulation models. Wea. Forecasting, 17, 1152-1162.

Chang, E. K. M., 2013: CMIP5 projection of significant reduction in extratropical cyclone activity over North America. J. Climate, 26, 9903-9922.

— Y. Y. Guo, and X. Xia, 2012: CMIP5 multi-model ensemble projection of storm track change under global warming. J. Geophys. Res., 117, D23118, doi:10.1029/2012JD018578. 
Christiansen, D. E., S. L. Markstrom, and L. E. Hay, 2011: Impacts of climate change on the growing season in the United States. Earth Interact., 15, doi:10.1175/2011EI376.1.

Chylek, P., J. Li, M. K. Dubey, M. Wang, and G. Lesins, 2011: Observed and model simulated 20th century Arctic temperature variability: Canadian Earth System Model CanESM2. Atmos. Chem. Phys. Discuss., 11, 22 893-22 907, doi:10.5194/ acpd-11-22893-2011.

Colbert, A. J., B. J. Soden, G. A. Vecchi, and B. P. Kirtman, 2013: Impact of climate change on North Atlantic tropical cyclone tracks. J. Climate, 26, 4088-4095.

Colle, B. A., Z. Zhang, K. Lombardo, P. Liu, E. Chang, and M. Zhang, 2013: Historical evaluation and future prediction of eastern North American and western Atlantic extratropical cyclones in the CMIP5 models during the cool season. J. Climate, 26, 6882-6903.

Collins, M., S. F. B. Tett, and C. Cooper, 2001: The internal climate variability of a HadCM3, a version of the Hadley Centre coupled model without flux adjustments. Climate Dyn., 17, $61-$ 81, doi:10.1007/s003820000094.

Das, T., M. D. Dettinger, D. R. Cayan, and H. G. Hidalgo, 2011: Potential increase in floods in California's Sierra Nevada under future climate projections. Climatic Change, 109, 71-94.

Diffenbaugh, N. S., and M. Scherer, 2011: Observational and model evidence of global emergence of permanent, unprecedented heat in the 20th and 21st centuries. Climatic Change, 107, 615624.

, J. S. Pal, R. J. Trapp, and F. Giorgi, 2005: Fine-scale processes regulate the response of extreme events to global climate change. Proc. Natl. Acad. Sci. USA, 102, 15774-15778.

Donner, L. J., and Coauthors, 2011: The dynamical core, physical parameterizations, and basic simulation characteristics of the atmospheric component AM3 of the GFDL global coupled model CM3. J. Climate, 24, 3484-3519.

Duffy, P. B., and C. Tebaldi, 2012: Increasing prevalence of extreme summer temperatures in the U.S. Climatic Change, 111, $487-495$.

Dufresne, J.-L., and Coauthors, 2013: Climate change projections using the IPSL-CM5 Earth System Model: From CMIP3 to CMIP5. Climate Dyn., 40, 2123-2165.

Elsner, M. M., and Coauthors, 2010: Implications of 21st century climate change for the hydrology of Washington State. Climatic Change, 102, 225-260.

Fassnacht, S. R., 2006: Upper versus lower Colorado River sub-basin streamflow: Characteristics, runoff estimation and model simulation. Hydrol. Processes, 20, 2187-2205, doi:10.1002/hyp.6202.

Francina, D., J. Canon, and J. Valdes, 2010: IPCC-AR4 climate simulations for the southwestern US: The importance of future ENSO projections. Climatic Change, 99, 499-514.

Francis, J. A., and S. J. Vavrus, 2012: Evidence linking Arctic amplification to extreme weather in mid-latitudes. Geophys. Res. Lett., 39, L06801, doi:10.1029/2012GL051000.

Gent, P. R., and Coauthors, 2011: The Community Climate System Model version 4. J. Climate, 24, 4973-4991.

Gleckler, P. J., K. E. Taylor, and C. Doutriaux, 2008: Performance metrics for climate models. J. Geophys. Res., 113, D06104, doi:10.1029/2007JD008972.

Gutzler, D. S., and T. O. Robbins, 2011: Climate variability and projected change in the western United States: Regional downscaling and drought statistics. Climate Dyn., 37, 835-849.

Hamlet, A. F., and D. P. Lettenmaier, 2007: Effects of 20th century warming and climate variability on flood risk in the western U.S. Water Resour. Res., 43, W06427, doi:10.1029/2006WR00509.
Hay, L. E., S. L. Markstrom, and C. Ward-Garrison, 2011: Watershed-scale response to climate change through the twenty-first century for selected basins across the United States. Earth Interact., 15, doi:10.1175/2010EI370.1.

Hayhoe, K., and Coauthors, 2004: Emission pathways, climate change, and impacts on California. Proc. Natl. Acad. Sci. USA, 101, 12 422-12 427.

Hazeleger, W., and Coauthors, 2010: EC-Earth: A seamless Earth system prediction approach in action. Bull. Amer. Meteor. Soc., 91, 1357-1363.

Held, I. M., and M. Zhao, 2011: The response of tropical cyclone statistics to an increase in $\mathrm{CO}_{2}$ with fixed sea surface temperatures. J. Climate, 24, 5353-5364.

Hodges, K. I., 1994: A general method for tracking analysis and its application to meteorological data. Mon. Wea. Rev., 122, 2573-2586.

, 1995: Feature tracking on the unit sphere. Mon. Wea. Rev., 123, 3458-3465.

Horel, J. D., 1984: Complex principal component analysis: Theory and examples. J. Appl. Meteor., 23, 1660-1673.

Jiang, X.-A., E. D. Maloney, J.-L. F. Lin, and D. E. Waliser, 2013: Simulations of the east North Pacific intraseasonal variability in CMIP5 GCMs. J. Climate, 26, 3489-3510.

Jones, C. D., and Coauthors, 2011: The HadGEM2-ES implementation of CMIP5 centennial simulations. Geosci. Model Dev., 4, 543-570, doi:10.5194/gmd-4-543-2011.

Jungclaus, J. H., and Coauthors, 2006: Ocean circulation and tropical variability in the coupled model ECHAM5/MPI-OM. J. Climate, 19, 3952-3972.

Karnauskas, K. B., A. Giannini, R. Seager, and A. J. Busalacchi, 2013: A simple mechanism for the climatological midsummer drought along the Pacific coast of Central America. Atmósfera, 26, 261-281.

Kim, D., A. H. Sobel, A. D. Del Genio, Y. Chen, S. Camargo, M.-S. Yao, M. Kelley, and L. Nazarenko, 2012: The tropical subseasonal variability simulated in the NASA GISS general circulation model. J. Climate, 25, 4641-4659.

Klein, S. A., X. Jiang, J. Boyle, S. Malyshev, and S. Xie, 2006: Diagnosis of the summertime warm and dry bias over the U.S. Southern Great Plains in the GFDL climate model using a weather forecasting approach. Geophys. Res. Lett., 33, L18805, doi:10.1029/2006GL027567.

Knutson, T., and Coauthors, 2010: Tropical cyclones and climate change. Nat. Geosci., 3, 157-163, doi:10.1038/ngeo779.

Kug, J.-S., S.-I. An, Y.-G. Ham, and I.-S. Kang, 2010: Changes in El Niño and La Niña teleconnections over North PacificAmerica in the global warming simulations. Theor. Appl. Climatol., 100, 275-282.

Kumar, A., B. Jha, and M. L'Heureux, 2010: Are tropical SST trends changing the global teleconnection during La Niña? Geophys. Res. Lett., 37, L12702, doi:10.1029/2010GL043394.

Kumar, S., J. Kinter III, P. Dirmeyer, Z. Pan, and J. Adams, 2013: Multidecadal climate variability and the "warming hole" in North America: Results from CMIP5 twentieth- and twentyfirst-century climate simulations. J. Climate, 26, 3511-3527.

Kunkel, K. E., X.-Z. Liang, J. Zhu, and Y. Lin, 2006: Can CGCMs simulate the twentieth-century "warming hole" in the central United States? J. Climate, 19, 4137-4153.

Kwok, R., and D. A. Rothrock, 2009: Decline in Arctic sea ice thickness from submarine and ICESat records: 1958-2008. Geophys. Res. Lett., 36, L15501, doi:10.1029/2009GL039035.

Langenbrunner, B., and J. D. Neelin, 2013: Analyzing ENSO teleconnections in CMIP models as a measure of model 
fidelity in simulating precipitation. J. Climate, 26, 44314446.

Latif, M., N. Keenlyside, and J. Bader, 2007: Tropical sea surface temperature, vertical wind shear, and hurricane development. Geophys. Res. Lett., 34, L01710, doi:10.1029/2006GL027969.

Lau, N.-C., and M. J. Nath, 2012: A model study of heat waves over North America: Meteorological aspects and projections for the twenty-first century. J. Climate, 25, 4761-4784.

- A. Leetma, and M. J. Nath, 2008: Interactions between the responses of North American climate to El Niño-La Niña and to the secular warming trend in the Indian-western Pacific Oceans. J. Climate, 21, 476-494.

Lawrence, D. M., and A. G. Slater, 2010: The contribution of snow condition trends to future ground climate. Climate Dyn., 34 (7-8), 969-981.

Lee, S.-K., D. B. Enfield, and C. Wang, 2011: Future impact of differential interbasin ocean warming on Atlantic hurricanes. J. Climate, 24, 1264-1275.

Leibensperger, E. M., and Coauthors, 2012: Climatic effects of 1950-2050 changes in US anthropogenic aerosols-Part 2: Climate response. Atmos. Chem. Phys., 12, 3349-3362, doi:10.5194/acp-12-3349-2012.

Liang, X.-Z., J. Pan, J. Zhu, K. E. Kunkel, J. X. L. Wang, and A. Dai, 2006: Regional climate model downscaling of the U.S. summer climate and future change. J. Geophys. Res., 111, D10108, doi:10.1029/2005JD006685.

Magaña, V., J. A. Amador, and S. Medina, 1999: The midsummer drought over Mexico and Central America. J. Climate, 12, $1577-1588$

Mahajan, S., G. R. North, R. Saravanan, and M. G. Genton, 2012: Statistical significance of trends in monthly heavy precipitation over the U.S. Climate Dyn., 38, 1375-1387.

Maloney, E. D., and S.-P. Xie, 2013: Sensitivity of MJO activity to the pattern of climate warming. J. Adv. Modeling Earth Sys., 5, 32-47, doi:10.1029/2012MS000171.

— D. B. Chelton, and S. K. Esbensen, 2008: Subseasonal SST variability in the tropical eastern North Pacific during boreal summer. J. Climate, 21, 4149-4167.

McKee, T. B., N. J. Doesken, and J. Kleist, 1993: The relationship of drought frequency and duration to time scales. Proc. Eighth Conf. on Applied Climatology, Anaheim, CA, Amer. Meteor. Soc., 179-184.

,-- , and — 1995 : Drought monitoring with multiple time scales. Proc. Ninth Conf. on Applied Climatology, Dallas, TX, Amer. Meteor. Soc., 233-236.

Meehl, G. A., and C. Tebaldi, 2004: More intense, more frequent and longer lasting heat waves in the 21 st century. Science, $\mathbf{3 0 5}$, 994-997.

—_, and H. Teng, 2007: Multi-model changes in El Niño teleconnections over North America in a future warmer climate. Climate Dyn., 29, 779-790.

,-- , and G. Branstator, 2006: Future changes of El Niño in two global coupled climate models. Climate Dyn., 26, 549566.

—, C. Covey, K. E. Taylor, T. Delworth, R. J. Stouffer, M. Latif, B. McAvaney, and J. F. B. Mitchell, 2007: THE WCRP CMIP3 multimodel dataset: A new era in climate change research. Bull. Amer. Meteor. Soc., 88, 1383-1394.

_ J. M. Arblaster, and G. Branstator, 2012a: Mechanisms contributing to the warming hole and the consequent U.S. east-west differential of heat extremes. J. Climate, 25, 6394-6408.

- W. M. Washington, J. M. Arblaster, A. Hu, H. Teng, and C. Tebaldi, 2012b: Climate system response to external forcings and climate change projections in CCSM4. J. Climate, 25, 3661-3683.

Meier, W. N., J. Stroeve, A. Barrett, and F. Fetterer, 2012: A simple approach to providing a more consistent Arctic sea ice extent time series from the 1950 s to present. Cryosphere, 6, 13591368, doi:10.5194/tc-6-1359-2012.

Meinshausen, M., and Coauthors, 2011: The RCP greenhouse gas concentrations and their extensions from 1765 to 2300 . Climatic Change, 109, 213-241.

Moore, B. J., P. J. Neiman, F. M. Ralph, and F. E. Barthold, 2012: Physical processes associated with heavy flooding rainfall in Nashville, Tennessee, and vicinity during 1-2 May 2010: The role of an atmospheric river and mesoscale convective systems. Mon. Wea. Rev., 140, 358-378.

Moss, R. H., and Coauthors, 2010: The next generation of scenarios for climate change research and assessment. Nature, 463, 747756, doi:10.1038/nature08823.

Neelin, J. D., M. Munnich, H. Su, J. E. Meyerson, and C. E. Holloway, 2006: Tropical drying trends in global warming models and observations. Proc. Natl. Acad. Sci. USA, 103, 6110-6115, doi:10.1073/pnas.0601798103.

_ B. Langenbrunner, J. E. Meyerson, A. Hall, and N. Berg, 2013: California winter precipitation change under global warming in the Coupled Model Intercomparison Project phase 5 ensemble. J. Climate, 26, 6238-6256.

Pan, Z., R. W. Arritt, E. S. Takle, W. J. Gutowski Jr., C. J. Anderson, and M. Segal, 2004: Altered hydrologic feedback in a warming climate introduces a "warming hole." Geophys. Res. Lett., 31, L17109, doi:10.1029/2004GL020528.

_ _ X. Liu, S. Kumar, Z. Gao, and J. Kinter, 2013: Intermodel variability and mechanism attribution of central and southeastern U.S. anomalous cooling in the twentieth century as simulated by CMIP5 models. J. Climate, 26, 62156237.

Pierce, D. W., T. P. Barnett, B. D. Santer, and P. J. Gleckler, 2009: Selecting climate models for regional climate change studies. Proc. Natl. Acad. Sci. USA, 106, 8441-8446.

Portig, W. H., 1961: Some climatological data of Salvador, Central America. Weather, 16, 103-112.

Qu, X., and A. Hall, 2007: What controls the strength of snowalbedo feedback? J. Climate, 20, 3971-3981.

Räisänen, J., 2008: Warmer climate: Less or more snow? Climate Dyn., 30, 307-319.

Rauscher, S. A., F. Giorgi, N. S. Diffenbaugh, and A. Seth, 2008: Extension and intensification of the meso-American midsummer drought in the twenty-first century. Climate Dyn., 31, $551-571$

Robinson, W. A., R. Reudy, and J. E. Hansen, 2002: General circulation model simulations of recent cooling in the eastcentral United States. J. Geophys. Res., 107, 4748, doi:10.1029/ 2001JD001577.

Rotstayn, L. D., M. A. Collier, Y. Feng, H. B. Gordon, S. P. O'Farrell, I. N. Smith, and J. Syktus, 2010: Improved simulation of Australian climate and ENSO-related rainfall variability in a GCM with an interactive aerosol treatment. Int. J. Climatol., 30, 1067-1088.

Ruiz-Barradas, A., and S. Nigam, 2010: Great Plains precipitation and its SST links in twentieth-century climate simulations, and twenty-first- and twenty-second-century climate projections. J. Climate, 23, 6409-6429.

Schwartz, M. D., R. Ahas, and A. Aasa, 2006: Onset of spring starting earlier across the Northern Hemisphere. Global Change Biol., 12, 343-351. 
Seager, R., and G. A. Vecchi, 2010: Greenhouse warming and the 21st century hydroclimate of southwestern North America. Proc. Natl. Acad. Sci. USA, 107, 21277-21 282.

— , and Coauthors, 2007: Model projections of an imminent transition to a more arid climate in southwestern North America. Science, 316, 1181-1184.

Serra, Y. L., G. N. Kiladis, and M. F. Cronin, 2008: Horizontal and vertical structure of easterly waves in the Pacific ITCZ. J. Atmos. Sci., 65, 1266-1284.

,-- , and K. I. Hodges, 2010: Tracking and mean structure of easterly waves over the Intra-Americas Sea. J. Climate, 23, 4823-4840.

Seth, A., M. Rojas, and S. A. Rauscher, 2010: CMIP3 projected changes in the annual cycle of the South American monsoon. Climatic Change, 98, 331-357, doi:10.1007/s10584-009-9736-6.

_ , S. A. Rauscher, M. Rojas, A. Giannini, and S. J. Camargo, 2011: Enhanced spring convective barrier for monsoons in a warmer world? Climatic Change, 104, 403-414.

Sheffield, J., and E. F. Wood, 2008: Projected changes in drought occurrence under future global warming from multi-model, multi-scenario, IPCC AR4 simulations. Climate Dyn., 13, 79105, doi:10.1007/s00382-007-0340-z.

_ , and Coauthors, 2013a: North American climate in CMIP5 experiments. Part I: Evaluation of historical simulations of continental and regional climatology. J. Climate, 26, 9209-9245.

_ , and Coauthors, 2013b: North American climate in CMIP5 experiments. Part II: Evaluation of historical simulations of intraseasonal to decadal variability. J. Climate, 26, 9247-9290.

Smith, T. M., R. W. Reynolds, T. C. Peterson, and J. Lawrimore, 2008: Improvements to NOAA's historical merged land-ocean surface temperature analysis (1880-2006). J. Climate, 21, 2283-2296.

Solomon, S., D. Qin, M. Manning, Z. Chen, M. Marquis, K. Averyt, M. Tignor, and H. L. Miller Jr., Eds., 2007: Climate Change 2007: The Physical Science Basis. Cambridge University Press, 996 pp.

Stevenson, S. L., 2012: Significant changes to ENSO strength and impacts in the twenty-first century: Results from CMIP5. Geophys. Res. Lett., 39, L17703, doi:10.1029/2012GL052759.

- B. Fox-Kemper, M. Jochum, R. Neale, C. Deser, and G. Meehl, 2012: Will there be a significant change to El Niño in the twentyfirst century? J. Climate, 25, 2129-2145.

Stroeve, J., M. M. Holland, W. Meier, T. Scambos, and M. Serreze, 2007: Arctic sea ice decline: Faster than forecast. Geophys. Res. Lett., 34, L09501, doi:10.1029/2007GL029703.

_ V. Kattsov, A. Barrett, M. Serreze, T. Pavlova, M. Holland, and W. N. Meier, 2012a: Trends in Arctic sea ice extent from CMIP5, CMIP3 and observations. Geophys. Res. Lett., 39, L16502, doi:10.1029/2012GL052676.

_, M. C. Serreze, M. M. Holland, J. E. Kay, J. Malanik, and A. P. Barrett, 2012b: The Arctic's rapidly shrinking sea ice cover: A research synthesis. Climatic Change, 110, 1005-1027, doi:10.1007/s10584-011-0101-1.

Swanson, K. L., 2008: Nonlocality of Atlantic tropical cyclone intensities. Geochem. Geophys. Geosyst., 9, Q04V01, doi:10.1029/ $2007 \mathrm{GC} 001844$.

Taylor, K. E., R. J. Stouffer, and G. A. Meehl, 2012: An overview of CMIP5 and the experiment design. Bull. Amer. Meteor. Soc., 93, 485-498.

Tebaldi, C., K. Hayhoe, J. M. Arblaster, and G. A. Meehl, 2006: Going to the extremes. Climatic Change, 79, 185-211.

_ J. M. Arblaster, and R. Knutti, 2011: Mapping model agreement on future climate projections. Geophys. Res. Lett., 38, L23701, doi:10.1029/2011GL049863.
Teng, H., W. M. Washington, and G. A. Meehl, 2008: Interannual variations and future change of wintertime extratropical cyclone activity over North America in CCSM3. Climate Dyn., 30, 673-686.

Thorncroft, C., and K. Hodges, 2001: African Easterly wave variability and its relationship to Atlantic tropical cyclone activity. J. Climate, 14, 1166-1179.

Trenberth, K. E., 1997: The definition of El Niño. Bull. Amer. Meteor. Soc., 78, 2771-2777.

Vecchi, G. A., and B. J. Soden, 2007: Increased tropical Atlantic wind shear in model projections of global warming. Geophys. Res. Lett., 34, L08702, doi:10.1029/2006GL028905.

, K. Swanson, and B. Soden, 2008: Whither hurricane activity? Science, 322, 687-689.

, M. Zhao, H. Wang, G. Villarini, A. Rosati, A. Kumar, I. M. Held, and R. Gudgel, 2011: Statistical-dynamical predictions of seasonal north Atlantic hurricane activity. Mon. Wea. Rev., 139, 1070-1082.

Veres, M. C., and Q. Hu, 2013: AMO-forced regional processes affecting summertime precipitation variations in the central United States. J. Climate, 26, 276-290.

Voldoire, A., and Coauthors, 2013: The CNRM-CM5.1 global climate model: Description and basic evaluation. Climate Dyn., 40, 2091-2121, doi:10.1007/s00382-011-1259-y.

Volodin, E. M., N. A. Diansky, and A. V. Gusev, 2010: Simulating present-day climate with the INMCM4.0 coupled model of the atmospheric and oceanic general circulations. Izv. Atmos. Oceanic Phys., 46, 414-431.

Wallace, J. M., G.-H. Lim, and M. L. Blackmon, 1988: Relationship between cyclone tracks, anticyclone tracks and baroclinic waveguides. J. Atmos. Sci., 45, 439-462.

Wang, B., and X. Xu, 1997: Northern Hemisphere summer monsoon singularities and climatological intraseasonal oscillation. J. Climate, 10, 1071-1085.

Wang, C., and S.-K. Lee, 2008: Global warming and United States landfalling hurricanes. Geophys. Res. Lett., 35, L02708, doi:10.1029/2007GL032396.

,-- , and D. B. Enfield, 2008: Climate response to anomalously large and small Atlantic warm pools during the summer. J. Climate, 21, 2437-2450.

Wang, G., 2005: Agricultural drought in a future climate: Results from 15 global climate models participating in the IPCC 4th assessment. Climate Dyn., 25, 739-753.

Wang, H., S. Schubert, M. Suarez, J. Chen, M. Hoerling, A. Kumar, and P. Pegion, 2009: Attribution of the seasonality and regionality in climate trends over the United States during 19502000. J. Climate, 22, 2571-2590.

Watanabe, M., and Coauthors, 2010: Improved climate simulation by MIROC5: Mean states, variability, and climate sensitivity. J. Climate, 23, 6312-6335.

Watanabe, S., and Coauthors, 2011: MIROC-ESM: Model description and basic results of CMIP5-20c3m experiments. Geosci. Model Dev., 4, 845-872.

Wehner, M., D. R. Easterling, J. H. Lawrimore, R. R. Heim, R. S. Vose, and B. D. Santer, 2011: Projections of future drought in the continental United States and Mexico. J. Hydrometeor., 12, 1359-1377.

Wilks, D. S., 2006: On "field significance" and the false discovery rate. J. Appl. Meteor. Climatol., 45, 1181-1189.

Wittenberg, A. T., 2009: Are historical records sufficient to constrain ENSO simulations? Geophys. Res. Lett., 36, L12702, doi:10.1029/2009GL038710.

Xie, S.-P., C. Deser, G. A. Vecchi, J. Ma, H. Teng, and A. T. Wittenberg, 2010: Global warming pattern formation: 
Sea surface temperature and rainfall. J. Climate, 23, 966986.

Xin, X., T. Wu, and J. Zhang, 2013: Introduction of CMIP5 experiments carried out with the climate system models of Beijing Climate Center (in Chinese). Adv. Climate Change Res., 4, 41-49.

Yeh, S. W., J. S. Kug, B. Dewitte, M. H. Kwon, B. P. Kirkman, and F. F. Jin, 2009: El Niño in a changing climate. Nature, 461, 511514, doi:10.1038/nature08316.

Yin, J. H., 2005: A consistent poleward shift of the storm tracks in simulations of 21st century climate. Geophys. Res. Lett., 32, L18701, doi:10.1029/2005GL023684.

Yukimoto, S., and Coauthors, 2012: A new global climate model of the Meteorological Research Institute: MRI-CGCM3-Model description and basic performance. J. Meteor. Soc. Japan, 90A, 23-64.

Zanchettin, D., A. Rubino, D. Matei, O. Bothe, and J. H. Jungclaus, 2012: Multidecadal-to-centennial SST variability in the MPI-ESM simulation ensemble for the last millennium. Climate Dyn., 39, 419-444, doi:10.1007/s00382-012-1361-9.

Zhang, Z. S., and Coauthors, 2012: Pre-industrial and mid-Pliocene simulations with NorESM-L. Geosci. Model Dev., 5, 523-533, doi:10.5194/gmd-5-523-2012.

Zhao, M., and I. M. Held, 2012: TC-permitting GCM simulations of hurricane frequency response to sea surface temperature anomalies projected for the late-twenty-first century. $\mathrm{J}$. Climate, 25, 2995-3009. 